Aus der Klinik für Kardiologie und Pneumologie

(Prof. Dr. med. G. Hasenfuß)

der Medizinischen Fakultät der Universität Göttingen

Ökonomische Relevanz von Herzinsuffizienz mit erhaltener Ejektionsfraktion und der Einfluss einer Therapie mit Spironolacton.

Ergebnisse der prospektiven, randomisierten und placebokontrollierten ALDO-DHF-Studie

\author{
INAUGURAL - DISSERTATION \\ zur Erlangung des Doktorgrades \\ der Medizinischen Fakultät der \\ Georg-August-Universität zu Göttingen
}

vorgelegt von

\title{
Ludwig Dettmann
}

aus

Wismar

Göttingen 2017 
Dekan: $\quad$ Prof. Dr. rer. nat. Heyo K. Kroemer

Referent: $\quad$ Prof. Dr. Frank Edelmann

Korreferentin: $\quad$ Prof. Dr. Eva Hummers-Pradier

Drittreferent: $\quad$ Prof. Dr. Thomas Meyer

Datum der mündlichen Prüfung: 14. Juni 2018 
Hiermit erkläre ich, die Dissertation mit dem Titel

"Ökonomische Relevanz von Herzinsuffizienz mit erhaltener Ejektionsfraktion und der Einfluss einer Therapie mit Spironolacton.

Ergebnisse der prospektiven, randomisierten und placebokontrollierten ALDO-DHF-Studie"

eigenständig angefertigt und keine anderen als die von mir angegebenen Quellen und Hilfsmittel verwendet zu haben.

Göttingen, den 03.Juni 2018 


\section{Inhaltsverzeichnis}

$\begin{array}{lll}1 & \text { EINLEITUNG } & 7\end{array}$

$\begin{array}{lll}1.1 & \text { Definition und Formen der Herzinsuffizienz } & 7\end{array}$

1.2 Herzinsuffizienz mit erhaltener linksventrikulärer Funktion 8

1.2.1 Epidemiologie und Ätiologie 8

$\begin{array}{lll}1.2 .2 & \text { Pathophysiologie } & 10\end{array}$

$\begin{array}{ll}\text { 1.2.3 Diagnostik und Therapie } & 12\end{array}$

1.3 Ökonomische Aspekte der Herzinsuffizienz und ihrer Folgen 15

1.3.1 Entwicklung der Gesundheitsausgaben 15

1.3.2 Demographische Entwicklung 18

1.3.3 Relevanz der ökonomischen Betrachtung 18

1.3.4 Ausgaben für Herzinsuffizienz 19

$\begin{array}{lll}1.4 & \text { Fragestellung und Zielsetzung der vorliegenden Arbeit } & 21\end{array}$

2 PATIENTENKOLLEKTIV UND METHODEN 22

2.1 Die ALDO-DHF-Studie $\quad 22$

2.1.1 Zielsetzung und Studiendesign $\quad 22$

2.1.2 Rekrutierung der Patienten $\quad 22$

$\begin{array}{lll}2.1 .3 & \text { Ein- und Ausschlusskriterien } & 23\end{array}$

$\begin{array}{lll}2.1 .4 & \text { Studienmedikation } & 23\end{array}$

$\begin{array}{llr}2.2 & \text { Anamnese } & \mathbf{2 4}\end{array}$

2.2.1 Erhebung der Krankenhausaufenthalte und Arztkontakte 25

2.2.2 Erhebung der regelmäßig eingenommenen Medikamente 25

$\begin{array}{llr}2.3 & \text { Untersuchungen } & 26\end{array}$

2.4 Gesundheitsökonomische Evaluation $\quad 28$

$\begin{array}{lll}2.4 .1 & \text { Einführung und Studientypen } & 28\end{array}$

\begin{tabular}{ll}
2.4 .2 & Kostenarten \\
\hline
\end{tabular}

2.4.3 Perspektiven und Zeithorizont 30

2.4.4 Methoden der Kostenbestimmung 30

2.5 Preisgerüst der relevanten Variablen $\quad 31$

$\begin{array}{lll}2.5 .1 & \text { Medikamentenpreise } & 31\end{array}$

2.5.2 Berechnung der Arztkontaktwerte $\quad 32$

2.5.3 Kosten für Hospitalisierungen 33

$\begin{array}{lll}2.6 & \text { Statistische Auswertung } & 33\end{array}$

$3 \quad$ ERGEBNISSE $\quad 35$

3.1 Deskriptive Analyse der Baselinevariablen $\quad 35$

3.2 Deskriptive Analyse der Arztkontakte und Krankenhaus- bzw. Reha-aufenthalte und deren Kosten 37

3.3 Deskriptive Analyse des Medikamentenverbrauches und der resultierenden Kosten 41 
4 DISKUSSION

4.1 Kurze Ergebnisdarstellung

4.2 Einordnung der Ergebnisse in den Stand der Forschung

4.3 Limitationen der Arbeit

62

4.4 Fazit und Ausblick

63

5 ZUSAMMENFASSUNG

65

6 LITERATURVERZEICHNIS

7 ABKÜRZUNGSVERZEICHNIS

8 TABELLEN UND ABBILDUNGEN 
$-6-$ 


\section{Einleitung}

\subsection{Definition und Formen der Herzinsuffizienz}

Die Herzinsuffizienz (Heart Failure/ HF) ist ein Syndrom, das durch eine abnormale Funktion und Struktur des Herzmuskels verursacht wird und mit typischen Symptomkonstellationen einhergeht (McMurray et al. 2012). Zu diesen Symptomen gehören Dyspnoe, verminderte Leistungsfähigkeit, Nykturie und Unterschenkelödeme. Zusätzlich lassen sich häufig klinische Zeichen wie pulmonale Rasselgeräusche, ein verbreiterter Herzspitzenstoß oder eine Jugularvenenstauung feststellen.

Die Komplexität der Erkrankung ermöglicht verschiedene Einteilungen. So kann man den zeitlichen Verlauf, die betroffene Herzkammer, die Ejektionsfraktion, die Belastbarkeit, den Kompensationsgrad oder den Schweregrad beurteilen. Eine der gängigsten Einteilungen hat die New York Heart Association (NYHA) etabliert, die die Leistungsfähigkeit der Patienten in vier Stadien beschreibt.

\begin{tabular}{|l|l|}
\hline NYHA-Stadium I: & $\begin{array}{l}\text { Herzerkrankung ohne körperliche Leistungseinschränkung. Alltägli- } \\
\text { che körperliche Belastung verursacht keine inadäquate Erschöpfung } \\
\text { oder Luftnot }\end{array}$ \\
\hline NYHA-Stadium II: & $\begin{array}{l}\text { Herzerkrankung mit geringer Einschränkung der körperlichen Leis- } \\
\text { tungsfähigkeit. Bereits alltägliche Belastungen verursachen inadä- } \\
\text { quate Erschöpfung, Luftnot oder Angina Pectoris. }\end{array}$ \\
\hline NYHA-Stadium III: & $\begin{array}{l}\text { Herzerkrankung mit höhergradigen Einschränkungen der Leistungs- } \\
\text { fähigkeit. Keine Beschwerden in Ruhe, jedoch bereits bei leichter } \\
\text { körperlicher Aktivität }\end{array}$ \\
\hline NYHA-Stadium IV: & $\begin{array}{l}\text { Herzerkrankung mit Beschwerden bei allen körperlichen Aktivitäten } \\
\text { und bereits in Ruhe. Bettlägerigkeit. }\end{array}$ \\
\hline
\end{tabular}

Tabelle 1: Einteilung der Herzinsuffizienz nach NYHA-Stadien

Die Leitlinien des American College of Cardiology und der American Heart Association (ACC/ AHA) ermöglichen eine Klassifikation der Herzinsuffizienz und ihrer Ätiologie, in der bereits Risikofaktoren und asymptomatische strukturelle Herzveränderungen erwähnt werden (Hunt et al. 2005).

Im Stadium A sind Risikofaktoren für eine HF vorhanden, ohne dass eine strukturelle Herzer- 
krankung oder Symptomatik der HF vorliegt. Im Stadium B gehen die Risikofaktoren bereits mit strukturellen Veränderungen des Herzmuskels einher, aber weiterhin ohne Symptome oder Zeichen der HF. Stadium C ist charakterisiert durch strukturelle Schäden des Herzens, verbunden mit derzeitigen oder früheren Symptomen der Herzinsuffizienz. Das Stadium D beschreibt schließlich eine terminale Herzinsuffizienz, die eine spezielle Therapie erfordert.

Eine Herzaktion besteht aus der Systole, in der das Blut aus dem Herzen gepumpt wird und der Diastole, in der der Herzmuskel erschlafft und so eine erneute Füllung ermöglicht. Je nach zugrundeliegendem Pathomechanismus kann entweder die eine oder die andere Phase gestört sein, sodass man die Herzinsuffizienz auch in eine systolische und eine diastolische Form unterscheiden kann. Bei der systolischen Herzinsuffizienz liegt eine eingeschränkte linksventrikuläre Ejektionsfraktion $(\mathrm{LVEF}=\mathrm{EF})$ vor, die bei gesunden Menschen in der Regel $55 \%$ überschreitet und bei der systolischen Dysfunktion je nach Literatur unter 50\% liegt. Bei der diastolischen Insuffizienz liegt diese Einschränkung nicht vor, stattdessen liegt eine diastolische Dysfunktion zugrunde.

Bei der diastolischen Dysfunktion handelt es sich um eine verminderte Relaxationsfähigkeit, einhergehend mit einer erhöhter Steifigkeit des Herzmuskels. Sie kann zunächst asymptomatisch sein und tritt deutlich häufiger auf als die systolische Dysfunktion. Außerdem kann die diastolische Dysfunktion mit einer normalen oder eingeschränkten systolischen Funktion einhergehen, also auch bei einer systolischen Herzinsuffizienz vorliegen. Daher ist man in den letzten Jahren zu einer anderen Terminologie übergegangen, die von Paulus et al. (2007) empfohlen wurde. Danach entspricht die systolische Herzinsuffizienz der HFrEF (heart failure with reduced ejection fraction) und die diastolische Herzinsuffizienz der HFpEF (heart failure with preserved ejection fraction).

Für die HFpEF fordern Paulus et al. (2007) drei Kriterien. Zunächst müssen Zeichen oder Symptome der Herzinsuffizienz vorliegen. Ferner darf die Ejektionsfraktion nicht oder nur leicht eingeschränkt sein (LVEF > 50\%). Schließlich ist der Nachweis einer diastolischen Dysfunktion notwendig.

\subsection{Herzinsuffizienz mit erhaltener linksventrikulärer Funktion}

\subsubsection{Epidemiologie und Ätiologie}

Die chronische Herzinsuffizienz ist mit einer Prävalenz von 2 bis 3\% in der Gesamtbevölkerung vertreten (McMurray et al. 2012). In der Gruppe der 70- bis 80-Jährigen liegt die Prävalenz bereits bei 10 bis $20 \%$. Die Bedeutung der HFpEF hat dabei in den letzten zwei Jahrzehnten dramatisch zugenommen. Die Prävalenz der Erkrankung stieg von 38\% auf 54\% aller 
Herzinsuffizienzfälle (Owan et al. 2006). Der Anstieg erklärt sich aus der steigenden Zahl der Patienten mit normaler Ejektionsfraktion bei vergleichsweise stabiler Zahl der Fälle mit eingeschränkter EF. Dieser Zusammenhang lässt sich unter anderem mit einer deutlichen Altersabhängigkeit der HFpEF erklären. So steigt die Prävalenz mit zunehmendem Alter stark an, was bei einer steigenden Lebenserwartung in der westlichen Welt den wachsenden Anteil erklärt.

Ältere Studien beschreiben die Prognose der HFpEF besser als die der HFrEF, jedoch deutlich schlechter als die des gesunden Vergleichskollektives. Vasan et al. (1999) erfassten im Rahmen der Framingham-Studie eine 1-Jahres-Mortalität von 8,7\% bei Patienten mit HFpEF gegenüber 18,9\% bei Patienten mit HFrEF. Im Kontrollkollektiv lag die Mortalität nur bei 34\%, das mittlere Alter bei der Betrachtung betrug 73 Jahre.

Neuere Studien legen allerdings nahe, dass sich Morbidität und Mortalität beider Herzinsuffizienz-Entitäten einander annähern. So beobachteten Bhatia et al. (2006) in einer kanadischen Studie 2802 Patienten, die mit Herzinsuffizienz hospitalisiert wurden und stellten fest, dass sich weder die 1-Jahres-Mortalität noch die Rate erneuter Krankenhauseinweisungen signifikant voneinander unterschieden. Auch Bursi et al. (2006) sahen in ihrer Studie eine fast identische 6-Monats-Mortalität von etwa $16 \%$ bei HFpEF und HFrEF. Andere neuere Studien bestätigen diese Beobachtungen, z.B. auch für die 5-Jahres-Überlebensrate (Owan et al. 2006).

Eine diastolische Funktionsstörung ist nachweislich mit einer Reihe anderer Begleiterkrankungen und Risikofaktoren assoziiert. Zu den wichtigsten zählen ein arterieller Hypertonus, eine koronare Herzerkrankung und ein Diabetes mellitus. So konnte bei neu diagnostizierten Hypertonikern je nach Grenzwerten eine Prävalenz der diastolischen Dysfunktion von 1059\% festgestellt werden (Almuntaser et al. 2007). Auch Angeja und Grossmann (2003) erkannten aufgrund von Ergebnissen aus der Framingham-Studie die arterielle Hypertonie als den wichtigsten Risikofaktor. Owan et al. (2006) fanden in 53\% der Fälle von HFpEF eine KHK vor. Stahrenberg et al. (2010) postulierten einen signifikanten Zusammenhang zwischen dem Grad der diastolischen Dysfunktion und dem Glukosemetabolismus der Probanden und bestätigten damit ältere Studien. In einer Göttinger Studie wurden hypertensive Patienten mit und ohne Diabetes mellitus in Hinblick auf den Grad ihrer diastolischen Dysfunktion verglichen. Auch hier zeigte sich bei den Diabetikern ein höherer Anteil von Patienten mit schwerer diastolischer Dysfunktion (Wachter et al. 2007).

Daneben spielen diverse andere Risikofaktoren für die Entstehung der HFpEF eine Rolle, die in zahlreichen Studien erkannt wurden. Dazu zählen Adipositas (van Putte-Katier et al. 2008), 
das weibliche Geschlecht (Redfield et al. 2005), Hyperlipoproteinämie (Elesber et al. 2007) und Niereninsuffizienz (Hayashi et al. 2006).

\subsubsection{Pathophysiologie}

Der zugrundeliegende Pathomechanismus für die HFpEF ist die sogenannte diastolische Dysfunktion (DD). Ursächlich sind eine erhöhte Steifigkeit des Herzmuskels (passive Compliance-Störung) und eine verminderte (aktive) Relaxation.

Die in der Systole vorangehende Kontraktion des Herzens ist in mehreren Stufen abhängig von Kalzium. Zunächst steigt der zytosolische Kalziumspiegel durch aus dem sarkoplasmatischen Retikulum freigesetztes Kalzium an. Dies wird über eine elektromechanische Kopplung des Ryanodin- und Dihydropyridin-Rezeptors unter Einfluss von extrazellulärem Kalzium vermittelt. Das Kalzium bindet an Troponin C und ermöglicht durch die Interaktion von Aktin und Myosin die Muskelkontraktion. Die Relaxation ist nur möglich, wenn der zytosolische Kalziumspiegel wieder sinkt und das Kalzium den kontraktilen Proteinkomplex verlässt. Dazu befördert einerseits die Kalziumpumpe des sarkoplasmatischen Retikulums (SERCA) das Kalzium zurück in das SR und andererseits der Natrium-Kalzium-Austauscher das Kalzium nach extrazellulär. Hasenfuß und Wachter (2008) benennen diesbezüglich drei Störungen der Relaxation.

1. Eine gestörte Kalziumelimination

2. Gesteigerte Kalziumempfindlichkeit der kontraktilen Proteine

3. Von Kalzium unabhängige Verlängerung der Ankopplung von Myosin und Aktin. Letztere wurde von Borbély et al. (2005) mit Veränderungen in der Myosinisoform in Verbindung gebracht. Die Kalziumelimination ist als energieabhängiger Prozess auf die Bereitstellung von genügend ATP angewiesen und damit bei Ischämie und Hypoxie eingeschränkt, was eine diastolische Dysfunktion begünstigen kann. Als ein wichtiges Strukturprotein des Zytoskeletts wurde das Titin erkannt, welches in der Diastole gedehnt wird und ebenfalls in verschiedenen Isoformen mit Unterschieden in der Dehnbarkeit und damit in der diastolischen Funktion einhergeht (Linke und Grützner 2008).

Daneben können auch andere Veränderungen des myokardialen Zytoskelettes eine diastolische Dysfunktion verstärken, auf die hier nicht weiter eingegangen werden soll.

Die der Pathogenese der erhöhten passiven Steifigkeit des Myokards zugrundeliegenden Prozesse spielen sich vor allem in der extrazellulären Matrix ab. Eine wesentliche Rolle scheint das gestörte Verhältnis von Kollagenbiosynthese und Kollagenabbau zugunsten einer gesteigerten Synthese zu spielen. Überwiegen die Gewebeinhibitoren der Metalloproteinasen (engl. 
tissue inhibitors of metalloproteinases, TIMP) sind die von den Matrixmetalloproteinasen (MMP) begünstigten Abbauprozesse des Kollagens gehemmt, was eine Fibrosierung und damit erhöhte Steifigkeit des Myokards bedingt (Ahmed et al. 2006). Die Autoren fanden dabei auch heraus, dass der Grad der Fibrosierung mit der Konzentration an Gewebeinhibitoren positiv korreliert.

Auch extramyokardiale Faktoren sind beteiligt an der Regulation des Kollagenumsatzes und damit am Grad der Steifigkeit des Herzmuskels. Einerseits bewirken eine erhöhte Vor- und Nachlast eine gesteigerte Kollagensynthese, andererseits spielt die neurohumorale Aktivität eine entscheidende Rolle und hier neben dem sympathischen Nervensystem vor allem das Renin-Angiotensin-Aldosteron-System (RAAS) (Zile und Brutsaert 2002).

Aldosteron ist ein Steroidhormon, welches hauptsächlich in der Nebenniere gebildet wird. Der physiologisch stärkste Stimulus zur Sekretion von Aldosteron ist das Angiotensin II, ebenfalls Teil des RAAS. Jedoch findet die Produktion auch unabhängig davon in anderen Geweben statt, z.B. in Blutgefäßen oder im Myokard (Mizuno et al. 2001, Satoh et al. 2002). Dies ist insbesondere bei Patienten mit Bluthochdruck zu beobachten (Yamamoto et al. 2002).

Die Wirkung von Aldosteron wird über den Mineralokortikoidrezeptor vermittelt, es dient in erster Linie der Regulierung des Salz- und Wasserhaushalts, wofür es auf transkriptioneller Ebene im distalen Nephron angreift.

Darüber hinaus ist schon lange bekannt, dass sowohl Angiotensin II als auch Aldosteron über ihren Einfluss auf die Kollagensynthese eine Fibrosierung des Myokards und in der Folge eine Hypertrophie und vermehrte Steifigkeit des Herzens begünstigen. Dies wurde sowohl an Fibroblastenkulturen gezeigt (Brilla et al. 1994) als auch in klinischen Studien bestätigt (Schunkert et al. 1997). Auch entzündliche Veränderungen des Myokards unter Einfluss von Aldosteron konnten nachgewiesen werden, die o.g. negative Veränderungen der diastolischen Funktion verstärken können (Rocha et al. 2002).

Schließlich wurden Zusammenhänge von erhöhten Aldosteron-Spiegeln mit ventrikulären Arrhythmien, endothelialer Dysfunktion und Inhibition der Stickstoffmonoxidsynthese beschrieben (Struthers und MacDonald 2004).

Der Plasma-Aldosteron-Spiegel steigt mit dem Alter an, woraus sich die steigende Prävalenz der HFpEF bei älteren Menschen unter anderem erklären lässt.

Die Aldosteron-Antagonisten Spironolacton und Eplerenon wirken kompetitiv am Mineralokortikoidrezeptor, der auch im Herzen exprimiert wird, und helfen, die genannten Effekte chronisch erhöhter Aldosteron-Spiegel zu reduzieren. 
Zwar zählen Aldosteron-Antagonisten zu den Diuretika, jedoch hat Spironolacton in der niedrigen Dosierung von $25 \mathrm{mg}$ pro Tag kaum einen senkenden Einfluss auf die Vor- und Nachlast, da es nicht relevant diuretisch wirksam ist. Vielmehr stehen folgende Wirkmechanismen im Vordergrund:

- Hemmung des myokardialen und vaskulären Remodellings (Zannad et al. 2001)

- Prävention von Hypokaliämie und Herzrhythmusstörungen (Tang et al. 2005)

- Aufrechterhaltung der endothelialen Funktion (Bauersachs et al. 2002, Farquharson et al. 2000)

- Verminderung von interstitieller und perivaskulärer Fibrose (Jewell et al. 2006)

- Abnahme myokardialer Steifigkeit (Querejeta et al. 2004).

\subsubsection{Diagnostik und Therapie}

Wie bereits erwähnt, beruht die Diagnose der HFpEF auf folgenden Kriterien: Zeichen oder Symptome der Herzinsuffizienz müssen vorhanden sein, die EF darf nicht, oder nur leicht eingeschränkt sein und schließlich muss eine relevante strukturelle Herzerkrankung und/ oder diastolische Dysfunktion nachgewiesen sein.

Zur Erhebung der nötigen Befunde kommen neben einer ausführlichen Anamnese und körperlichen Untersuchung u.a. EKG, Echokardiographie, Laboruntersuchungen, Spiroergometrie und Röntgen-Thorax, in Ausnahmefällen auch invasive Verfahren zum Einsatz.

Die Guidelines im ESC-Consensus-Statement fordern eine echokardiographisch bestimmte linksventrikuläre Ejektionsfraktion von unter 50\%, um das zweite oben genannten Kriterien zu erfüllen. Zusätzlich soll der linksventrikuläre enddiastolische Volumenindex (LVEDVI) berücksichtigt werden, der zum Ausschluss einer signifikanten linksventrikulären Dilatation nicht größer als $97 \mathrm{ml} / \mathrm{m}^{2}$ sein darf.

Der Nachweis einer diastolischen Dysfunktion kann invasiv hämodynamisch oder mittels Echokardiographie erbracht werden. Die Herzkatheteruntersuchung bietet dabei zuverlässige Ergebnisse, da die Druck- und Volumenbeziehungen direkt gemessen werden können. Jedoch hat sich in der Routinediagnostik die Echokardiographie durchgesetzt, deren für den Diagnose-Algorithmus der ESC wichtigste Parameter hier kurz erläutert werden sollen.

Zunächst kann in der konventionellen 2D-Ansicht nach Zeichen einer DD gesucht werden, die durch die Hypertrophie des linken Herzens hervorgerufen werden. Konkret sind das ein linksventrikulärer Massenindex $(\mathrm{LVMI})>122 \mathrm{~g} / \mathrm{m}^{2}$ bei Frauen und $>149 \mathrm{~g} / \mathrm{m}^{2}$ bei Männern, sowie ein linksatrialer Volumenindex $(\mathrm{LAVI})>40 \mathrm{ml} / \mathrm{m}^{2}$. 
Außerdem wird das transmitrale Einflussprofil im Pulsed-Wave-Doppler (PW-Doppler) beurteilt. Die Messungen beinhalten die frühe und späte Mitralklappenflussgeschwindigkeit (EWelle und A-Welle), die isovolumetrische Relaxationszeit (IVRT) und die Dezelerationszeit (DT). Letztere gilt bei über $280 \mathrm{~ms}$ als verlängert. Das Verhältnis von E zu A erlaubt eine Einteilung der DD in drei Grade. Im Gesunden beträgt E/A $>1$ und sinkt im Stadium der gestörten Relaxation (Grad 1) auf Werte $<1$. Bei zunehmender DD (Grad 2) kommt es zur sogenannten Pseudonormalisierung mit Werten $>1$ und im Stadium des restriktiven Füllungsmusters $(\mathrm{Grad} 3)$ ist $\mathrm{E} / \mathrm{A}>2$.

Im Gewebedoppler wird die Mitralklappenanulusgeschwindigkeit gemessen und die Werte $\mathrm{e}^{\prime}$ für die frühe und $\mathrm{A}^{\prime}$ für die späte Verformungsgeschwindigkeit ermittelt. Nun kann der Quotient E/e' berechnet werden, dem im diagnostischen Algorithmus eine besondere Rolle zukommt, da er sehr gut mit dem (invasiv gemessenen) linksventrikulären enddiastolischen Druck (LVEDP) korreliert (Kasner et al. 2007). Bei E/e' > 15 liegt mit hoher Wahrscheinlichkeit eine DD vor, bei E/e' $<8$ sind die Druckverhältnisse nicht pathologisch verändert. Bei Werten im „Graubereich“ zwischen 8 und 15 muss der Quotient im Kontext mit anderen Messwerten und den natriuretischen Peptiden (s.u.) beurteilt werden.

Dies gilt auch für eine verlängerte DT, einen erhöhten LAVI oder LVMI und ein E/AVerhältnis $<1$, all diese Parameter erreichen, singulär gemessen, nicht die Spezifität wie E/e' Aufgrund dieses Spektrums an Untersuchungsmethoden folgerten Erbel et al. schon 2002, dass die Abklärung einer DD zu einer Domäne der Echokardiographie zähle.

Die Messung der natriuretischen Peptide BNP und NT-proBNP stellt einen weiteren Baustein in der Diagnostik der DD dar und dient auch der Prognoseabschätzung und Verlaufskontrolle. Der physiologische Reiz zur Ausschüttung von BNP bzw. seinem Vorläufermolekül ist ein Dehnungsreiz oder eine Druckbelastung des linken Ventrikels, dessen Produktion quantitativ am bedeutendsten ist. Das n-terminale Spaltprodukt des Vorläufermoleküls von BNP heißt NT-proBNP. Dies ist stabiler als BNP und wurde daher in der ALDO-DHF-Studie gemessen. Werte größer als 220 pg/ml (NT-proBNP) bzw. 200 pg/ml (BNP) deuten mit einem positiven prädiktiven Wert von über $80 \%$ auf eine DD hin (Tschöpe et al. 2005) und sind daher wichtige Parameter im Diagnosealgorithmus.

Obwohl die diastolische Herzinsuffizienz mittlerweile gut und standardisiert diagnostiziert werden kann, sind die die therapeutischen Optionen bislang unzureichend und zum Großteil noch empirisch.

Zur Senkung der Mortalität und zur Steigerung der Lebensqualität werden drei übergeordnete Therapieziele verfolgt (Schmidt und Pieske 2012). Zum einen müssen die Symptome behan- 
delt werden, die sich z.B. aus der zentralvenösen Stauung ergeben. Zum anderen sollte eine Kausaltherapie erfolgen, die sowohl die für die diastolische Dysfunktion ursächlichen als auch die den Krankheitsprozess auslösenden bzw. verstärkenden Begleiterkrankungen adressiert. Und schließlich ist eine Intervention notwendig, die auf die mit dem Krankheitsprozess assoziierten Pathomechanismen abzielt, wie beispielsweise der neurohumoralen Aktivierung (Zile und Brutsaert 2002).

Die wichtigsten Maßnahmen zur Symptomkontrolle sind die Senkung des pulmonalvenösen Druckes und die Förderung einer ausreichend langen Diastole, wenn möglich bei normofrequentem Sinusrhythmus. Dazu eignen sich zur medikamentösen Vor- und Nachlastsenkung Diuretika (z.B. Schleifendiuretika) und Nitrate, die allerdings aufgrund der Gefahr einer Hypotonie vorsichtig und individuell angepasst dosiert werden sollen. Wachter und Hasenfuß (2002) betonen die Wichtigkeit von Sinusrhythmus und Frequenzkontrolle z.B. durch Betaoder Kalziumkanalblocker insbesondere im Stadium der gestörten Relaxation, um eine optimale Ventrikelfüllung in der Diastole zu gewährleisten. Zusätzlich sinkt dabei der myokardiale Sauerstoffverbrauch und die Durchblutung des Myokards in der Diastole wird verbessert, was insbesondere bei hypertrophen Herzen vorteilhaft ist.

Im Rahmen der Kausaltherapie sind zunächst die konsequente Therapie einer myokardialer Ischämie, ggf. mit Herzkatheterintervention oder ACVB-Operation und die antihypertensive Behandlung essentiell.

Für eine Reihe von Begleiterkrankungen gilt, dass ihre Behandlung ebenfalls förderlich für die Herzinsuffizienzsymptomatik sein kann. Dazu zählen Diabetes mellitus, obstruktives Schlafapnoesyndrom (Klemmstein 2012), Anämie, Lungenerkrankungen wie COPD und Adipositas.

Die medikamentöse Langzeittherapie greift auf die gleichen Substanzgruppen zurück, wie sie in den Leitlinien zur Therapie der HFrEF vorkommen. Die wenigen größeren Studien, die eine Überlegenheit einzelner Präparate gegen Placebo beweisen wollten, fielen jedoch ernüchternd aus.

Die bedeutendste Studie zur Wirksamkeit von ACE-Hemmern war die PEP-CHF-Studie von Cleland et al. (2006). Der kombinierte primäre Endpunkt aus Gesamtmortalität und Krankenhausaufenthalten aufgrund einer Herzinsuffizienz unterschied sich in Therapie- und Placebogruppe nicht signifikant voneinander.

Neben mehreren kleinen Studien wurde die Wirkung von AT1-Rezeptorblockern in der CHARM-Preserved-Studie (Candesartan vs. Placebo) (Yusuf et al. 2003) und in der IPRESERVE-Studie (Irbesartan vs. Placebo) (Massie et al. 2008) untersucht. Auch bei diesen 
beiden großen randomisierten und kontrollierten Studien mit insgesamt über 7000 Patienten konnte keine signifikante Überlegenheit der getesteten Substanzen gegenüber dem Placebo in Hinblick auf Mortalität und Hospitalisierungsrate nachgewiesen werden.

Für den Einsatz von Statinen sprechen u.a. Daten einer Beobachtungsstudie von Fukuta et al. (2005) und eine retrospektive Analyse von Shah et al. (2008), die auf eine Senkung der Mortalität hinweist.

Aldosteron-Antagonisten sind, wie aus der Pathophysiologie der HFpEF hervorgeht, ein vielversprechender Ansatz in der Therapie und daher Gegenstand der in dieser Arbeit beschriebenen ALDO-DHF-Studie (Edelmann et al. 2013). Diese und die TOPCAT-Studie (Pitt et al. 2014) stellen die größten randomisierten und Placebo-kontrollierten Studien dar, die die Wirkung von Spironolacton gegen Placebo untersuchen. Bei gleichen primären Endpunkten (kardiovaskuläre Mortalität und Hospitalisierungen aufgrund von Herzinsuffizienz) unterscheiden die Studien sich u.a. in den sekundären Endpunkten maximale Sauerstoffaufnahme $\mathrm{VO}_{2} \mathrm{max}$ und Veränderung der diastolischen Funktion (ALDO-DHF) (Edelmann et al. 2010).

Während die Ergebnisse von ALDO-DHF eine Besserung der diastolischen Funktion und damit der linksventrikulären Funktion unter Spironolacton aufzeigen, konnte in beiden Studien keine Überlegenheit der Spironolactongabe im Hinblick auf die primären Endpunkte Hospitalisierung und Tod nachgewiesen werden.

Zur Verbesserung von Lebensqualität und Belastbarkeit sind eine Reihe nicht medikamentöser Maßnahmen sinnvoll - dazu zählen Raucherentwöhnung, Gewichtskontrolle und regelmäBiges körperliches Training (u. a. Edelmann et al. 2011).

\section{3 Ökonomische Aspekte der Herzinsuffizienz und ihrer Folgen}

\subsubsection{Entwicklung der Gesundheitsausgaben}

Die Gesundheitsausgaben in Deutschland sind in den letzten Jahrzehnten beständig gestiegen. Allein zwischen 2003 und 2011 entwickelten sie sich laut Statistischem Bundesamt (Statistisches Bundesamt 2014) von 239,7 Mrd. Euro zu 300,4 Mrd. Euro. Im Jahr 2012 überstiegen sie somit zum ersten Mal die Marke von 300 Mrd. Euro (Quelle: Statistisches Bundesamt, Pressemitteilung 2014). 


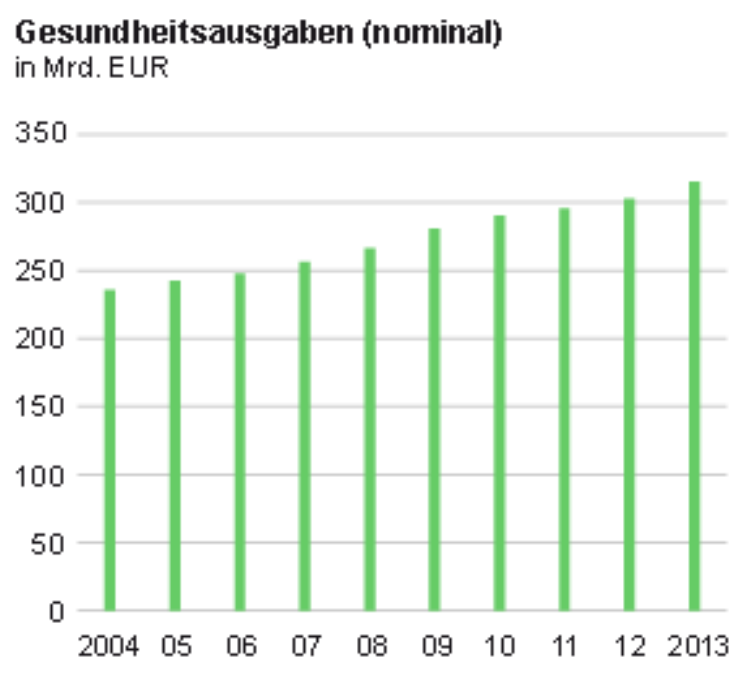

(9) Statistisches Bundesant, Wiesbaden 2015

Abb. 1: Gesundheitsausgaben nominal 2004-2013

Ihr Anteil am Bruttoinlandsprodukt schwankt je nach Wirtschaftswachstum, liegt jedoch beständig über 10\%, im Jahre 2012 bei 11,3\%.

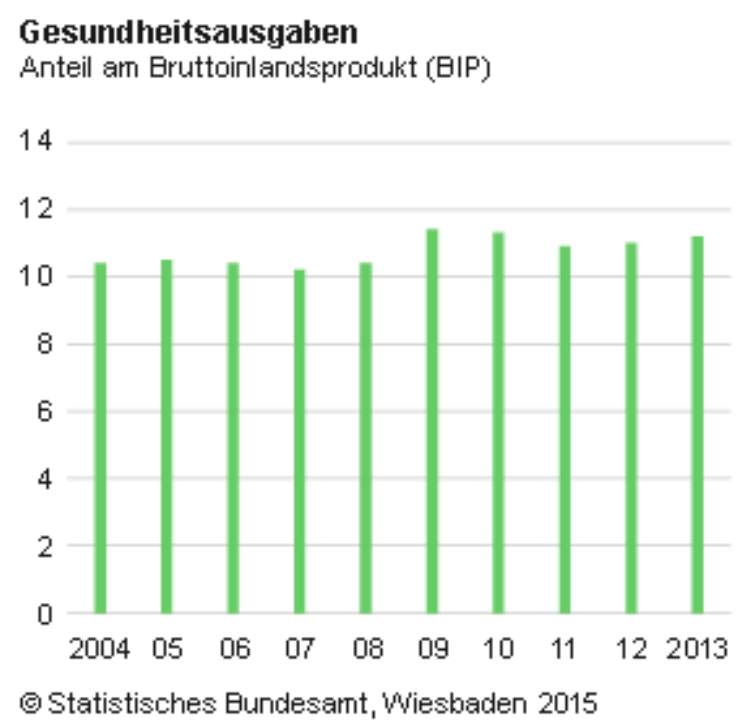

Abb. 2: Anteil der Gesundheitsausgaben am Bruttoinlandsprodukt 2004-2013

Je Einwohner stiegen die Gesundheitsausgaben von 2900 Euro im Jahre 2003 auf 3740 Euro 2012. 


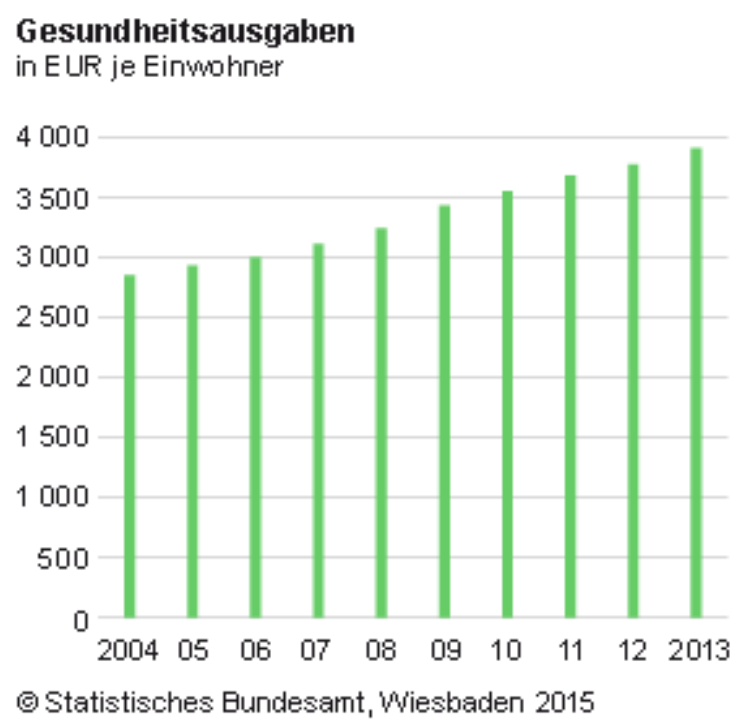

Abb. 3: Gesundheitsausgaben je Einwohner 2004-2013

Die Ausgaben für Krankheiten des Kreislaufsystems waren im Jahr 2008 im Vergleich zu anderen Krankheitsklassen mit 450 Euro pro Kopf am höchsten und zeigten eine starke $\mathrm{Zu}-$ nahme im höheren Alter (Statistisches Bundesamt, Krankheitskosten).

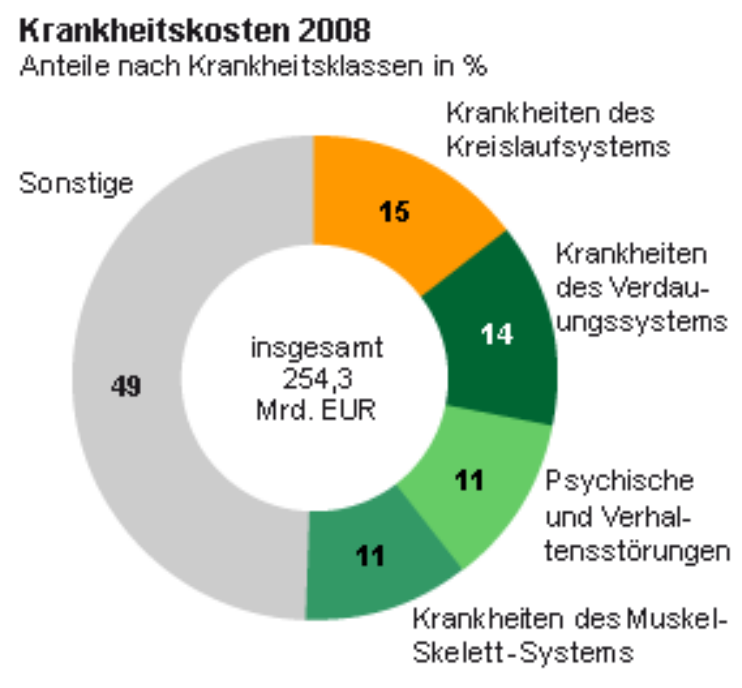

(G) Statistisches Bundesant, Wiesbaden 2015

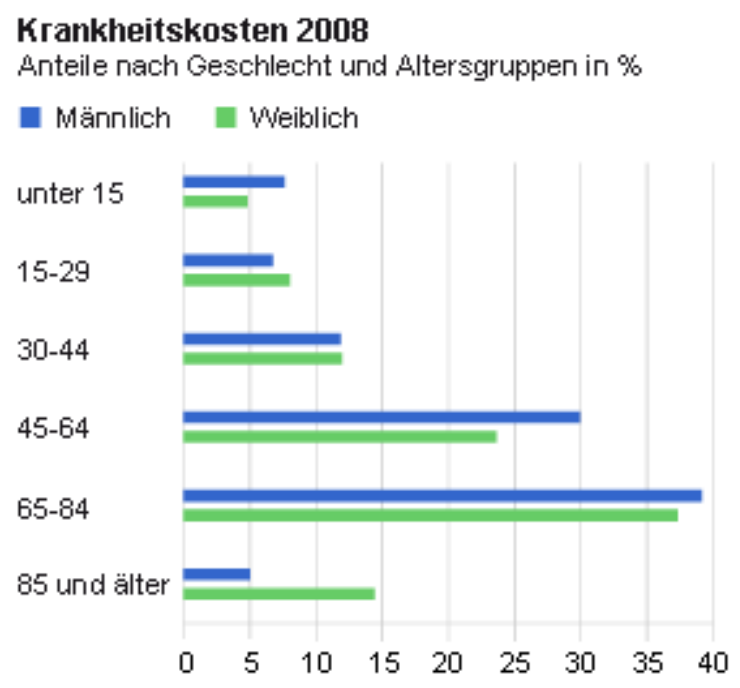

(9) Statistisches Bundesamt, Wiesbaden 2015

Abb. 4: Krankheitskosten nach Klasse

Abb. 5: Krankheitskosten nach Alter und Geschlecht

Diese Entwicklung hin zu höheren Kosten ist augenscheinlich auf eine demographische Veränderung hin zu einer älteren Gesellschaft zurückzuführen, auf die im Folgenden aufgrund ihrer Wichtigkeit kurz eingegangen wird. Jedoch greift sie als Erklärung zu kurz. Weitere wichtige Faktoren, die die Ausgaben im Gesundheitssystem wesentlich beeinflussen, sind Bildung und Einkommen sowie die Ausgestaltung des Leistungskatalogs, die Einführung 
neuer Gesundheitstechnologien und die Zulassung von Leistungserbringern (Bowles und Greiner 2012).

\subsubsection{Demographische Entwicklung}

Die Entwicklung der Bevölkerung in Deutschland lässt sich mit dem Begriff ,,doppelter Alterungsprozess“ beschreiben (Bowles und Greiner 2012). Gemeint ist die Kombination aus der anhaltend niedrigen Geburtenrate und der steigenden Lebenserwartung, die in einer absoluten und relativen Zunahme älterer Menschen in der Gesellschaft resultiert.

Abb. 6 zeigt exemplarisch die Bevölkerungspyramiden der Jahre 2012 und 2050.
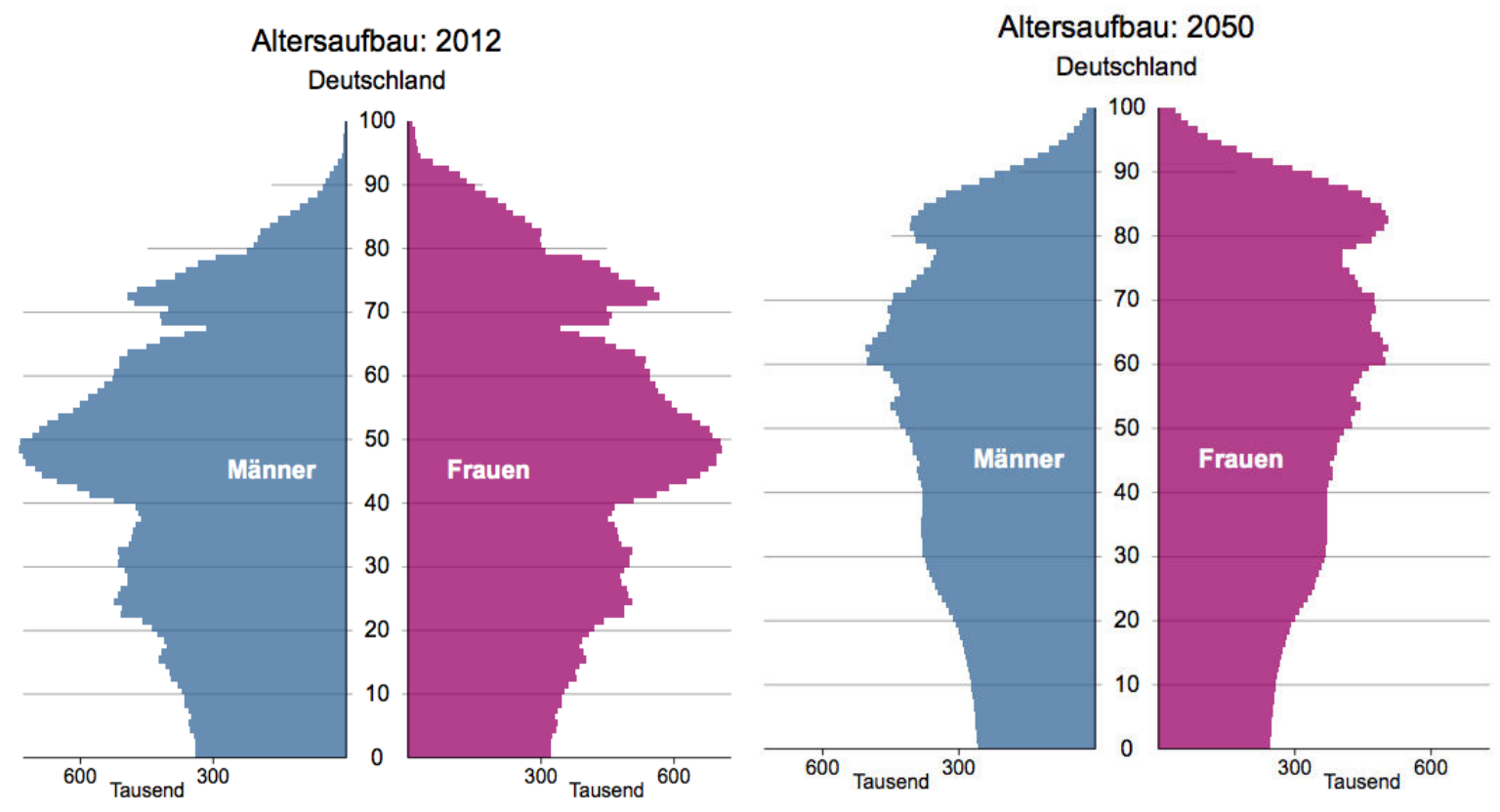

Abb. 6: Bevölkerungspyramiden 2012 und 2050

(Statistisches Bundesamt 2015, Bevölkerungsvorausberechnung)

\subsubsection{Relevanz der ökonomischen Betrachtung}

Grundlage aller gesundheitsökonomischen Überlegungen ist das sogenannte Allokationsproblem, welches die Frage nach der Verteilung begrenzter Ressourcen beschreibt. Die o.g. Entwicklungen tragen zu dieser Problematik bei, indem die Einnahmen- und Ausgabenseite im Gesundheitssystem vor allem durch die Altersstruktur, kostspielige medizinische Innovationen und die steigende Inanspruchnahme medizinischer Leistungen in ein ungünstiges Verhältnis gelangen.

Daher erlangen gesundheitsökonomischen Betrachtungen zunehmende Bedeutung, um politische Entscheidungsträger sowohl über Kosten von Erkrankungen als auch ökonomische Ef- 
fektivität von Therapiestrategien zu informieren. Sie stellen somit einen Baustein gesundheitspolitischer Entscheidungsprozesse dar.

Der in dieser Arbeit angestrebte Analysetyp ist die sogenannte Krankheitskostenanalyse und gehört zu den nicht-vergleichenden Studien (siehe Kapitel 2.4.1). Damit lässt ihr Ergebnis per se keine konkrete Handlungsempfehlung zu, wie es beispielsweise eine Kosten-NutzenAnalyse täte (Schöffski und v.d. Schulenburg 2012). Ihr Wert liegt vielmehr im Aufzeigen der volkswirtschaftlichen Bedeutung einerseits und im Bereitstellen von Daten für vergleichende Analysen andererseits. Ein weiterer wichtiger Aspekt ist der Erkenntnisgewinn aus Subgruppenanalysen, in denen z.B. Stadien der Erkrankung, demographische Parameter oder Komorbiditäten genauer untersucht werden und eine Identifizierung von besonders kostenintensiven Patientengruppen möglich wird. Dies kann etwa in Leitlinien praktische Anwendung finden, damit Ressourcen besonders fokussiert eingesetzt werden können.

\subsubsection{Ausgaben für Herzinsuffizienz}

Die jährlichen Ausgaben für Herzinsuffizienz steigen stetig und stellen eine enorme Belastung des Gesundheitswesens dar. So betrugen die Krankheitskosten für Herzinsuffizienz nach Angaben des Statistischen Bundesamtes im Jahr 20022375 Mio. Euro und 2008 bereits 3228 Mio. Euro (Statistisches Bundesamt Krankheitskosten 2008). In den westlichen Industrienationen, auch in Deutschland, ist sie für 1-2\% der direkten Krankheitskosten verantwortlich (Neumann et al. 2009)

Zugck et al. (2009) fanden heraus, dass Patienten mit Herzinsuffizienz im Durchschnitt 2,3fach höhere Gesamtkosten pro Krankenversicherten verursachen, wobei der Großteil der Kosten (72\%) im stationären Bereich anfällt. Patienten im NYHA-Stadium IV sind etwa 8bis 30-mal teurer als solche im NYHA-Stadium II (Klein 1999).

Die höheren Kosten bei zunehmender Schwere der Erkrankung sind leicht nachvollziehbar und wurden in anderen Untersuchungen bestätigt. So zeigten Biermann et al. (2011) Kostensteigerungen von 71\% zwischen Patienten mit NYHA I und NYHA IV auf. Die Autoren berechneten auf Grundlage von Daten verschiedener Studien des Kompetenznetzes Herzinsuffizienz Kosten von 3150 Euro pro Patienten für das Jahr 2009. Auf die stationäre Behandlung entfielen mit 74\% mit Abstand die meisten Kosten, Rehabilitation, Medikation und ambulante Arztkontakte fielen mit 9\%, 9\% und 8\% ins Gewicht.

Auch international wird das Problem dramatisch steigender Kosten erkannt, absolute Zahlen und Anteile schwanken jedoch stark zwischen Studien und Ländern. Die American Heart 
Association geht in einem Rechenmodell von einer Verdreifachung der Kosten bis 2030 aus (Heidenreich et al. 2013). Braunschweig et al. (2011) beschreiben einen Anstieg der Ausgaben für Herzinsuffizienz in den USA von 24,3 Mrd. USD im Jahre 2003 zu 39,2 Mrd. USD im Jahre 2010. Interessanterweise ist in diesem Zeitraum kein Anstieg des Anteils der Kosten an den Gesamtkosten kardiovaskulärer Erkrankungen zu beobachten, was auf die ähnlich dramatische Zunahme anderer Krankheitsentitäten des Herz-Kreislauf-Systems zurück schlieBen lässt. Die Autoren berechneten einen Anteil von 60\% der Gesamtkosten der Herzinsuffizienz für Hospitalisierung, auf Medikation und Hausarztbesuche entfielen 9 bzw. 7\%.

In einem Review zum Thema führt der Autor Simon Stewart zahlreiche weitere Studien aus den 1990er Jahren an, darunter aus den Niederlanden, England und Spanien, die den Anteil der Gesamtausgaben im Gesundheitssystem durch Herzinsuffizienz ebenfalls zwischen 1 und 2\% vermuten und den Kosten durch Hospitalisierung über zwei Drittel der Kosten zuschreiben (Stewart 2005). Der Autor vermutet aufgrund der Studienlage sogar, die Kosten würden unterschätzt, da die Herzinsuffizienz häufig nicht als primäre Diagnose kodiert werde.

\subsubsection{Ausgaben für Herzinsuffizienz mit erhaltener Ejektionsfraktion}

Trotz der annährend gleichen Prävalenz von Herzinsuffizienz mit erhaltener und reduzierter EF fällt die Datenlage für die HFpEF auch in Bezug auf die Krankheitskosten sehr gering aus. Alle der o.g. Studien und Daten differenzieren entweder gar nicht zwischen beiden Entitäten oder beschreiben Daten der systolischen Herzinsuffizienz.

Eine schwedische Studie untersuchte die ökonomische Last von HFpEF und berechnete durchschnittliche Krankheitskosten von umgerechnet 11.344 Euro pro Patient und Jahr (Stålhammar et al. 2014). 80\% der Kosten gingen dieser Studie nach auf Hospitalisierungen zurück. Eingeschränkt wird die Aussagekraft der Studie u.a. durch das mit 137 Patienten eher kleine Kollektiv und das retrospektive Studiendesign, in dem einheitliche Ein- und Ausschlusskriterien rückwirkend nicht kontrolliert werden konnten.

Biermann et al. (2012) führten eine Analyse mit Daten aus dem Kompetenznetz Herzinsuffizienz durch, in der Krankheitskosten und deren Zusammensetzung von systolischer und diastolischer Herzinsuffizienz verglichen wurden. 4714 Patienten mit Herzinsuffizienz (Durchschnittsalter 64,5 \pm 13,2 Jahre, 31.2\% weiblich, NYHA I-IV) aus zehn unabhängigen Studien bildeten die Studienpopulation, allerdings war bei dem Großteil die EF erhalten ( $n=3530)$. Die Patienten aus der HFpEF-Gruppe waren mit 66,8 Jahren \pm 13,0 etwas älter als die der HFrEFGruppe (Durchschnittsalter 63,7 Jahre \pm 13,2) und häufiger weiblichen Geschlechts (53,3\% vs. $23,8 \%$ ). Die Ergebnisse lassen sich in folgenden Kernaussagen zusammenfassen: 
1. Die Gesamtkosten der HFrEF sind deutlich höher als die der HFpEF (3373€ vs. $1271 €$ pro Kopf/ Jahr).

2. Den größten Kostenfaktor bilden mit ca. $74 \%$ der Gesamtkosten in beiden Gruppen Hospitalisierungen.

3. Auch die Verteilung der übrigen erfassten Ressourcenverbräuche ist bei Patienten mit HFrEF und Patienten mit HFpEF annährend identisch, es entfallen 10\% bzw. 9\% auf RehaAufenthalte, $8 \%$ bzw. 9\% auf ambulante Arztkontakte und 8\% auf Ausgaben für Medikamente.

\subsection{Fragestellung und Zielsetzung der vorliegenden Arbeit}

Die genannte Kostenentwicklung und Ausführung zur Epidemiologie der HFpEF zeigen, dass eine Auseinandersetzung mit dem Ressourcenverbrauch und den Kosten bei dieser Krankheit unumgänglich ist, um darauf aufbauend eine sinnvolle Verteilung der begrenzten Mittel im Gesundheitswesen anzustreben. Szucs (2003) sieht daher auch für die HFpEF die Notwendigkeit, dass Präventions- und Therapiemaßnahmen nicht nur sicher und wirksam, sondern auch kosteneffektiv sein müssen.

Die vorliegende Arbeit versucht, eine Krankheitskostenanalyse der diastolischen Herzinsuffizienz (berechnet für das Jahr 2011) für das ambulante stabile Kollektiv der ALDO-DHFStudie unter Einbeziehung von Medikation, Krankenhaus- und Reha-Aufenthalten sowie Kontakten zu Hausärzten bzw. Kardiologen zu erstellen.

Folgende Fragen werden adressiert:

a) Wie setzen sich die Gesamtkosten zusammen?

b) Gibt es einen Einfluss auf die Kosten durch die Therapie mit Spironolacton?

c) Was sind Prädiktoren für höhere Kosten? 


\section{Patientenkollektiv und Methoden}

\subsection{Die ALDO-DHF-Studie}

\subsubsection{Zielsetzung und Studiendesign}

Die ALDO-DHF-Studie (Aldosteron-Rezeptor-Blockade bei diastolischer Herzinsuffizienz) ist eine multizentrische, prospektive, randomisierte und kontrollierte Studie, an deren Durchführung zehn Zentren in Deutschland und Österreich beteiligt waren.

Sie wurde im Rahmen des Teilprojektes 7 (TP 7) „Diastolische Dysfunktion“ des Kompetenznetzes Herzinsuffizienz (www.knhi.de) durchgeführt.

Die Durchführung erfolgte doppelt verblindet in zwei Studienarmen, in denen Patienten unter der Einnahme von Spironolacton mit denen unter der Einnahme eines Placebos verglichen wurden.

Die primäre Fragestellung der Studie war, ob Patienten mit diastolischer Herzinsuffizienz von der Gabe von Spironolacton im Hinblick auf maximale Leistungsfähigkeit, Befunde in der Echokardiographie, Lebensqualität und bestimmte Laborparameter profitieren. Die detaillierte Auswertung wurde 2013 veröffentlicht (Edelmann et al. 2013). Des Weiteren wurden Angaben zu Arztkontakten, Reha- und Krankenhausaufenthalten und Medikation anamnestisch im Gespräch mit Doktoranden oder Study Nurses bei den Visiten erfasst.

Nach Screening und Baseline wurden die Patienten alle drei Monate zur Follow-UpUntersuchung einbestellt und so insgesamt über einen Zeitraum von 12 Monaten beobachtet. Die Durchführung der Studie erstreckte sich über den Zeitraum März 2007 bis April 2012.

\subsubsection{Rekrutierung der Patienten}

Zum Screening wurden alle ambulanten und stationären Patienten der teilnehmenden Zentren eingeladen, die Zeichen und Symptome der Herzinsuffizienz aufwiesen und bei denen keine reduzierte LVEF beschrieben war. Dafür wurden Arztbriefe und Echo-Befunde gesichtet. Telefonisch konnte vorab durch gezielte Fragen nach Symptomatik und Vorerkrankungen die Zahl der Screening-Teilnehmer eingegrenzt werden.

Beim Screening erfolgte eine mündliche sowie schriftliche Aufklärung über die Teilnahme an der Studie durch einen der Studienärzte. Um die Teilnahmebedingungen zu evaluieren, erfolgten nun klinische Untersuchungen, detaillierte Anamnese, echokardiographische Untersuchung, Laboruntersuchung und ein Belastungstest mittels Spiroergometrie.

Waren alle Kriterien zur Teilnahme erfüllt, und die Einwilligung lag schriftlich vor, wurden die Patienten im Verhältnis 1:1 auf Verum- und Placebogruppe randomisiert. 
Um die Reproduzierbarkeit zu gewährleisten, wurden die echokardiographische und die spiroergometrische Untersuchung bei der Baseline-Untersuchung wiederholt, die etwa eine Woche nach dem Screening durchgeführt wurde.

\subsubsection{Ein- und Ausschlusskriterien}

Für eine Studienteilnahme kamen männliche und weibliche Patienten ab 50 Jahren infrage, die Zeichen und Symptome der Herzinsuffizienz aufwiesen und der NYHA-Klasse II oder III zuzuordnen waren. Die echokardiographischen Parameter mussten einer diastolischen Dysfunktion entsprechen, insbesondere durfte die LVEF nicht $<50 \%$ liegen.

In der Spiroergometrie gehörte eine maximale Sauerstoffaufnahme $\left(\mathrm{VO}_{2} \max \right)<25 \mathrm{ml} / \mathrm{kg} / \mathrm{min}$ zu den Einschlusskriterien.

Schließlich war die schriftliche Einwilligung des Patienten nach einem zuvor durchgeführten Aufklärungsgespräch Voraussetzung für den Einschluss in die Studie.

Ausschlusskriterien wurden so gewählt, dass andere, z.B. pulmonale Ursachen der Symptome ausgeschlossen und Risiken für mögliche Nebenwirkungen der chronischen AldosteronRezeptor-Blockade minimiert werden konnten. Dazu gehörten u. a. pulmonale Erkrankungen mit einer $\mathrm{VC}<80 \%$ oder einer FEV $1<80 \%$, die im Screening mittels Spirometrie ermittelt wurden. Außerdem das Vorliegen eines BMI $>36 \mathrm{~kg} / \mathrm{m}^{2}$, einer signifikanten Koronarstenose $>50 \%$, bestehende Angina-Pectoris-Beschwerden, renale Dysfunktion mit einem Kreatinin von $>1,8 \mathrm{mg} / \mathrm{dl}$ bzw. einer eGFR $<30 \mathrm{ml} / \mathrm{min} / 1,73 \mathrm{~m}^{2}$. Im Labor ließen bestimmte Veränderungen eine Teilnahme nicht zu, darunter ein Kalium $\geq 5,1 \mathrm{mmol} / \mathrm{l}$, Hämoglobin $\leq 11 \mathrm{~g} / \mathrm{dl}$ und ein Hämatokrit $\leq 33 \%$. Die regelmäßige Einnahme von Medikamenten durfte sich innerhalb von 2 Wochen vor dem Screening nicht verändert haben, eine bekannte Intoleranz gegen Aldosteron-Rezeptor-Antagonisten durfte nicht bestehen. Ebenso führten regelmäßige Einnahmen von NSAR, Insulin bei Diabetes mellitus, hochdosiertes ASS (> $500 \mathrm{mg} / \mathrm{d}$ ) und Kaliumsubstitution zum Ausschluss. Schließlich gehörten auch psychische Erkrankungen, die Studie und Compliance negativ beeinflussen könnten, wie Demenz oder bekannter Drogenabusus zu den Ausschlusskriterien.

\subsubsection{Studienmedikation}

Bei der Studienmedikation handelte es sich um Spironolacton (Verospiron T $®$ ) in der Dosierung 25mg pro Tag. Verospiron T und das Placebopräparat wurden als Tablette appliziert. Die Patienten wurden angehalten, morgens eine Tablette mit dem Frühstück mit etwas Flüssigkeit einzunehmen. Die Zuteilung zu den zwei Gruppen erfolgte doppelt verblindet im Verhältnis 1:1, d.h. weder Arzt noch Patient wusste, ob Verum oder Placebo eingenommen wurde. 
Bei Kaliumwerten $>5,2 \mathrm{mmol} / \mathrm{l}$ und nicht-schwerwiegenden Nebenwirkungen konnte die Dosierung zeitweise auf $25 \mathrm{mg}$ jeden zweiten Tag herabgesetzt werden.

Die Studienmedikation wurde abgesetzt bei Hyperkaliämie (Kalium > 5,5 mmol/l), Hyperkaliämie-bedingten klinischen Symptomen, Verschlechterung der Nierenfunktion mit einem Serum-Kreatinin > 2,5 mg/dl, Angina pectoris Beschwerden oder Gynäkomastie.

\subsection{Anamnese}

Bei jedem Patientenkontakt wurde ein ausführliches Anamnesegespräch von einem Doktoranden oder einer Study Nurse geführt. Die Patientenangaben wurden durch Vorbefunde und Arztbriefe, ggf. durch körperliche Untersuchung bestätigt oder ergänzt.

Arztkontakte, Krankenhausaufenthalte und Medikation sind in dieser Arbeit von besonderer Relevanz, sodass ihre Erhebung gesondert beschrieben wird.

Anamnestisch erfasst wurden in der Baseline zunächst Symptome der Herzinsuffizienz, insbesondere Belastungs- und Ruhedyspnoe, Ödeme, Orthopnoe, paroxysmale nächtliche Dyspnoe, nächtlicher Husten, Nykturie, Müdigkeit und Leistungsschwäche.

Dann wurden die kardiovaskulären Risikofaktoren Diabetes Mellitus, arterielle Hypertonie, Hyperlipidämie, Hyperurikämie, Schlafapnoesyndrom, familiäre Vorbelastung (Myokardinfarkt vor dem 60. Lebensjahr bei leiblichen Eltern, Geschwistern und Kindern), sowie Rauchund Trinkgewohnheiten (Menge und Dauer des Konsums) erfragt. Außerdem wurden bisherige kardiovaskuläre Interventionen abgefragt - im Einzelnen koronare oder periphere Revaskularisation, Bypass-OPs, sonstige Gefäß-OPs, Herzklappen-OPs, Schrittmacher-/ Defibrillatorenimplantationen und Herztransplantation.

Bei den kardialen Diagnosen wurde nach Angina-Pectoris-Beschwerden gefragt, erlittenen Myokardinfarkten, primären Herzklappenerkrankungen, angeborenen und erworbenen Herzfehlern (soweit möglich echokardiographisch bestätigt oder diagnostiziert), Vorhofflimmern und bekannter Kardiomyopathie.

Schließlich wurden Angaben zu aktuellen Nebendiagnosen evaluiert, dazu zählten pAVK, zerebrovaskuläre Erkrankungen, erlittene Synkopen, COPD, primär pulmonale Hypertonie, Depression, HIV-Infektion, chronische Hepatitis B oder C, Leberzirrhose und maligne Erkrankungen. Bei Frauen wurde das Jahr der Menopause erfragt.

Um weitere Daten zur Lebensqualität und soziodemographischen Parametern zu erhalten, erhielten die Patienten standardisierte Fragebögen, bei deren Beantwortung bei Bedarf ein Doktorand oder einer Study Nurse erklärend zur Seite stand. Diese waren der 36-Item Short 
Form Health Survey (SF-36), der Minnesota Living With Heart Failure Questionnaire, der Patient Health Questionnaire und die Hospital Anxiety and Depression Scale.

Diese in der Baseline erfassten Angaben wurden in den Follow-Up-Visiten aktualisiert. Symptome der Herzinsuffizienz wurden erneut erhoben, ebenso wie neue Nebendiagnosen, kardiovaskuläre Interventionen der jeweils vergangenen drei Monate und neu aufgetretene bzw. gestellte kardiale Diagnosen.

\subsubsection{Erhebung der Krankenhausaufenthalte und Arztkontakte}

Im Rahmen der Baseline wurden alle Arztkontakte und Krankenhaus- bzw. Reha-Aufenthalte der letzten 12 Monate vor Studienbeginn erfragt, die wegen der Herzinsuffizienz in Anspruch genommen worden waren. Dabei wurde lediglich die Anzahl der jeweiligen Kontakte bzw. Aufenthalte dokumentiert, also weder der genaue Grund, noch die Dauer des Aufenthaltes. Unterschieden wurde dabei in Hausarztkontakte, Kardiologenkontakte, Krankenhaus- und Reha-Aufenthalte.

In den Follow-Up-Visiten wurde dann die Anzahl der in den jeweils vergangenen drei Monaten stattgefundenen o.g. Kontakte und Aufenthalte aufgrund von Herzinsuffizienz erhoben. Zusätzlich wurden in diesen Visiten die Tage der Aufenthalte dokumentiert. Bei mehreren Aufenthalten wurden dabei die Tage der einzelnen Aufenthalte summiert.

\subsubsection{Erhebung der regelmäßig eingenommenen Medikamente}

Die aktuelle Medikation, also alle regelmäßig eingenommen Medikamente, wurde ebenfalls in jeder Visite anamnestisch erfasst. Die Patienten wurden gebeten, wenn möglich eine Auflistung der Medikamente und deren Dosierungen zu den Visiten mitzubringen, um Vollständigkeit zu gewährleisten. Abgefragt wurden nacheinander alle relevanten Medikamente, unterteilt in verschiedene Gruppen.

Diese waren kardiovaskuläre Medikamente (ACE-Hemmer, AT1-Rezeptorantagonisten, Betablocker, Thiazide, Schleifendiuretika, Aldosteron-Antagonisten, kaliumsparende Diuretika, andere Diuretika, Herzglykoside, Nitrate, Kalziumantagonisten, Antiarrhythmika), Lipidsenker (Statine, andere Lipidsenker), Antikoagulantien (ASS, andere Plättchenhemmer, Vitamin K-Antagonisten, andere Antikoagulantien), Antidiabetika (Insulin, orale Antidiabetika), pulmonale Medikamente (orale Substanzen, Inhalativa), andere Medikamente (Antidepressiva, Schlaf- und Beruhigungsmittel, Allopurinol, Antiphlogistika), sonstige Medikamente (nicht den o.g. Gruppen zugehörig) und orale Kontrazeptiva bzw. postmenopausale Hormone. 
In den Follow-Up-Visiten wurde nach Änderungen in der Medikation oder Dosierung gefragt, die in den jeweils vergangenen drei Monaten stattgefunden hatten. Wann genau diese Änderung erfolgt war, wurde nicht erfasst.

\subsection{Untersuchungen}

Die Patienten wurden zunächst körperlich, insbesondere kardiologisch untersucht. Besonders wurde auf Zeichen der Herzinsuffizienz geachtet, wie z.B. Beinödeme, pulmonale Rasselgeräusche oder gestaute Halsvenen.

Anschließend erfolgte nach mindestens 30-minütiger Ruhezeit und im nicht-nüchternen $\mathrm{Zu}$ stand die Blutentnahme zur Basislabordiagnostik und weiterführender spezieller Labordiagnostik. Neben einem Blutbild und Elektrolyten wurden Nieren- und Leberfunktionsparameter, das Glykohämoglobin, die Fraktionen der Blutfette und die alkalische Phosphatase bestimmt. Hinzu kam die quantitative Messung des NT-proBNP und Galectin-3 aus dem Blutplasma.

Als einfach durchzuführender Test zur Abschätzung von Prognose und Schwere einer Herzinsuffizienz wurde dann der sogenannte 6-Minuten-Gehtest durchgeführt.

Bei der Baseline-Untersuchung fand zusätzlich eine Lungenfunktionsuntersuchung statt, um die Ausschlusskriterien zu prüfen, also pulmonale Erkrankungen auszuschließen.

Ein 12-Kanal-Ruhe-EKG wurde zur Prüfung von Herzrhythmus und -frequenz, Lagetyp, Überleitungszeiten, Erregungsrückbildung und etwaigen Ischämie-bedingten Veränderungen angefertigt.

Eine der Hauptuntersuchungen zur Beurteilung der Leistungsfähigkeit und deren Verlauf unter Medikamenteneinnahme innerhalb der Studie war die Spiroergometrie. Diese wurde, von einem Arzt überwacht, unter ständiger Ableitung eines 12-Kanal-EKGs und engmaschiger manueller Blutdruckmessungen auf einem Fahrradergometer durchgeführt. Das Protokoll sah eine Anfangsbelastung von 20 Watt vor, die alle 2 Minuten um 20 Watt gesteigert wurde. Ziel war eine maximale Auslastung des Patienten entsprechend der gemessenen Werte, jedoch waren auch andere Abbruchkriterien wie Angina-Pectoris-Beschwerden oder extreme Blutdruckwerte oder eine subjektive Überlastung des Patienten zulässig. Eine Vielzahl von Parametern konnte über den Monitor erfasst und dokumentiert werden. Darunter Zeit, Arbeitslast in Watt, Sauerstoffaufnahme $\mathrm{VO}_{2}$ in $\mathrm{ml} / \mathrm{min}$, Sauerstoffaufnahme $\mathrm{VO}_{2} / \mathrm{kg}$ in $\mathrm{ml} / \mathrm{min} / \mathrm{kg}$, Kohlendioxidabgabe $\mathrm{VCO}_{2}$ in $\mathrm{ml} / \mathrm{min}$, Respiratorischer Quotient (RQ) $\mathrm{VCO}_{2} / \mathrm{VO}_{2}$, Herzfrequenz in Schläge/min und Blutdruckwerte in $\mathrm{mmHg}$, Atemminutenvolumen VE, die Quotienten $\mathrm{VE} / \mathrm{VCO}_{2}$ und $\mathrm{VE} / \mathrm{VO}_{2}$, Atemzugvolumen $\mathrm{AZV}$ und Atemfrequenz während der Spiroergometrie. Alle Werte wurden über ein Intervall von 10 Sekunden gemittelt. 
Die transthorakale Echokardiographie stellte eine weitere wesentliche Untersuchung zur Objektivierung der Herzfunktion, insbesondere der diastolischen Funktion, dar. Sie wurde von einem von den Core Labs für die Studie zertifizierten Prüfer durchgeführt und auf einem Videoband oder einer Optical disc aufgezeichnet. Die Messwerte wurden in die entsprechenden Befundbögen eingetragen, welche den Core Labs per Fax zugesandt wurden.

Zur Prüfung der systolischen Funktion wurde zunächst die linksventrikuläre Ejektionsfraktion LVEF gemessen. Eine EF $<50 \%$ galt als Ausschlusskriterium. Dann wurden alle Klappen auf relevante Stenosen oder Insuffizienzen untersucht. Schließlich erfolgte die Bestimmung des Grades der HFpEF.

Grad 0 (normales Füllungsmuster) verlangte einen Wert E/A $\geq 1$. Dieser Quotient ergibt sich aus der maximalen frühdiastolischen Einflussgeschwindigkeit E und dem Mitralklappenfluss bei Vorhofkontraktion A. Zusätzlich mussten zwei der drei folgenden Kriterien erfüllt sein:

1. $\mathrm{E} / \mathrm{e}^{\prime}<10 \mathrm{im}$ Gewebedoppler

2. Der maximale systolische Fluss (S) über der Pulmonalvenenklappe (PV) muss größer oder gleich dem maximalen diastolischen Fluss (D) sein

3. Auch beim Valsalvamanöver soll der E/A-Quotient $\geq 1$ bleiben.

Grad I ist das Stadium der verzögerten Relaxation, kennzeichnend ist ein E/A $<1$.

Grad II erfordert einen Quotienten E/A von Werten zwischen 1 und 2, weshalb man von einer Pseudonormalisierung spricht. Darüber hinaus müssen zwei der drei folgenden Kriterien erfüllt sein:

1. $\mathrm{E} / \mathrm{e}^{\prime} \geq 10$

2. Der maximale systolische pulmonalvenöse Druck ist kleiner als der maximale diastolische Fluss

3. Im Valsalvamanöver sinkt E/A auf Werte unter 1, was als Demaskierung bezeichnet wird.

Grad III (restriktives Füllungsmuster) erfordert ein E/A $\geq 2$ und zwei der folgenden Kriterien:

1. $\mathrm{E} / \mathrm{e}^{\prime} \geq 15$

2. Der maximale systolische pulmonalvenöse Druck ist kleiner als der maximale diastolische Fluss

3. Unter Valsalvamanöver sinkt $\mathrm{E} / \mathrm{A}<1$. 
Grad IV entspricht einer irreversiblen Restriktion.

\begin{tabular}{|c|c|c|c|c|}
\hline $\begin{array}{l}\text { Diastolische } \\
\text { Funktion }\end{array}$ & $\begin{array}{l}\text { Normal } \\
\text { Grad } 0\end{array}$ & $\begin{array}{l}\text { Verzögerte } \\
\text { Relaxation } \\
\text { Grad I }\end{array}$ & $\begin{array}{l}\text { Pseudonormale } \\
\text { Füllung } \\
\text { Grad II }\end{array}$ & $\begin{array}{l}\text { Restriktion } \\
\text { Reversibel irreversibel } \\
\text { Grad III Grad IV }\end{array}$ \\
\hline Parameter & & & & \\
\hline \multirow{2}{*}{$\mathrm{E} / \mathrm{A}$} & $\geq 1$ & $<1$ & $\geq 1$ und $<2$ & $\geq 2$ \\
\hline & $\begin{array}{l}\text { UND } \\
2 \text { von } 3 \\
\text { Kriterien }\end{array}$ & & $\begin{array}{l}\text { UND } \\
2 \text { von } 3 \text { Kriterien }\end{array}$ & $\begin{array}{l}\text { UND } 2 \text { von } 3 \text { Kriterien } \\
\text { und Valsalvamanöver }\end{array}$ \\
\hline$E / e^{6}$ & $<10$ & & $\geq 10$ & $\geq 15$ \\
\hline PV: S/D & $\geq 1$ & & $<1$ & $<1$ \\
\hline $\mathrm{E} / \mathrm{A}_{\text {Valsalva }}$ & $\geq 1$ & & $<1$ & $\geq 1$ \\
\hline
\end{tabular}

Tabelle 2: Klassifikation der Diastolischen Funktion in ALDO-DHF (Edelmann et al. 2010)

\subsection{Gesundheitsökonomische Evaluation}

\subsubsection{Einführung und Studientypen}

Gesundheitsökonomie ist die Analyse der wirtschaftlichen Aspekte des Gesundheitswesens unter Verwendung von Konzepten der ökonomischen Theorie (Schöffski, v.d. Schulenburg 2012). Die folgende kurze Zusammenfassung und Erklärung der verschiedenen Analysearten ist angelehnt an die Ausführungen des Buches Gesundheitsökonomische Evaluationen (4. Auflage, 2012) von Schöffski und v. d. Schulenburg.

Gesundheitsökonomische Evaluationen können vergleichend und nicht-vergleichend durchgeführt werden. Zu den nicht-vergleichenden Studien werden die Kostenanalyse und die Krankheitskostenanalyse gezählt. Sie bieten im Hinblick auf die Frage der Verteilung von Ressourcen keine hinreichenden Informationen, da sie lediglich die durch medizinische Maßnahmen oder eine Krankheit anfallenden Kosten bestimmen (Schöffski, v. d. Schulenburg, 2012).

a) Die Kostenanalyse stellt die einfachste Form der gesundheitsökonomischen Evaluation dar. Sie bestimmt die Kosten, die eine medizinische Maßnahme bzw. eine Behandlung verursacht. 
b) Die Krankheitskostenanalyse ist eine relativ häufig durchgeführte Sonderform der Kostenanalyse, bei der die gesamtgesellschaftliche Bedeutung im Sinne der volkswirtschaftlichen Belastung einer Krankheit beleuchtet wird. Dazu werden alle durch die Krankheit und ihre Folgen verursachten Kosten ermittelt (z.B. für Diagnosestellung, Therapie, Produktionsausfall etc.).

Die vergleichenden Studienformen ermöglichen den Vergleich zwischen zwei oder mehr Behandlungsalternativen und können daher helfen, die Allokation im Gesundheitswesen zu verbessern (Schöffski, v. d. Schulenburg, 2012).

Zu ihnen zählen

a) Die Kosten-Kosten-Analyse hat das Ziel, unter verschiedenen medizinischen Maßnahmen die kostengünstigste herauszufinden. Dabei muss natürlich von einer Ergebnisgleichheit ausgegangen werden. Die Kosten der Maßnahmen werden separat berechnet und dann miteinander verglichen.

b) Die Kosten-Nutzen-Analyse stellt alle Faktoren von Kosten und Nutzen einander gegenüber und bewertet ihr Verhältnis. Dazu werden diese Faktoren auf beiden Seiten in monetären Größen betrachtet, auch solche, die eigentlich als nicht monetär messbar gelten (sog. intangible Komponenten, siehe unten).

c) Die Kosten-Wirksamkeits-Analyse vergleicht im Gegensatz dazu die Kosten medizinischer Maßnahmen mit ihren nicht-monetären Effekten. Als Parameter dieser Effekte kommen verschiedene medizinische oder epidemiologische Größen infrage, z.B. Senkung des Blutdrucks, Anzahl gewonnener Lebensjahre etc..

d) Die Kosten-Nutzwert-Analyse stellt den Kosten den Nutzwert aus Sicht des Patienten gegenüber. Es werden Lebensqualität und Lebenserwartung berücksichtigt, die häufig im Konzept der qualitätskorrigierten Lebensjahre (QUALY = Quality Adjusted Life Years) ausgedrückt werden.

Der in dieser Arbeit genutzte Analysetyp ist die Krankheitskostenanalyse.

\subsubsection{Kostenarten}

Bei ökonomischen Bewertungen im Gesundheitswesen werden Kosten grundsätzlich in drei Gruppen aufgeteilt - direkte Kosten, indirekte Kosten und intangible Kosten (Szucs 2003). 
Die direkten Kosten umfassen alle medizinischen und nicht-medizinischen Kosten, die im direkten Zusammenhang mit der Erkrankung stehen. Sie umfassen unter anderem Kosten für ärztliche Behandlung, Diagnosestellung, Medikamente, sonstige Therapieaufwendungen, Krankentransporte und viele andere.

Als indirekte Kosten bezeichnet man die mortalitäts- oder morbiditätsbedingten Ausfälle an Produktivität z.B. durch Krankschreibungen, vorzeitigen Tod oder vorzeitige Berentung. Sie werden daher auch volkswirtschaftliche Kosten genannt (Szucs 2003).

Intangible Kosten sind schwer zu messen, da sie sich nicht in Geldwerten quantifizieren lassen. Zu dieser Kategorie gehören z.B. Schmerz, Verlust an Lebensqualität und Trauer.

In dieser Arbeit stehen die direkten Kosten im Vordergrund, weil die zur Berechnung der anderen Kostenarten notwendigen Parameter in der ALDO-DHF-Studie nicht erhoben wurden. Durch den Zusammenhang von hohem Alter und der Erkrankung HFpEF dürften die indirekten Kosten auch eine deutlich kleinere Rolle spielen als etwa bei Krankheiten wie HIV oder KHK, von der viel mehr Patienten im berufsfähigen Alter betroffen sind.

\subsubsection{Perspektiven und Zeithorizont}

Für die Bewertung der Ergebnisse einer gesundheitsökonomischen Analyse ist die Frage der eingenommenen Perspektive wichtig und vorab zu klären. Die umfassendste und in der vorliegenden Arbeit gewählte Perspektive ist die der Gesellschaft, die gesamtwirtschaftliche Konsequenzen berücksichtigt. Im Gegensatz zu anderen möglichen Sichtweisen wie der Krankenkassen-, Krankenhaus- oder Patientenperspektive werden hier alle Kostenfaktoren einbezogen, soweit ihre Berechnung mit den vorhandenen Daten möglich ist, unabhängig davon, bei wem diese Kosten anfallen.

Der Zeithorizont der erhobenen Daten schließt 12 Monate vor Baseline bis zur abschließenden Untersuchung 12 Monate nach Einschluss in die Studie ein.

\subsubsection{Methoden der Kostenbestimmung}

Nach Schöffski und v.d. Schulenburg (2012) gibt es zwei Möglichkeiten der Durchführung einer Krankheitskostenstudie. Diese werden Top-Down- und Bottom-Up-Ansatz genannt. Der Unterschied besteht beispielsweise darin, ob die Daten prospektiv oder retrospektiv erhoben werden und in der sogenannten Aggregationsebene, auf der sie erfasst und weiterverarbeitet werden. Bei dem Bottom-Up-Ansatz ist der Aggregationsgrad gering, was bedeutet, dass die Daten auf der Ebene einzelner Patienten erhoben werden. In der vorliegenden Arbeit wird dieser Ansatz zur Bestimmung des Ressourcenverbrauchs verwendet. Die Datenerfassung 
kann auf verschiedene Art und Weise erfolgen. Die Erhebung im Rahmen einer kontrollierten klinischen Studie wie in der vorliegenden Arbeit ist nach Icks et al. (2010) der Goldstandard für die Beobachtung von Interventionseffekten, da eine Kostenerfassung sehr detailliert möglich ist und sich Kostendaten und Effekte auf das gleiche Patientenkollektiv beziehen. $\mathrm{Zu}$ kleine Fallzahlen und oft kurze Beobachtungszeiträume werden als Nachteile angeführt.

\subsection{Preisgerüst der relevanten Variablen}

Zur Kostenberechnung ist es notwendig, neben der Menge auch den Preis der einzelnen Ressourcen zu erheben. Die Preise im Gesundheitssystem werden jedoch nicht wie in anderen Märkten allein durch Angebot und Nachfrage bestimmt, sondern auch staatlich reguliert und durch Verhandlungen von staatlichen und halbstaatlichen Institutionen beeinflusst (Schöffski, v.d. Schulenburg 2012).

Erschwerend kommt hinzu, dass sich die Preise je nach gewählter Perspektive deutlich unterscheiden. Eine stationäre Behandlung belastet den Kostenträger (Krankenkasse) beispielsweise deutlich weniger als die Gesellschaft, die auch für Arbeitsausfall, Personal- und Investitionskosten etc. aufkommen muss.

In Deutschland werden häufig die empirischen Bewertungsansätze von Krauth et al. (2005) für gesundheitsökonomische Analysen genutzt, die zwar eine gute Vergleichbarkeit ermöglichen, jedoch nicht mehr sehr aktuell sind.

Indirekte Kosten, wie sie z.B. durch Frührente oder Abwesenheit am Arbeitsplatz entstehen, konnten mit den in der ALDO-DHF-Studie erfassten Daten nicht berechnen werden.

Als Referenzjahr bei der Berechnung wurde das Jahr 2011 gewählt, weil der überwiegende Teil der Daten aus diesem Jahr stammt.

Im Folgenden wird für die einzelnen Ressourcenverbräuche dargestellt, nach welcher monetären Bewertung die Kostenkalkulation durchgeführt wurde.

\subsubsection{Medikamentenpreise}

Wie oben beschrieben, wurden von allen regelmäßig eingenommenen Medikamenten Wirkstoffname und Tagesdosis erfasst. Für die Bepreisung der Medikamente wurde die ROTE LISTE aus dem Jahr 2011 als Grundlage gewählt, da das Jahr 2011 als Basisjahr identifiziert wurde. Für jeden Wirkstoff wurde der Preis des günstigsten Generikums und der größten frei verkäuflichen Packungsgröße (N3) zugrunde gelegt und daraus der Preis pro mg dieses Wirkstoffes ermittelt.

Vor der Berechnung wurden die Wirkstoffnamen des Studiendatensatzes noch einmal auf 
Abweichungen in der Rechtschreibung bzw. die fälschliche Eingabe von Handelsnamen untersucht und entsprechend korrigiert. Kleinere Modifikationen des Primärdatensatzes gab es auch, wenn Wirkstoffe offensichtlich der falschen Gruppe zugeordnet worden waren - diese wurden in die korrekte Gruppe verschoben. Präparate, die zwar einer Gruppe zugeordnet werden konnten, aber nur einmal im gesamten Datensatz vorkamen, wurden aus Gründen der Übersichtlichkeit vernachlässigt.

Folgende Gruppen von Medikamenten wurden in der Berechnung berücksichtigt: Betablocker, ACE-Hemmer, Herzglykoside, Statine, andere Lipidsenker, Antikoagulantien, Nitrate, orale Antidiabetika, Insuline, Antiarrhythmika, Kalziumantagonisten, AT1-Antagonisten, Diuretika und pulmonale Medikamente.

\subsubsection{Berechnung der Arztkontaktwerte}

Zur Berechnung der Kosten für ambulante Arztgesuche wurde auf die von Krauth et al. (2005) vorgeschlagenen Kontaktwerte zurückgegriffen. Diese stammen aus dem Jahr 1999 und wurden aus Abrechnungsdaten der Kassenärztlichen Vereinigungen gewonnen. Für den hier verwendeten gesellschaftlichen Kontaktwert wurde von den Autoren eine Stichprobe von Versicherten des Verbandes der Privaten Krankenversicherungen berücksichtigt.

Die Anzahl der Arztkonsultationen je Patient wurde mit dem gesellschaftlichen Kontaktwert der jeweiligen Facharztgruppe multipliziert, nachdem dieser inflationsbereinigt worden war. Dazu wurde ein Quotient aus dem Verbraucherpreisindex (VPI) des Jahres 2011 (Referenzjahr) und dem des Jahres 1999 gebildet und dieser mit den Kontaktwerten aus dem Jahr 1999 multipliziert (Tabelle 3).

Die relevanten Facharztgruppen waren Kardiologen und Hausärzte. Da sowohl Allgemeinmediziner als auch Internisten hausärztlich tätig sind, wurde der Durchschnitt der beiden Kontaktwerte genommen.

\begin{tabular}{|l|l|l|l|}
\hline & $\begin{array}{l}\text { gesellschaftlicher Kontaktwert } \\
\text { pro Arztkontakt im Jahr 1999 }\end{array}$ & $\begin{array}{l}\text { Inflationsausgleich } \\
* \text { (VPI 2011/VPI 1999) }\end{array}$ & $\begin{array}{l}\text { Gesellschaftlicher Kontaktwert } \\
\text { pro Arztkontakt im Jahr 2011 }\end{array}$ \\
\hline Allgemeinmediziner & 15,24 & $* 110,7 / 91,4$ & 18,46 \\
hausärztlicher Internist & 17,71 & $* 110,7 / 91,4$ & 21,45 \\
Hausarzt durchschnittlich & 16,48 & $* 110,7 / 91,4$ & $\mathbf{1 9 , 9 5}$ \\
Kardiologe & 58,75 & $* 110,7 / 91,4$ & $\mathbf{7 1 , 1 6}$ \\
\hline
\end{tabular}

Tabelle 3: Kontaktwerte in € nach Facharztgruppe, inflationsbereinigt für das Jahr 2011 VPI = Verbraucherpreisindex. Modifiziert nach Krauth et al. (2005) 


\subsubsection{Kosten für Hospitalisierungen}

Nach Krauth et al. (2005) können für die stationäre Versorgung drei Bewertungsansätze unterschieden werden: der bundesdurchschnittliche Tagespflegesatz, abteilungsspezifische bundesdurchschnittliche Tagespflegesätze und Fallpauschalen.

Im Gespräch mit den Patienten wurden bei Baseline die Anzahl der Krankenhausaufenthalte aufgrund von Herzinsuffizienz der letzten zwölf Monate erfragt, in den Visiten auch zusätzlich die Gesamtzahl der Tage.

Die konkreten DRGs zur Herzinsuffizienz heißen F62 A-C, wobei A, B und C den Schweregrad angeben. Diese Hauptdiagnosen sind im Datensatz nicht vorhanden, sodass aus den Fallzahlen der jeweiligen DRG aus dem Jahr 2011 (Statistisches Bundesamt, DRG-Statistik 2011) ein gewichteter Mittelwert ihrer Bewertungsrelation berechnet wurde.

Die Bewertungsrelation multipliziert mit dem Bundesbasisfallwert für das Jahr 2011 ergibt dann die durchschnittlichen Kosten eines Aufenthaltes.

Jedoch gibt das DRG-System nur die Kosten aus Krankenkassensicht wieder, für die gesellschaftliche Betrachtung ist es nicht ausreichend. Dies liegt in der in Deutschland bestehenden dualen Finanzierung begründet, bei der die Investitionskosten für die stationäre Versorgung nicht von den Krankenkassen, sondern von den Bundesländern getragen werden. Der von Krauth et al. (2005) vorgeschlagene Betrag dieser sogenannten Kapitalkosten je Pflegetag wurde übernommen und für das Basisjahr inflationsbereinigt. Anschließend wurde er mit der Anzahl der Hospitalisierungstage multipliziert und das Produkt zu den Gesamtkosten addiert.

\subsection{Statistische Auswertung}

Nach der Erstellung des Preisgerüstes für die erhobenen Ressourcenverbräuche konnte die Berechnung der Kosten erfolgen. Die Einzelkosten, welche das Produkt der ermittelten Preise und der Ressourcenverbräuche darstellen, wurden zur Ermittlung der Krankheitskosten addiert.

Der Original-SPSS-Datensatz umfasst 3783 Variablen bei 422 eingeschlossenen Patienten. Daher bestand der erste Schritt darin, die Variablen zu selektieren, die für die Analyse benötigt werden. Dabei waren die Variablennamen im CRF nicht dieselben wie im Datensatz. Für die metrischen Baselinevariablen wurden die deskriptiven Kenngrößen getrennt für beide Therapiegruppen berechnet. Um zu überprüfen, ob die Verteilung der Baselinevariablen in den beiden Therapiegruppen übereinstimmt, wurden erstens gruppierte Boxplots erstellt und zweitens deskriptive p-Werte berechnet. In den Boxplots fiel auf, dass manche Variablen nicht normalverteilt sind. Daher wurden für alle Variablen der t-Test für zwei unabhängige 
Stichproben (mit Satterthwaite-Approximation bei Varianzheterogenität) und zusätzlich der nichtparametrische Wilcoxon-Mann-Whitney-Test (der keine Normalverteilung voraussetzt) durchgeführt.

Für die kategorialen Baselinevariablen wurden absolute und relative Häufigkeiten berechnet und zum Vergleich der beiden Therapiegruppen Chi-Square-Tests bzw. exakte Tests von Fisher (bei Zellhäufigkeiten <5) berechnet.

Für die Kostenanalyse bezüglich Arztkontakte und Krankenhaus- bzw. Reha-Aufenthalte wurden die Angaben der vier Visiten (3, 6, 9 und 12 Monate) zusammengefasst.

Bei den entsprechenden Variablen gab es auch fehlende Werte, die bei der Zusammenfassung mit Null gewertet wurden.

Die Medikamentenkosten wurden berechnet als Produkt von Anzahl der Tage, Tagesdosis in Einheit und Preis pro Einheit. Alle Kosten wurden grafisch mit gruppierten Histogrammen dargestellt.

Zusätzlich wurden die statistischen Kenngrößen berechnet und die beiden Therapiegruppen mit dem Wilcoxon-Test verglichen.

Der Einfluss möglicher Prädiktoren wurde auf die Gesamtkosten hin untersucht. Dabei wurden die Kosten zwischen den Gruppen aufgrund der schiefen Verteilung mit dem WilcoxonTest verglichen. Die metrischen Baseline-Variablen wurden mit Hilfe des Medians gruppiert. Weiterhin wurde der Einfluss möglicher Prädiktoren mit einer Regressionsanalyse untersucht. Dabei wurde aufgrund der schiefen Verteilung und der sehr großen Varianz das BinomialRegressionsmodell verwendet. In einem ersten Schritt wurden alle möglichen Prädiktoren in Einfachregression untersucht. Alle Prädiktoren mit einem p-Wert kleiner 0,2 wurden anschließend gemeinsam in einem multiplen Regressionsmodell analysiert. Dieses Modell wurde anschließend mit Hilfe einer Rückwärtsselektion soweit reduziert, bis nur noch Prädiktoren mit einem p-Wert kleiner 0,05 übrig blieben. Für dieses finale Modell wurden die Regressionsschätzer in incidence rate ratios (IRR) umgerechnet. 


\section{Ergebnisse}

\subsection{Deskriptive Analyse der Baselinevariablen}

An der Baseline-Untersuchung nahmen 422 Patienten teil. Nicht alle Patienten erschienen jedoch zu allen Visiten. Wenn ein Patient ab einem Zeitpunkt nicht mehr an der Studie teilnahm, wurden die vorhandenen Informationen bis zum Zeitpunkt des Drop-Outs verwendet. In Tabelle 4 sind die Patientenzahlen (absolut und relativ) der beiden Behandlungsgruppen angegeben, die nach der jeweiligen Visite aus der Studie ausschieden. Die Verteilung in den beiden Gruppen ist vergleichbar ( $p$-Wert des exakten Tests von Fisher $=0,22$ )

\begin{tabular}{|r|c|c|c|}
\hline \multicolumn{1}{r|}{} & Placebo & Verum & Gesamt \\
\hline $\mathbf{2}$ & $4(1,91)$ & $0(0,00)$ & 4 \\
\hline $\mathbf{3}$ & $6(2,87)$ & $5(2,35)$ & 11 \\
\hline $\mathbf{4}$ & $2(0,96)$ & $1(0,47)$ & 3 \\
\hline $\mathbf{5}$ & $1(0,48)$ & $3(1,41)$ & 4 \\
\hline $\mathbf{6}$ & $196(93,78)$ & $204(95,77)$ & 400 \\
\hline Summe & 209 & 213 & 422 \\
\hline
\end{tabular}

Tabelle 4: Dropouts absolut (und relativ) bis zur jeweiligen Visite, getrennt nach Verum und Placebo

In Tabelle 5 sind die deskriptiven Kenngrößen der metrischen Baselinevariablen, unterteilt nach Verum und Placebo, mit den jeweiligen p-Werten angegeben. Bei einem $\mathrm{p}$-Wert $<0,2$ kann von einer tendenziell unterschiedlichen Verteilung in den Gruppen gesprochen werden. Zur Berechnung der p-Werte kamen bei annährend normalverteilten Werten der t-Test und bei nicht-normal-verteilten Werten der Wilcoxon-Test zum Einsatz. Bei den normalverteilten Variablen ist der Mittelwert und die Standardabweichung angegeben, während bei den nichtnormalverteilten Variablen auf Median und Interquartilsrange (IQR) zurückgegriffen wird. 


\begin{tabular}{|c|c|c|c|c|c|c|c|c|c|c|c|}
\hline \multirow[b]{2}{*}{ Variable } & \multicolumn{5}{|c|}{ Verum } & \multicolumn{5}{|c|}{ Placebo } & \multirow[b]{2}{*}{$\mathbf{p}$} \\
\hline & $\mathbf{N}$ & MW & SD & MED & IQR & $\mathbf{N}$ & MW & SD & MED & IQR & \\
\hline Alter[J] & 213 & 66,9 & 7,7 & 67,0 & 12,0 & 209 & 66,7 & 7,5 & 68,0 & 11,0 & 0,8038 \\
\hline BMI $\left[\mathrm{kg} / \mathrm{m}^{2}\right]$ & 213 & 28,9 & 3,6 & 29,0 & 5,0 & 209 & 28,9 & 3,6 & 28,8 & 5,1 & 0,9644 \\
\hline $\mathrm{MAD}[\mathrm{mmHg}]^{*}$ & 213 & 97,6 & 11,4 & 96,3 & 16,0 & 209 & 98,2 & 12,2 & 98,0 & 14,7 & 0,5435 \\
\hline Pulsdruck[mmHg] & 213 & 55,8 & 14,8 & 54,0 & 19,0 & 209 & 55,8 & 15,8 & 55,0 & 20,0 & 0,9667 \\
\hline HF im EKG $[1 / \mathrm{min}]^{*}$ & 213 & 66,5 & 13,8 & 65,0 & 15,0 & 208 & 64,3 & 11,8 & 63,0 & 11,5 & 0,0815 \\
\hline eGFR $\left[\mathrm{ml} / \mathrm{min} / 1,73 \mathrm{~m}^{2}\right]$ & 211 & 79,3 & 19,2 & 77,7 & 25,6 & 208 & 78,1 & 18,3 & 77,9 & 24,9 & 0,5095 \\
\hline $\mathbf{V O}_{2} \max [\mathrm{ml} / \mathrm{min} / \mathrm{kg}]$ & 213 & 16,4 & 3,6 & 16,1 & 4,4 & 209 & 16,4 & 3,5 & 16,3 & 4,6 & 0,8731 \\
\hline E/e'(medial)* & 213 & 12,7 & 3,6 & 11,9 & 4,3 & 209 & 12,8 & 4,4 & 11,9 & 3,6 & 0,6252 \\
\hline log10NTproBNP & 204 & 2,2 & 0,5 & 2,3 & 0,6 & 195 & 2,2 & 0,4 & 2,2 & 0,5 & 0,5052 \\
\hline LAVI $\left[\mathrm{ml} / \mathrm{m}^{2}\right]^{*}$ & 212 & 28,2 & 9,1 & 26,4 & 10,4 & 208 & 27,8 & 7,7 & 26,7 & 9,7 & 0,9586 \\
\hline $\operatorname{LVMI}\left[\mathrm{ml} / \mathrm{m}^{2}\right]^{*}$ & 212 & 107,9 & 29,2 & 106,8 & 29,8 & 209 & 109,3 & 26,8 & 107,4 & 35,8 & 0,5347 \\
\hline $\mathrm{Hb}[\mathrm{g} / \mathrm{dll}]^{*}$ & 213 & 13,8 & 1,2 & 13,8 & 1,5 & 209 & 13,8 & 1,3 & 13,8 & 1,8 & 0,8135 \\
\hline VACI* & 213 & 0,5 & 0,2 & 0,5 & 0,3 & 209 & 0,5 & 0,2 & 0,5 & 0,2 & 0,0849 \\
\hline
\end{tabular}

Tabelle 5: Deskriptive Kenngrößen der metrischen Baselinevariablen und dazugehörige p-Werte zum Vergleich der Therapiegruppen.

Die mit *gekennzeichneten Variablen sind nicht normalverteilt, weshalb die dort angegebenen $\mathrm{p}$-Werte mittels Wilcoxon-Test ermittelt wurden

Unter Verwendung der o.g. Grenze scheinen sich die Gruppen tendenziell bezüglich des VACI und der Herzfrequenz ( $p=0,08$ und $p=0,08$ ) zu unterscheiden. Dieses Ergebnis ist bei der sehr großen Fallzahl und den klinisch eher unbedeutenden Unterschieden als Zufallsprodukt zu werten, welches trotz der Randomisierung entstanden ist, und soll nicht weiter diskutiert werden.

Für die kategorialen Baseline-Variablen sind in Tabelle 6 die absoluten und relativen Häufigkeiten und die deskriptiven p-Werte angegeben. Letztere wurden mit Ausnahme der COPD, für die aufgrund der kleinen Fallzahl der Fisher-Test zur Anwendung kam, mittels ChiSquare-Test ermittelt. Hier scheinen sich die Therapiegruppen hinsichtlich der Inzidenz von Hyperlipoproteinämie, COPD und chronotroper Inkompetenz zu unterscheiden $(p=0,11, p=$ $0,05$ und $\mathrm{p}=0,14)$. 


\begin{tabular}{|l|l|l|l|}
\hline & Verum & Placebo & p \\
\hline Variable & & $110(53)$ & 0,9150 \\
\hline KHK & $111(52)$ & $78(37)$ & 0,2188 \\
\hline Arterielle Hypertonie & $92(43)$ & $190(91)$ & 0,5565 \\
\hline Hyperlipoproteinämie & $197(92)$ & $143(68)$ & 0,1123 \\
\hline Diabetes mellitus & $130(61)$ & $34(16)$ & 0,8611 \\
\hline ZerebrovaskuläreErkrankung & $36(17)$ & $22(11)$ & 0,9279 \\
\hline pAVK & $23(11)$ & $10(5)$ & 0,4338 \\
\hline COPD & $7(3)$ & $3(1)$ & 0,0535 \\
\hline Vorhofflimmern & $11(5)$ & $36(17)$ & 0,3746 \\
\hline Depression & $30(14)$ & $25(12)$ & 0,5939 \\
\hline Schlafapnoesyndrom & $22(10)$ & $21(10)$ & 0,2569 \\
\hline NYHA III & $29(14)$ & $26(12)$ & 0,3659 \\
\hline Pauluskriterien positiv & $33(15)$ & $109(52)$ & 0,9934 \\
\hline Chronotrope Inkompetenz & $111(52)$ & $16(8)$ & 0,1356 \\
\hline
\end{tabular}

Tabelle 6: Absolute (und relative) Häufigkeiten der kategorialen Baseline-Variablen in den beiden Therapiegruppen und deskriptive $\mathrm{p}$-Werte der entsprechenden Tests

\subsection{Deskriptive Analyse der Arztkontakte und Krankenhaus- bzw. Reha- aufenthalte und deren Kosten}

Bei Summation der deskriptiven Kenngrößen aller Visiten wurden die fehlenden Werte als Null gewertet. Die Ergebnisse der Summationen wurden mit Hilfe von Kreuztabellen für die Gesamtzahl der Krankenhausaufenthalte und -Tage sowie der Reha-Aufenthalte und -Tage validiert. Die folgende Tabelle 7 zeigt die Kenngrößen für die Gesamtzahl der Arztkontakte, Krankenhaus- und Reha-Aufenthalte.

\begin{tabular}{|l|c|c|r|c|r|}
\hline Label & N & Min & Max & Median (Q1-Q3) & MW (SD) \\
\hline Hausarztkontakte & 418 & 0,0 & 48,0 & $1,0(0,0-2,0)$ & $1,8(3,4)$ \\
Kardiologenkontakte & 418 & 0,0 & 10,0 & $0,0(0,0-1,0)$ & $0,4(1,0)$ \\
Krankenhausaufenthalte & 418 & 0,0 & 5,0 & $0,0(0,0-0,0)$ & $0,2(0,6)$ \\
KH-Aufenthalte Tage & 62 & 0,0 & 38,0 & $4,0(2,0-9,0)$ & $6,6(7,4)$ \\
Reha-Aufenthalte & 418 & 0,0 & 3,0 & $0,0(0,0-0,0)$ & $0,1(0,2)$ \\
Reha-Aufenthalt Tage & 24 & 0,0 & 70,0 & $19,5(0,0-24,5)$ & $17,8(17,0)$ \\
\hline
\end{tabular}

Tabelle 7: Deskriptive Kenngrößen für die Arztkontakte und die Krankenhaus- bzw. Reha-Aufenthalte

Die sich daraus ergebenden Kosten wurden in Histogrammen visualisiert, wobei die NichtNormalverteilung deutlich wurde. Daher werden die Kenngrößen in der Tabelle 8 ebenfalls als Minimum, Maximum, Median und Quartile (Q1 und Q3) angegeben. Mittelwert und Standardabweichung wurden zu Zwecken besserer Vergleichbarkeit in der Diskussion ergänzt. Hervorzuheben sind aber die großen Standardabweichungen, die eine Einschränkung der Aus- 
sagekraft darstellen. Zur besseren Übersicht wurden außerdem gruppierte Boxplots für die einzelnen Posten erstellt (Abb. 7, 8 und 9).

\begin{tabular}{|l|c|c|r|c|c|}
\hline Label & N & Min & Max & Median (Q1-Q3) & MW (SD) \\
\hline Hausarztkosten & 422 & 0 & 958 & $20(0-40)$ & $35,3(67,9)$ \\
Kardiologenkosten & 422 & 0 & 712 & $0(0-71)$ & $31,2(68,5)$ \\
Krankenhauskosten & 422 & 0 & 18288 & $0(0-0)$ & $640,7(1995,7)$ \\
Rehakosten & 422 & 0 & 8478 & $0(0-0)$ & $122,3(693,3)$ \\
Gesamtkosten & 422 & 0 & 27146 & $40(0-142)$ & $829,4(2475,3)$ \\
(ohne Medikamente) & & & & & \\
\hline
\end{tabular}

Tabelle 8: Deskriptive Kenngrößen für die Kosten (in €) ohne Medikamente für die Gesamtgruppe

In Tabelle 9 sind die statistischen Kenngrößen, getrennt für die Therapiegruppen, und die deskriptiven p-Werte des Wilcoxon-Tests angegeben. Dabei zeigt sich kein Unterschied zwischen den beiden Therapiegruppen $(\mathrm{p}>0,2)$.

\begin{tabular}{|c|c|c|c|c|c|c|c|c|c|c|c|}
\hline \multirow[b]{2}{*}{ Label } & \multicolumn{5}{|c|}{ Placebo $\mathrm{N}=209$} & \multicolumn{5}{|c|}{ Verum $\mathrm{N}=\mathbf{2 1 3}$} & \multirow[t]{2}{*}{$\mathbf{p}$} \\
\hline & Min & Max & Med & Q1 & Q3 & Min & Max & Med & Q1 & Q3 & \\
\hline Hausarztkosten & 0 & 439 & 20 & 0 & 40 & 0 & 958 & 20 & 0 & 40 & 0,92 \\
\hline Kardiologenkosten & 0 & 712 & 0 & 0 & 71 & 0 & 285 & 0 & 0 & 0 & 0,85 \\
\hline Krankenhauskosten & 0 & 7431 & 0 & 0 & 0 & 0 & 18288 & 0 & 0 & 0 & 0,81 \\
\hline Rehakosten & 0 & 5208 & 0 & 0 & 0 & 0 & 8478 & 0 & 0 & 0 & 0,49 \\
\hline $\begin{array}{l}\text { Gesamtkosten } \\
\text { (ohne Medikamente) }\end{array}$ & 0 & 8974 & 40 & 0 & 142 & 0 & 27146 & 40 & 0 & 142 & 0,89 \\
\hline
\end{tabular}

Tabelle 9 : Deskriptive Kenngrößen (getrennt für die Therapiegruppen) und deskriptive p- Werte des Wilcoxon-Tests für die Kosten (in €) ohne Medikamente

Bezüglich der Hausarztkontakte hat ein Viertel der Teilnehmer im Jahresverlauf keinen Kontakt gehabt und entsprechend keine Kosten verursacht. Der Median lag genau bei einem Kontakt.

75\% hatten höchstens zwei Kontakte, wodurch etwa $40 €$ an Kosten entstanden. Das Maximum der Hausarztkontakte lag bei 48 pro Jahr. Abb. 7 zeigt die Verteilung der Hausarztkosten getrennt für die beiden Therapiegruppen. Es zeigt sich, dass sie bis auf einzelne Extremwerte fast identisch ist. 


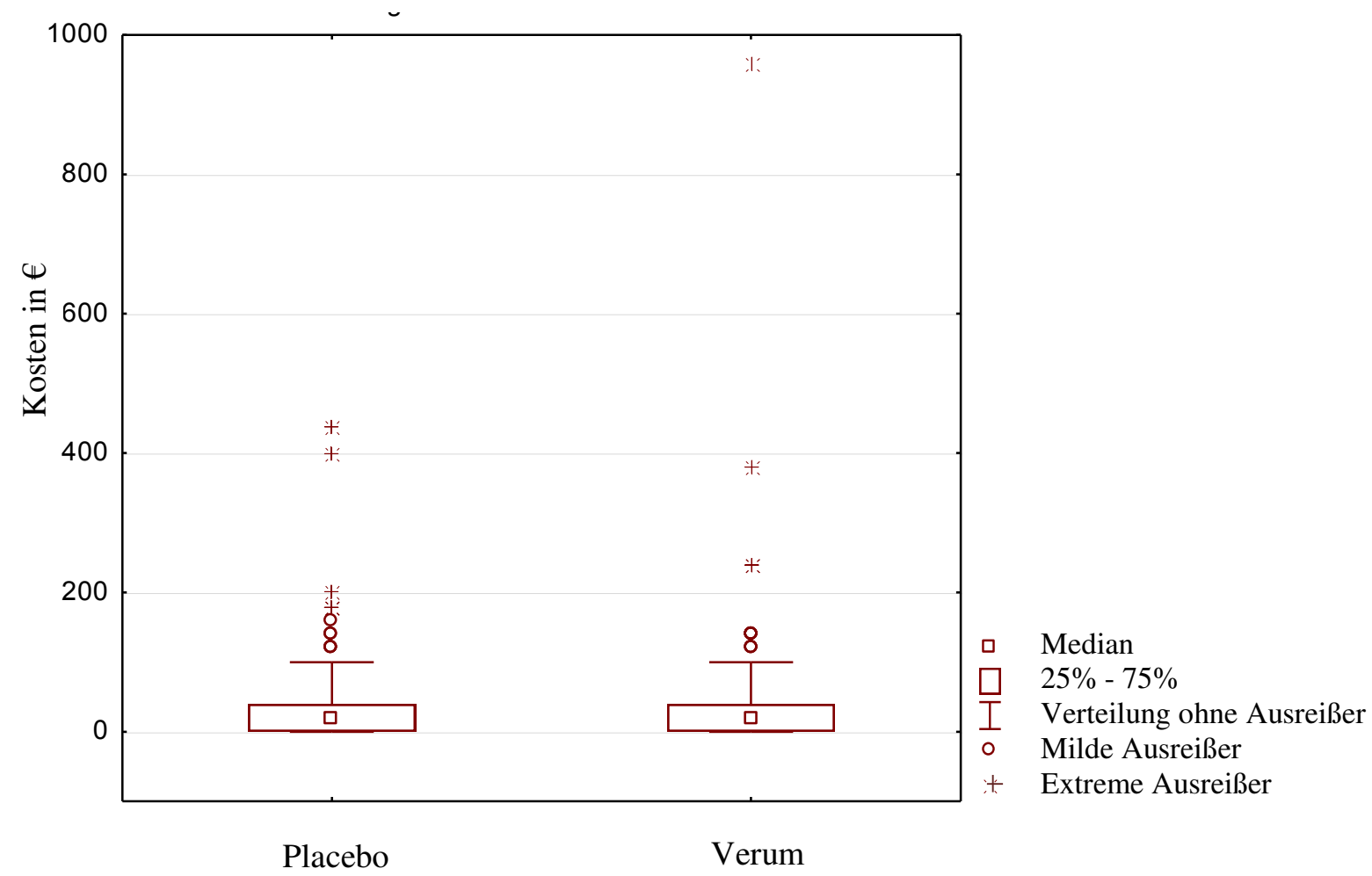

Abb. 7: Verteilung der Hausarztkosten in $€$ nach Verum und Placebo

Ähnlich verhält es sich mit den Kardiologenbesuchen, die aber insgesamt deutlich seltener waren. Hier hatten drei Viertel der Patienten maximal einen Kontakt und entsprechend entstanden höchstens $71 €$ Kosten für diesen ambulanten Facharztkontakt. Zehn Kardiologenkontakte waren das Maximum. Die Verteilung der durch Kardiologenkontakte entstandenen Kosten auf die zwei Therapiegruppen zeigt Abb. 8. Die medianen Kosten sind in beiden Gruppen mit $0 €$ gleich. In der Placebo-Gruppe ist aber der Interquartilsabstand und somit die Streuung der Daten größer, was in der Darstellung als höhere Box visualisiert wurde. Außerdem fällt auf, dass die zwei extremsten Werte (712 € und $356 €$ ) ebenfalls in der Placebo-Gruppe zu finden sind. Ein signifikanter Unterschied zwischen den Gruppen besteht dennoch nicht $(\mathrm{p}=$ $0,76)$.

Der Mittelwert $( \pm$ SD) der Kardiologenkosten liegt bei $31,20 €( \pm 68,48)$ pro Patient. 


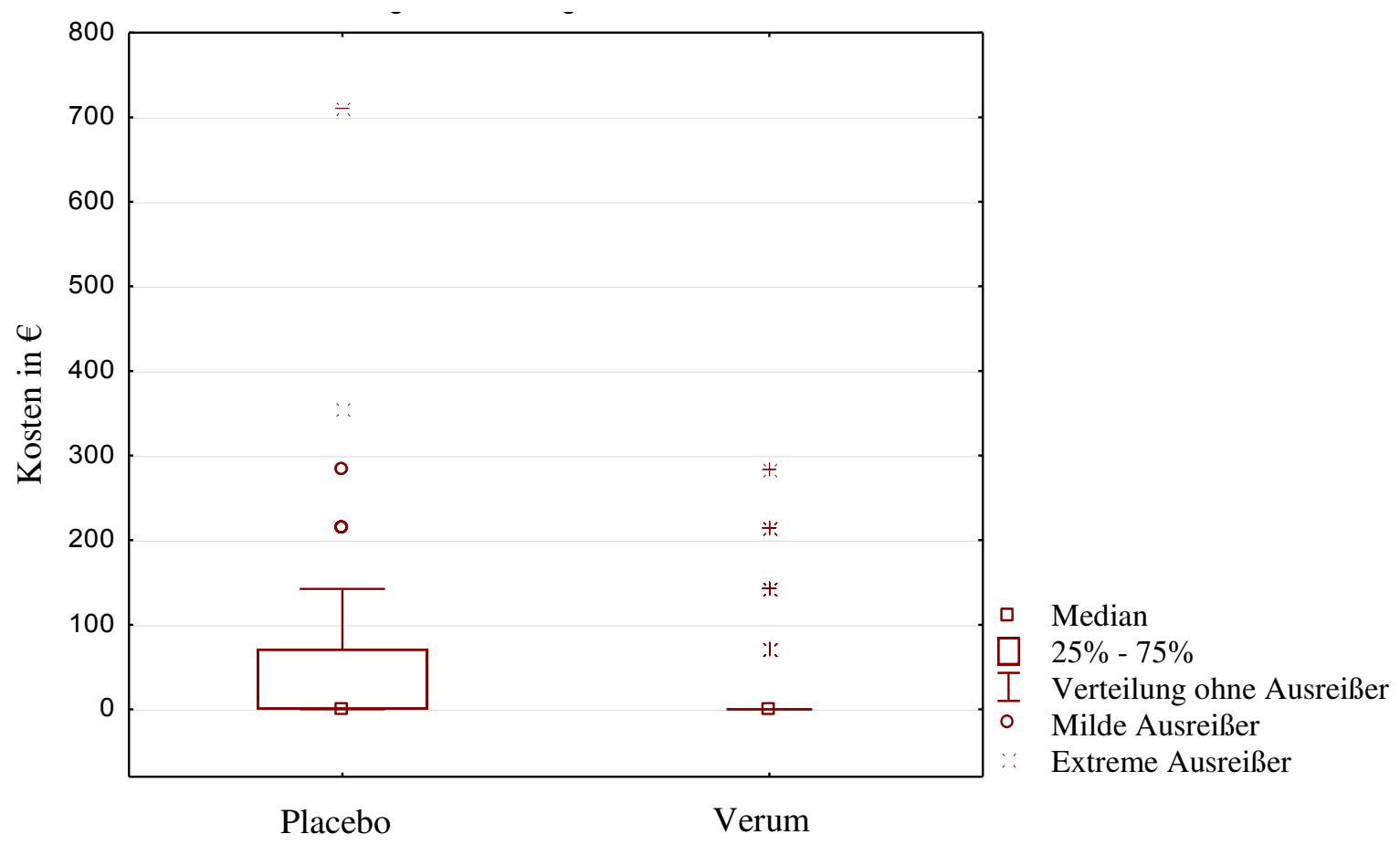

Abb. 8: Verteilung der Kardiologenkosten in $€$ nach Verum und Placebo

Es folgt die Betrachtung der Kosten, die durch Hospitalisierung aufgrund von Herzinsuffizienz entstanden sind. Insgesamt hatten 62 Patienten über den Studienzeitraum mindestens einen Krankenhausaufenthalt aufgrund von Herzinsuffizienz, die übrigen 360 Patienten dagegen keinen. Bei maximal 5 Hospitalisierungen pro Patient lag die aufsummierte Anzahl der Krankenhaustage bei maximal 38. Hier entstanden Kosten von über $18.000 €$. Bei mindestens $75 \%$ der Patienten lagen die Kosten für diesen Posten jedoch bei $0 €$. Beim Vergleich der Therapiegruppen (auf die Visualisierung wurde aufgrund der Verteilung verzichtet) fällt auf, dass die vier Extremwerte der Kosten (18.288 €, $16.742 €, 14.798 €$ und $9.891 €)$ alle in die Verumgruppe fallen. Ein signifikanter Unterschied diese Kostenkomponente betreffend konnte zwischen den Gruppen dennoch nicht gefunden werden $(\mathrm{p}=0,87)$.

Im Durchschnitt entstanden hier Kosten von 640,65 € ( $\pm 1995,70)$ pro Patient - eine Zusammenschau insbesondere mit Median und IQR ist aber notwendig.

24 Patienten hatten einen oder mehrere Reha-Aufenthalte, welche durchschnittlich knapp 18 Tage dauerten. Die übrigen 398 Patienten benötigten keine Reha-Maßnahme, entsprechend fielen mediane Kosten von $0 €$ an (Q1 und Q3 ebenfalls $0 €$ ). Die höchste Zahl der aufsummierten Reha-Tage lag allerdings bei 70, was mit hohen Kosten von $8.478 €$ ins Gewicht fällt. 
Betrachtet man den Mittelwert, liegt dieser daher bei immerhin $122 €( \pm 2475)$. Einen signifikanten Unterschied in der Verteilung auf die Therapiegruppen gab es ebenfalls nicht $(\mathrm{p}=$ $0,49)$.

Insgesamt belaufen sich die Kosten (noch ohne Medikamente) auf durchschnittlich 829,38€ $( \pm 2475,31)$ pro Patient. Aufgrund der schiefen Verteilung sind die medianen Kosten allerdings nur bei $40 €$ und bei $75 \%$ der Patienten bei weniger als $142 €$. Das Maximum liegt bei $27.146 €$, bedingt durch die hohen Hospitalisierungskosten bei diesem Patienten.

\subsection{Deskriptive Analyse des Medikamentenverbrauches und der resultie- renden Kosten}

Bei der Baseline-Untersuchung wurde erhoben, welche Medikamente (nach Gruppen) die Patienten einnehmen. Zusätzlich wurde bei der Baseline-Untersuchung für jede Medikamentengruppe konkret nach den Präparaten mit Dosierung gefragt. Bei jeder der folgenden Studien-Visiten wurde abgefragt, ob sich seit der letzten Visite die Medikation bzw. die Dosierung geändert hatte. Die Häufigkeiten der Änderungen sind in Tabelle 10 gegeben (die relativen Häufigkeiten beziehen sich auf die Anzahl der Patienten, die bis zu der jeweiligen Visite noch in der Studie waren). Bei der Visite nach einer Woche wurden nur wenige Änderungen verzeichnet. Bei allen anderen Visiten gab es bei einem Viertel bis einem Drittel der Patienten Änderungen.

\begin{tabular}{|l|c|c|}
\hline & Absolut (N=) & \multirow{2}{*}{ Relativ (\%) } \\
\cline { 1 - 1 } Änderung zwischen letzter Visite und & & 3 \\
\hline Visite Woche 1 & 13 & 25 \\
\hline Visite Monat 3 & 103 & 33 \\
\hline Visite Monat 6 & 133 & 30 \\
\hline Visite Monat 9 & 119 & 29 \\
\hline Visite Monat 12 & 117 & \\
\hline
\end{tabular}

Tabelle 10: Absolute und relative Häufigkeiten der Änderung von Medikation und/oder Dosis zu den jeweiligen Visiten

Zählt man nun pro Patient zusammen, bei wie vielen Visiten es Änderungen gab (maximal 5), ist zu sehen, dass für ca. ein Drittel der Patienten gar keine Änderungen verzeichnet wurden und für ein weiteres Drittel nur eine Änderung (Tabelle 11). 


\begin{tabular}{|c|l|r|r|r|}
\hline Anzahl Änderungen & $\begin{array}{l}\text { Absolut } \\
(\mathbf{N}=)\end{array}$ & Relativ (\%) & $\begin{array}{l}\text { Kumulativ } \\
\text { (N=) }\end{array}$ & $\begin{array}{l}\text { Kumulativ } \\
\text { relativ (\%) }\end{array}$ \\
\hline $\mathbf{0}$ & 143 & 33,9 & 143 & 33,9 \\
\hline $\mathbf{1}$ & 136 & 32,2 & 279 & 66,1 \\
\hline $\mathbf{2}$ & 94 & 22,3 & 373 & 88,4 \\
\hline $\mathbf{3}$ & 35 & 8,3 & 408 & 96,7 \\
\hline $\mathbf{4}$ & 14 & 3,3 & 422 & 100,0 \\
\hline
\end{tabular}

Tabelle 11: Absolute und relative Häufigkeiten (einzeln und kumulativ) der Patientenbezogenen Anzahl an Änderungen von Medikation und/oder Dosis.

Die Gruppenzuordnung der Medikamente im Datensatz unterscheidet sich teilweise von der Zuordnung, die in der Analyse zur Anwendung kam. In Tabelle 12 sind die Gruppen gegenübergestellt. Außerdem sind in dieser Tabelle die absoluten und relativen Häufigkeiten der Patienten, für die mindestens ein Präparat der Medikamentengruppe zu mindestens einem Zeitpunkt dokumentiert war, abzulesen. Etwa Dreiviertel der Patienten nahmen Betablocker (73\%), etwas mehr als die Hälfte Antikoagulantien (59\%), welche auch Thrombozytenaggregationshemmer mit einschlossen. Ebenfalls etwas mehr als die Hälfte (56\%) der Patienten nahmen Statine ein. Etwas weniger als die Hälfte der Patienten nahmen andere Diuretika (46\%), ACE-Hemmer (46\%) und AT1-Antagonisten (39\%). Die für die Berechnung zuvor durchgeführten Modifikationen sind im Methodenteil dieser Arbeit beschrieben.

\begin{tabular}{|c|c|c|}
\hline $\begin{array}{l}\text { Medikamentengruppe im } \\
\text { Datensatz }\end{array}$ & $\begin{array}{l}\text { Medikamentengruppe in } \\
\text { weiteren Analysen }\end{array}$ & $\begin{array}{l}\text { \# (\%) Patienten mit } \\
\text { mindestens einem } \\
\text { Präparat der Gruppe }\end{array}$ \\
\hline Betablocker & Betablocker & $310(73 \%)$ \\
\hline Andere Plättchenhemmer & \multirow{4}{*}{ Antikoagulantien } & \multirow{4}{*}{251 (59\%) } \\
\hline ASS & & \\
\hline Vit.-K-Antagonisten & & \\
\hline Andere Antikoagulantien & & \\
\hline Statine & Statine & $236(56 \%)$ \\
\hline Andere Diuretika & \multirow{2}{*}{ Andere Diuretika } & \multirow{2}{*}{$196(46 \%)$} \\
\hline Thiazide & & \\
\hline ACE-Hemmer & ACE-Hemmer & 195 (46\%) \\
\hline AT1-Antagonisten & AT1-Antagonisten & $165(39 \%)$ \\
\hline Ca-Antagonisten & Kalzium-Antagonisten & $121(29 \%)$ \\
\hline Schleifendiuretika & Schleifendiuretika & $73(17 \%)$ \\
\hline Orale Antidiabetika & Antidiabetika oral & $50(22 \%)$ \\
\hline Nitrate (Dauermedikation) & Nitrate (Dauermedikation) & $41(10 \%)$ \\
\hline Antidepressiva & Antidepressiva & $37(9 \%)$ \\
\hline Andere Lipidsenker & Andere Lipidsenker & $34(8 \%)$ \\
\hline Antiarrhythmika & Antiarrhythmika & $33(8 \%)$ \\
\hline Inhalativa & \multirow{2}{*}{ Pulmonale Medikamente } & \multirow{2}{*}{$22(5 \%)$} \\
\hline Orale Substanzen & & \\
\hline
\end{tabular}




\begin{tabular}{|llc|}
\hline Insulin & Insuline & $15(4 \%)$ \\
\hline Herzglykoside & Herzglykoside & $8(2 \%)$ \\
\hline Sonstiges & Wenn passend, in andere & - \\
& Gruppen & - \\
\hline Kaliumsparende Diuretika & --- (keine Einträge) & - \\
\hline Allopurinol & --- & - \\
\hline Antiphlogistika & --- & - \\
\hline Schlaf-/Beruhigungsmittel & --- & - \\
\hline
\end{tabular}

Tabelle 12: Absolute und relative Häufigkeiten der Medikamentengruppen bezogen auf alle Zeitpunkte

In Tabelle 13 sind die absoluten und relativen Häufigkeiten für die Medikamentengruppen, getrennt nach Behandlungsgruppen, aufgeführt. Die deskriptiven Kenngrößen für den Patienten-basierten Preis pro Medikamentengruppe sind in Tabelle 14 angegeben und in Tabelle 15 getrennt für die beiden Behandlungsgruppen.

\begin{tabular}{|l|c|c|c|c|}
\hline \multirow{2}{*}{ Medikamentengruppe } & \multicolumn{2}{|c|}{ Verum } & \multicolumn{2}{c|}{ Placebo } \\
\cline { 2 - 5 } & Abs. (N=) & Rel. (\%) & Abs. (N=) & Rel. (\%) \\
\hline Antiarrhythmika & 12 & 6 & 21 & 10 \\
AT1-Antagonisten & 85 & 40 & 80 & 38 \\
Betablocker & 150 & 70 & 160 & 77 \\
Kalziumantagonisten & 47 & 22 & 74 & 35 \\
Antidepressiva & 21 & 10 & 16 & 8 \\
Schleifendiuretika & 46 & 22 & 27 & 13 \\
Herzglykoside & 4 & 2 & 4 & 2 \\
Insuline & 4 & 2 & 11 & 5 \\
Pulmonale Medikamente & 13 & 6 & 9 & 4 \\
Antikoagulantien & 132 & 62 & 119 & 57 \\
Andere Lipidsenker & 19 & 9 & 15 & 7 \\
Nitrate & 23 & 11 & 18 & 9 \\
Antidiabetika oral & 30 & 14 & 20 & 10 \\
Statine & 117 & 55 & 119 & 57 \\
ACE-Hemmer & 103 & 48 & 92 & 44 \\
Andere Diuretika & 97 & 46 & 99 & 47 \\
\hline
\end{tabular}

Tabelle 13: Absolute und relative Häufigkeiten der Medikamentengruppen, getrennt für die Behandlungsgruppen

Die medianen Kosten für viele der aufgeführten Medikamentengruppen betragen aufgrund des geringen Verbrauches $0 €$. Häufiger verordnete Wirkstoffe verursachen dagegen mediane Kosten von fast $17 €$ (Betablocker) oder fast $23 €$ (Statine). Im Einzelfall entstanden in einigen Gruppen maximale Kosten von deutlich über 1000 Euro pro Jahr und Patient (Antiarrhythmika 1313,6€, Antidepressiva 1894,9€ und Antikoagulantien 1109,5€).

Die medianen Gesamtkosten für Medikamente lagen bei $223 €$ pro Patient und Jahr. Das untere Quartil der Patienten verursachte dabei Kosten von $<100 €$ und das obere Quartil $>487 €$. 
Der Patient mit den höchsten Medikamentenkosten benötigte über ein Jahr Medikamente im Wert von $2935 €$. So erklärt sich auch der hohe Mittelwert der Medikamentenkosten von $358,70 €( \pm 396,52)$.

\begin{tabular}{|l|r|r|r|r|r|}
\hline Kosten für & Min & Max & Median & Q1 & \multicolumn{1}{c|}{ Q3 } \\
\hline Antiarrhythmika & 0,00 & 1313,61 & 0,00 & 0,00 & 0,00 \\
AT1-Antagonisten & 0,00 & 552,78 & 0,00 & 0,00 & 131,94 \\
Betablocker & 0,00 & 212,27 & 16,79 & 0,00 & 30,98 \\
Kalziumantagonisten & 0,00 & 209,75 & 0,00 & 0,00 & 11,97 \\
Antidepressiva & 0,00 & 1894,92 & 0,00 & 0,00 & 0,00 \\
Schleifendiuretika & 0,00 & 42,71 & 0,00 & 0,00 & 0,00 \\
Herzglykoside & 0,00 & 112,60 & 0,00 & 0,00 & 0,00 \\
Insuline & 0,00 & 489,02 & 0,00 & 0,00 & 0,00 \\
Pulmonologika & 0,00 & 832,03 & 0,00 & 0,00 & 0,00 \\
Antikoagulantien & 0,00 & 943,44 & 5,75 & 0,00 & 5,95 \\
Andere Lipidsenker & 0,00 & 883,43 & 0,00 & 0,00 & 0,00 \\
Nitrate & 0,00 & 214,31 & 0,00 & 0,00 & 0,00 \\
orale Antidiabetika & 0,00 & 1109,75 & 0,00 & 0,00 & 0,00 \\
Statine & 0,00 & 805,52 & 22,55 & 0,00 & 69,41 \\
ACE-Hemmer & 0,00 & 463,10 & 0,00 & 0,00 & 24,03 \\
andere Diuretika & 0,00 & 169,09 & 0,00 & 0,00 & 28,48 \\
Medikamente gesamt & 0,00 & 2935,15 & 223,00 & 99,55 & 486,97 \\
\hline
\end{tabular}

Tabelle 14: Deskriptive Kenngrößen für den Preis in $€$ in den jeweiligen Medikamentengruppen für die gesamte Studienpopulation (N=422) 


\begin{tabular}{|l|l|r|r|r|r|r|r|r|r|r|r|}
\hline & \multicolumn{1}{|l}{ Placebo (N= 209) } \\
\hline Variable & Min & Max & MED & Q1 & Q3 & Min & Max & MED & Q1 & Q3 & p \\
\hline Antiarrhythmika & 0,0 & 1313,6 & 0,0 & 0,0 & 0,0 & 0,0 & 1299,3 & 0,0 & 0,0 & 0,0 & 0,09 \\
AT1-Antagonisten & 0,0 & 552,8 & 0,00 & 0,0 & 180,0 & 0,0 & 469,3 & 0,0 & 0,0 & 121,3 & 0,82 \\
Betablocker & 0,0 & 156,3 & 16,8 & 0,8 & 33,7 & 0,0 & 212,3 & 16,8 & 0,0 & 29,4 & 0,32 \\
Kalziumantagonisten & 0,0 & 180,5 & 0,0 & 0,0 & 20,6 & 0,0 & 209,8 & 0,0 & 0,0 & 0,0 & 0,01 \\
Antidepressiva & 0,0 & 834,2 & 0,0 & 0,0 & 0,0 & 0,0 & 1894,9 & 0,0 & 0,0 & 0,0 & 0,45 \\
Schleifendiuretika & 0,0 & 26,0 & 0,0 & 0,0 & 0,0 & 0,0 & 42,7 & 0,0 & 0,0 & 0,0 & 0,02 \\
Herzglykoside & 0,0 & 112,6 & 0,0 & 0,0 & 0,0 & 0,0 & 45,2 & 0,0 & 0,0 & 0,0 & 0,98 \\
Insuline & 0,0 & 343,7 & 0,0 & 0,0 & 0,0 & 0,0 & 489,0 & 0,0 & 0,0 & 0,0 & 0,23 \\
Pulmonologika & 0,0 & 575,3 & 0,0 & 0,0 & 0,0 & 0,0 & 832,0 & 0,0 & 0,0 & 0,0 & 0,41 \\
Antikoagulantien & 0,0 & 943,4 & 5,7 & 0,0 & 5,9 & 0,0 & 868,4 & 5,8 & 0,0 & 6,0 & 0,28 \\
Andere Lipidsenker & 0,0 & 883,4 & 0,0 & 0,0 & 0,0 & 0,0 & 733,63 & 0,0 & 0,0 & 0,0 & 0,48 \\
Nitrate & 0,0 & 214,3 & 0,0 & 0,0 & 0,0 & 0,0 & 168,8 & 0,0 & 0,0 & 0,0 & 0,78 \\
orale Antidiabetika & 0,0 & 1109,8 & 0,0 & 0,0 & 0,0 & 0,0 & 840,7 & 0,0 & 0,0 & 0,0 & 0,24 \\
Statine & 0,0 & 805,5 & 22,5 & 0,0 & 50,2 & 0,0 & 619,4 & 22,9 & 0,0 & 82,5 & 0,68 \\
ACE-Hemmer & 0,0 & 157,9 & 0,0 & 0,0 & 24,0 & 0,0 & 463,1 & 0,0 & 0,0 & 24,0 & 0,46 \\
Andere Diuretika & 0,0 & 169,1 & 000 & 0,0 & 29,2 & 0,0 & 101,0 & 0,0 & 0,0 & 28,0 & 0,49 \\
Medikamente gesamt & 0,0 & 2206,4 & 218,3 & 98,3 & 525,7 & 0,0 & 2935,1 & 231,1 & 106,1 & 427,0 & 0,84 \\
\hline
\end{tabular}

Tabelle 15: Deskriptive Kenngrößen für den Preis in $€$ in den jeweiligen Medikamentengruppen, getrennt nach Behandlungsgruppen

Die Gesamtmedikamentenkosten, unterteilt nach Verum und Placebo, sind in Abb. 9 als Boxplots visualisiert. Es zeigt sich, dass die medianen Kosten annährend gleich sind und der Interquartilsabstand sehr ähnlich. Die Gesamtausgaben für Medikamente unterscheiden sich nicht signifikant voneinander $(\mathrm{p}=0,84)$. Tendenzielle Unterschiede gibt es in einzelnen Gruppen. So scheinen die Kalziumantagonisten in der Placebo-Gruppe höhere Kosten verursacht zu haben $(\mathrm{p}=0,01)$, während die Schleifendiuretika in der Verum-Gruppe mit etwas höheren Kosten assoziiert sind $(\mathrm{p}=0,02)$. 


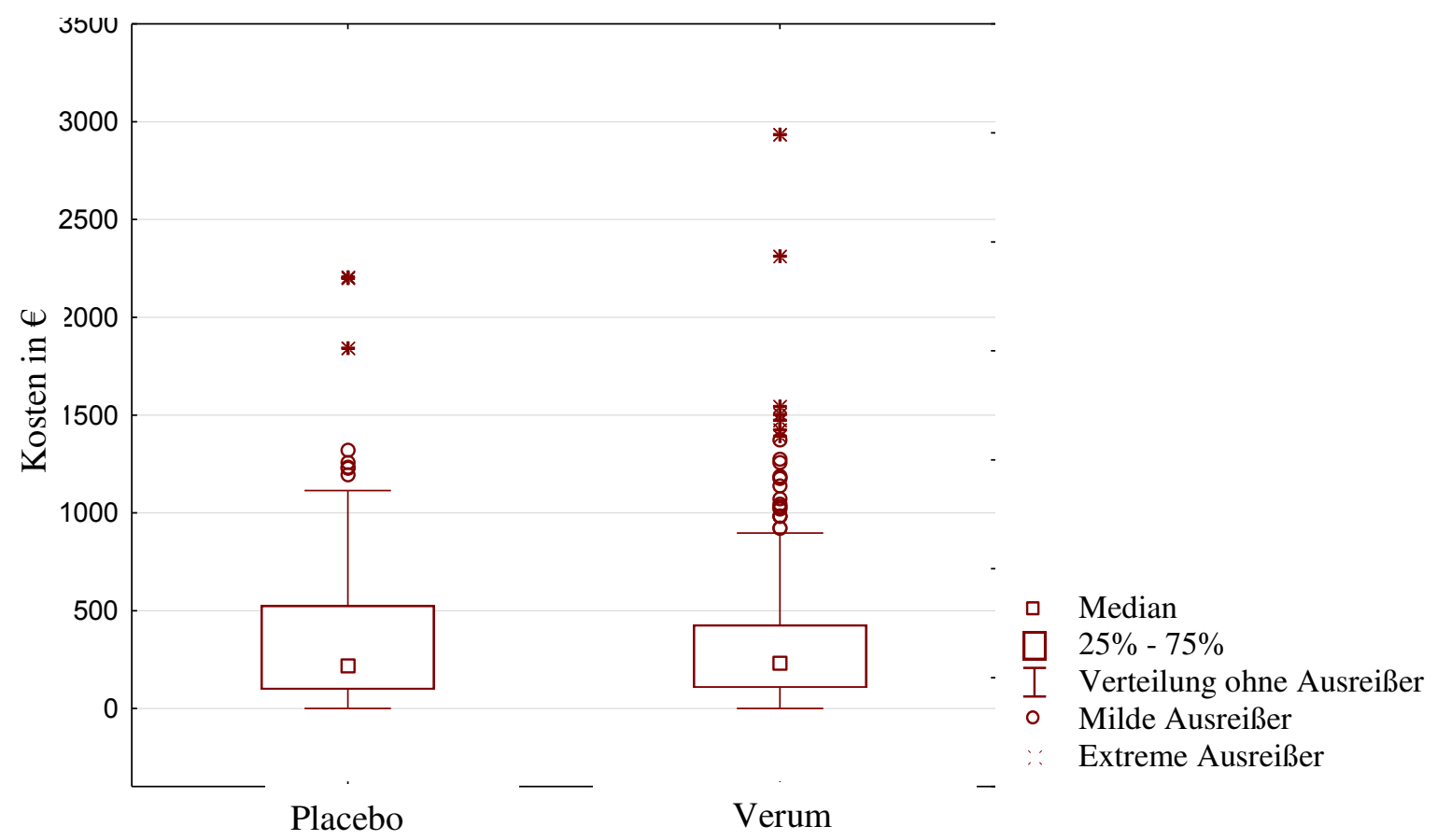

Abb. 9: Verteilung der Medikamentenkosten in $€$ nach Verum und Placebo

\subsection{Gesamtkosten und Einfluss möglicher Prädiktoren}

Die Gesamtkosten, die sich aus der ambulanten und stationären Versorgung sowie den Medikamentenkosten ergeben, sind nach Gruppen getrennt in Tabelle 16 gezeigt. Als logische Folge der oben beschriebenen Teilergebnisse zeigt sich auch hier kein signifikanter Unterschied $(\mathrm{p}=0,85)$.

Darunter zeigt Abb. 10 in Form eines Boxplots die Verteilung der Gesamtkosten des gesamten Kollektivs ohne Ausreißer. Der Median liegt hier bei 331,63€, 75\% der Patienten haben weniger als $1000 €$ an Kosten verursacht, 25\% sogar nur $<160 €$. Der Mittelwert liegt bei $1188,08 €( \pm 2475,31)$.

\begin{tabular}{|c|l|c|c|c|c|c|c|c|c|c|}
\hline \multicolumn{4}{|l|}{ Placebo (N=209) } & \multicolumn{4}{l|}{ Verum (N=213) } & \\
\hline Min & Max & Median & Q1 & Q3 & Min & Max & Median & Q1 & Q3 & p \\
\hline 0 & 10231 & 317 & 158 & 861 & 0 & 27420 & 332 & 156 & 1002 & 0.85 \\
\hline
\end{tabular}

Tabelle 16: Deskriptive Kenngrößen für die Gesamtkosten in $€$ in den beiden Therapiegruppen 


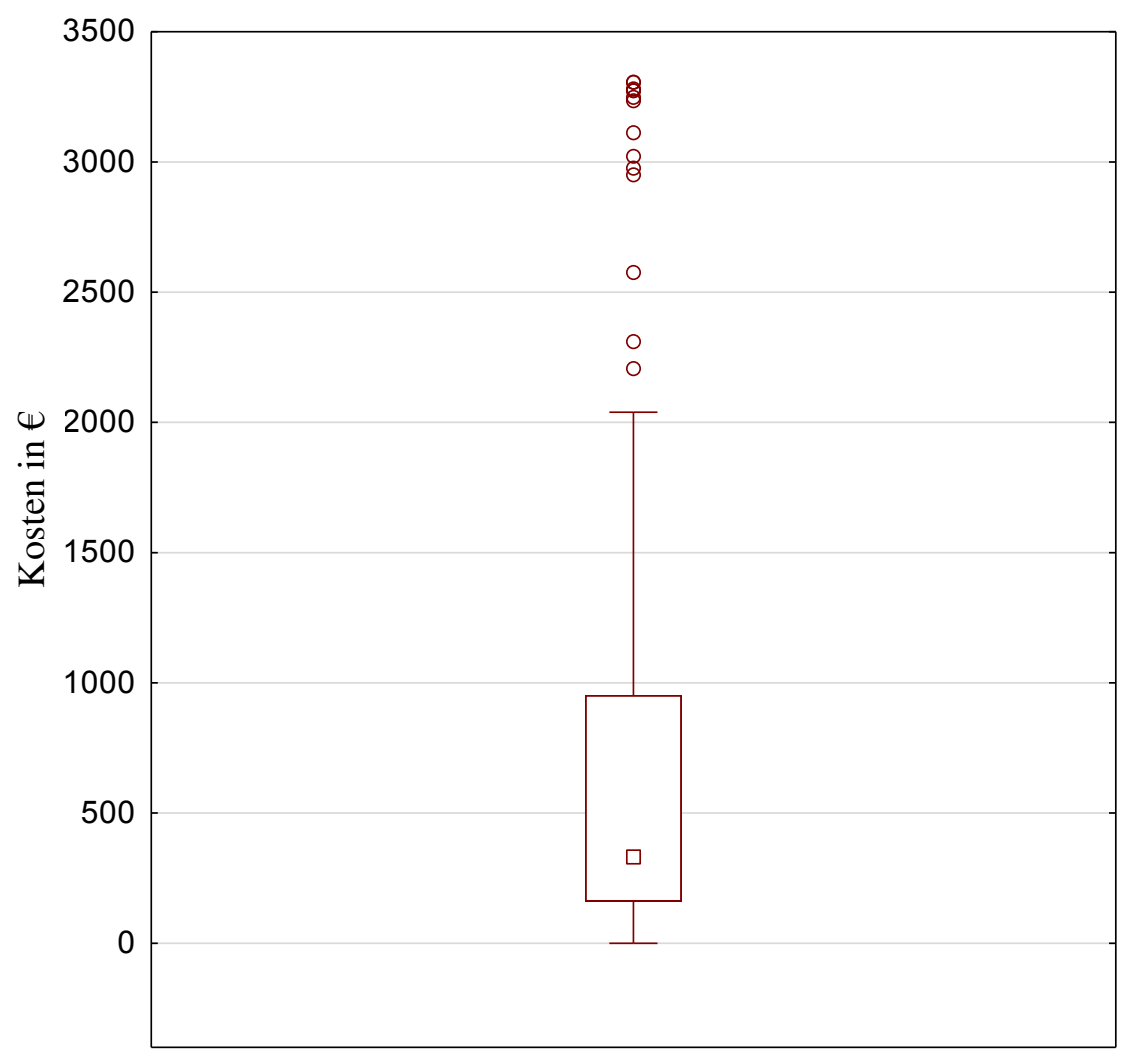

ㅁ Median $25 \%-75 \%$

I Verteilung ohne Ausreißer

- Milde Ausreißer

Extreme Ausreißer

Abb. 10: Verteilung der Gesamtkosten für Gesamtkohorte in $€$

Tabelle 17 zeigt eine Zusammenhangsanalyse zwischen Gesamtkosten und möglichen Prädiktoren. Für die Therapiegruppen wie auch für alle beschriebenen Baseline-Variablen sind der Median, die Interquartilsrange und der p-Wert des Wilcoxon-Tests angegeben.

Einige der Parameter scheinen einen Einfluss auf die Kosten zu haben. Die p-Werte $<0,05$ wurden hervorgehoben. 


\begin{tabular}{|c|c|c|c|c|c|}
\hline \multirow[b]{2}{*}{ Jeweilige Gruppe 1 vs. Gruppe 2} & \multicolumn{2}{|c|}{ Gruppe 1} & \multicolumn{2}{|c|}{ Gruppe 2} & \multirow[b]{2}{*}{ p-Wert } \\
\hline & Median & IQR & Median & IQR & \\
\hline Placebo vs. Verum & 317 & 702 & 332 & 846 & 0,85 \\
\hline Alter $\leq$ vs. $>67$ Jahre & 311 & 809 & 331 & 766 & 0,29 \\
\hline $\mathrm{BMI} \leq \mathrm{vs} .>29 \mathrm{~kg} / \mathrm{m}^{2}$ & 280 & 731 & 389 & 761 & 0,01 \\
\hline MAD $\leq$ vs. $>97.33 \mathrm{mmHg}$ & 340 & 843 & 310 & 646 & 0,36 \\
\hline Pulsdruck $\leq$ vs. $>55 \mathrm{mmHg}$ & 305 & 724 & 363 & 830 & 0,14 \\
\hline $\mathrm{HF} \leq \mathrm{vs} .>63 / \mathrm{min}$ & 338 & 856 & 319 & 689 & 0,79 \\
\hline GFR $\leq$ vs. $>77.77 \mathrm{ml} / \mathrm{min} / \mathrm{kg}$ & 406 & 829 & 276 & 513 & $<0,01$ \\
\hline $\mathrm{VO}_{2} \max \leq \mathrm{vs} .>16.25 \mathrm{ml} / \mathrm{min} / \mathrm{kg}$ & 373 & 804 & 298 & 661 & 0,01 \\
\hline E/e' $\leq$ vs. $>11.86$ & 275 & 896 & 379 & 654 & 0,01 \\
\hline $\log _{10}$ NTproBNP $\leq$ vs. $>2.20$ & 293 & 636 & 373 & 854 & 0,01 \\
\hline LAVI $\leq$ vs. $>26.54 \mathrm{ml} / \mathrm{m}^{2}$ & 287 & 527 & 380 & 869 & $<0,01$ \\
\hline LVMI $\leq$ Vs. $>107.01 \mathrm{ml} / \mathrm{m}^{2}$ & 305 & 682 & 341 & 881 & 0,37 \\
\hline $\mathrm{Hb} \leq \mathrm{vs} .>13.80 \mathrm{~g} / \mathrm{dl}$ & 338 & 866 & 312 & 652 & 0,12 \\
\hline $\mathrm{VACl} \leq$ vs. $>0.5$ & 344 & 862 & 318 & 646 & 0,31 \\
\hline männlich ( $n=201)$ vs. weiblich $(n=221)$ & 369 & 941 & 302 & 551 & 0,08 \\
\hline KHK $n(n=252)$ vs. j $(n=170)$ & 279 & 622 & 388 & 874 & $<0,01$ \\
\hline Art. Hypertonie $n(n=35)$ vs. j $(n=387)$ & 169 & 347 & 340 & 783 & $<0,01$ \\
\hline Hyperlipoproteinämie $n \quad(n=149)$ vs. j $(n=273)$ & 213 & 399 & 387 & 854 & $<0,01$ \\
\hline Diabetes mellitus $n(n=352)$ vs. j $(n=70)$ & 307 & 567 & 682 & 952 & $<0,01$ \\
\hline Zerebrovask. Erkrankung $n(n=377)$ vs. $j(n=45)$ & 320 & 773 & 428 & 739 & 0,14 \\
\hline PAVK $n(n=405)$ vs. $j(n=17)$ & 327 & 771 & 460 & 951 & 0,17 \\
\hline COPD $n(n=408)$ vs. $j(n=14)$ & 329 & 768 & 448 & 825 & 0,25 \\
\hline Vorhofflimmern $n(n=356)$ vs. j $(n=66)$ & 305 & 648 & 521 & 1266 & $<0,01$ \\
\hline Depression $n(n=375)$ vs. j $(n=47)$ & 312 & 704 & 548 & 1477 & 0,03 \\
\hline Schlafapnoesyndrom $n(n=372)$ vs. j $(n=50)$ & 318 & 783 & 402 & 747 & 0,12 \\
\hline NYHA II (n=363) vs. III (n=59) & 318 & 785 & 410 & 813 & 0,07 \\
\hline Pauluskrit. negativ ( $n=202)$ vs. pos. $(n=220)$ & 271 & 526 & 374 & 847 & $<0,01$ \\
\hline Chronotrope Inkomp. $n$ ( $n=397)$ vs. j $(n=25)$ & 332 & 797 & 288 & 459 & 0,54 \\
\hline
\end{tabular}

Tabelle 17: Zusammenhangsanalyse von Gesamtkosten und möglichen Prädiktoren Vergleich der vordefinierten Gruppen 1 und $2 \quad n=$ nein, $j=j a$

Im Folgenden sind die Ergebnisse der Regressionsanalyse dargestellt. Dabei sind in Tabelle 18 in den linken Spalten die Ergebnisse der Einfachregression abzulesen. Alle Prädiktoren mit einem p- Wert $<0,2$ wurden in das multiple Regressionsmodell aufgenommen. Die entsprechenden Ergebnisse des kompletten multiplen Regressionsmodells sind in Tabelle 18 in den rechts stehenden Spalten zu sehen. Die Ergebnisse des finalen Modells nach Rückwärtsselektion sind in Tabelle 19 dargestellt. Unter gleichzeitiger Berücksichtigung der jeweils anderen Prädiktoren beeinflussen also der $\mathrm{Hb}$-Wert, der $\mathrm{VO}_{2}$ max -Wert, das Geschlecht, das Vorliegen einer KHK, einer Hyperlipoproteinämie oder Vorhofflimmern sowie das NYHA-Stadium die Gesamtkosten. Dabei sind ein möglichst hoher Hb-Wert und das 
weibliche Geschlecht ein Prädiktor für niedrigere Kosten (negativer Schätzer) und die übrigen Parameter für höhere Kosten.

\begin{tabular}{|c|c|c|c|c|c|c|c|c|}
\hline \multirow[b]{3}{*}{ Prädiktor } & \multicolumn{4}{|c|}{ Einfachregression } & \multicolumn{4}{|c|}{ Multiple Regression } \\
\hline & \multirow[b]{2}{*}{ Schätzer } & \multicolumn{2}{|c|}{$95 \% \mathrm{KI}$} & \multirow[b]{2}{*}{ p-Wert } & \multirow[b]{2}{*}{ Schätzer } & \multicolumn{2}{|c|}{$95 \% \mathrm{KI}$} & \multirow[b]{2}{*}{ p-Wert } \\
\hline & & von & bis & & & von & bis & \\
\hline $\mathrm{Hb}$ & $-0,168$ & 0,274 & 0,061 & 0,002 & $-0,185$ & 0,304 & 0,067 & 0,002 \\
\hline LAVI & 0,013 & 0,003 & 0,030 & 0,120 & $-0,004$ & 0,024 & 0,016 & 0,694 \\
\hline log10 NTproBNP & 0,484 & 0,198 & 0,770 & 0,001 & 0,050 & 0,362 & 0,462 & 0,812 \\
\hline MAD & $-0,010$ & 0,021 & 0,001 & 0,079 & 0,004 & 0,008 & 0,016 & 0,540 \\
\hline Pulsdruck & 0,002 & 0,007 & 0,011 & 0,616 & & & & \\
\hline $\mathrm{HF}$ & $-0,0002$ & 0,008 & 0,008 & 0,961 & & & & \\
\hline GFR & $-0,007$ & 0,014 & 0,0004 & 0,066 & $-0,004$ & 0,011 & 0,004 & 0,332 \\
\hline $\mathrm{VACl}$ & $-0,492$ & 1,291 & 0,306 & 0,227 & & & & \\
\hline Alter & 0,003 & $-0,015$ & 0,021 & 0,738 & & & & \\
\hline $\mathrm{BMI}$ & $-0,019$ & 0,055 & 0,018 & 0,314 & & & & \\
\hline $\mathrm{VO}_{2} \max$ & 0,028 & 0,012 & 0,069 & 0,169 & 0,037 & 0,006 & 0,080 & 0,092 \\
\hline$E / e^{\prime}$ & 0,024 & 0,011 & 0,059 & 0,174 & 0,018 & 0,024 & 0,060 & 0,407 \\
\hline LVMI & 0,003 & 0,002 & 0,008 & 0,241 & & & & \\
\hline $\begin{array}{l}\text { Geschlecht } \\
\text { w. vs. m. }\end{array}$ & $-0,402$ & 0,668 & 0,136 & 0,003 & $-0,330$ & 0,650 & 0,011 & 0,043 \\
\hline KHK ja vs. nein & 0,508 & 0,238 & 0,777 & $<0,001$ & 0,167 & 0,174 & 0,509 & 0,337 \\
\hline $\begin{array}{l}\text { Hypertonie } \\
\text { ja vs nein }\end{array}$ & 0,242 & 0,243 & 0,727 & 0,329 & & & & \\
\hline HLP ja vs. nein & 0,441 & 0,163 & 0,719 & 0,002 & 0,579 & 0,248 & 0,909 & 0,001 \\
\hline DM ja vs. nein & 0,282 & 0,077 & 0,641 & 0,123 & 0,319 & $-0,054$ & 0,692 & 0,094 \\
\hline CERV ja vs. nein & $-0,059$ & 0,493 & 0,374 & 0,788 & & & & \\
\hline PAVK ja vs. nein & 0,363 & 0,317 & 1,043 & 0,296 & & & & \\
\hline COPD ja vs. nein & 0,407 & 0,339 & 1,154 & 0,285 & & & & \\
\hline VHF ja vs. nein & 0,533 & 0,167 & 0,899 & 0,004 & 0,674 & 0,294 & 1,055 & 0,001 \\
\hline
\end{tabular}




\begin{tabular}{|l|c|c|c|c|c|c|c|c|}
\hline $\begin{array}{l}\text { Depression } \\
\text { ja vs nein }\end{array}$ & 0,228 & 0,197 & 0,653 & 0,293 & \multicolumn{3}{|l|}{} \\
\cline { 1 - 5 } SAS ja vs. nein & 0,191 & 0,223 & 0,605 & 0,365 & & \\
\hline NYHA III vs. II & 0,423 & 0,038 & 0,807 & $\mathbf{0 , 0 3 1}$ & 0,348 & $-0,078$ & 0,775 & $\mathbf{0 , 1 1 0}$ \\
\cline { 1 - 5 } $\begin{array}{l}\text { Paulus } \\
\text { pos. vs. neg. }\end{array}$ & 0,335 & 0,069 & 0,602 & $\mathbf{0 , 0 1 4}$ & 0,153 & $-0,200$ & 0,506 & 0,396 \\
\hline Cl ja vs. nein & $-0,097$ & 0,664 & 0,470 & 0,737 & & & & \\
\hline
\end{tabular}

Tabelle 18: Punktschätzer und zugehörige Konfidenzintervalle der Einfachregression (links) und für ein Subset der Prädiktoren der multiplen Regression (rechts). $\mathrm{p}<0,2$ ist hervorgehoben

\begin{tabular}{|c|c|c|c|c|c|c|c|}
\hline \multirow[b]{2}{*}{ Prädiktor } & \multirow[b]{2}{*}{ Schätzer } & \multicolumn{2}{|l|}{$95 \% \mathrm{KI}$} & \multirow[b]{2}{*}{ p-Wert } & \multirow[b]{2}{*}{ IRR } & \multicolumn{2}{|l|}{$95 \% \mathrm{KI}$} \\
\hline & & von & bis & & & von & bis \\
\hline $\mathrm{Hb}$ & $-0,234$ & 0,348 & 0,120 & $<0,001$ & 0,79 & 0,706 & 0,88 \\
\hline $\mathrm{VO}_{2} \max$ & 0,048 & 0,009 & 0,086 & 0,015 & 1,049 & 1,00 & $1, \overline{09}$ \\
\hline Geschlecht w vs. m & $-0,480$ & 0,767 & 0,194 & 0,001 & 0,61 & 0,46 & 0,82 \\
\hline KHK ja vs. nein & 0,336 & 0,026 & 0,647 & 0,034 & 1,39 & 1,02 & 1,91 \\
\hline HLP ja vs. nein & 0,475 & 0,173 & 0,777 & 0,002 & 1,60 & 1,18 & 2,17 \\
\hline VHF ja vs. nein & 0,772 & 0,416 & 1,129 & $<0,001$ & 2,16 & 1,51 & 3,09 \\
\hline NYHA III vs. II & 0,495 & 0,113 & 0,878 & 0,011 & 1,64 & 1,12 & 2,40 \\
\hline
\end{tabular}

Tabelle 19: Punktschätzer mit Konfidenzintervall für das finale Modell und das incidence rate ratio (IRR) mit Konfidenzintervall 


\section{Diskussion}

\subsection{Kurze Ergebnisdarstellung}

Die vorliegende Arbeit hatte das Ziel, die durch Herzinsuffizienz mit erhaltener Pumpfunktion in Deutschland verursachten Kosten aus gesellschaftlicher Sicht zu schätzen. Außerdem sollte die Zusammensetzung der Kosten über die Ermittlung der Ressourcenverbräuche festgestellt werden. Ebenso war ein Ziel, zu beurteilen, ob und wie sehr die Behandlung mit dem Aldosteron-Antagonisten Spironolacton einen Einfluss auf die Kosten ausübt. Schließlich ging es um die Frage, ob Prädiktoren für höhere Kosten im Verlauf gefunden werden können. Die Ergebnisse lassen sich knapp wie folgt zusammenfassen:

1. Die Gesamtkosten pro Patient aus unserem ambulanten stabilen Kollektiv betrugen im Jahr durchschnittlich knapp $1200 €$, im Median dagegen nur etwa $330 €$, da drei Viertel der Patienten weniger als $1000 €$ Ausgaben verursachten.

2. Den höchsten Anteil daran hatten Kosten, die durch Hospitalisierung aufgrund von Herzinsuffizienz entstanden. Danach folgten in absteigender Reihenfolge Medikamente, RehaMaßnahmen und die ambulanten Arztbesuche.

3. Die Therapie mit Spironolacton hatte weder auf die einzelnen Ressourcenverbräuche noch auf die Gesamtkosten einen signifikanten Einfluss. Lediglich im Verbrauch einzelner Medikamentengruppen waren Unterschiede feststellbar.

4. Als unabhängige Prädiktoren für höhere Kosten zeigten sich das männliche Geschlecht, ein niedriger Hämoglobinwert, eine gute maximale Sauerstoffaufnahme $\mathrm{VO}_{2} \mathrm{max}$, und das Vorliegen einer KHK, Hyperlipoproteinämie und Vorhofflimmern.

Im Folgenden sollen diese Ergebnisse in den Kontext der wissenschaftlichen Forschung gestellt werden. Zunächst wird das Patientenkollektiv der ALDO-DHF-Studie diskutiert und mit anderen Studienkollektiven in Hinblick auf Ressourcenverbrauch und Kosten verglichen.

Danach folgen die Erörterung der Limitationen dieser Arbeit sowie die inhaltliche Auseinandersetzung mit den Ergebnissen.

\subsection{Einordnung der Ergebnisse in den Stand der Forschung}

Die ausführliche Beschreibung der ALDO-DHF-Studie und deren Ergebnisse wurde bereits veröffentlicht (Edelmann et al. 2013). Hintergrund sind die noch immer unbefriedigenden Therapieoptionen bei Herzinsuffizienz mit erhaltener Ejektionsfraktion trotz der hohen und 
steigenden Prävalenz (Owan et al. 2006). Die Studie wurde zwischen 2007 und 2012 durchgeführt und schloss 422 Patienten ein. Es zeigte sich, dass die Gabe von Spironolacton zusätzlich zur Behandlung der Risikofaktoren zwar die diastolische Funktion und das linksventrikuläre Remodelling verbessert, jedoch auf die Lebensqualität und die maximale Sauerstoffkapazität keinen Einfluss hat.

Der Primärdatensatz der ALDO-DHF-Studie diente als Grundlage für die vorliegende Analyse. Sie ist als Krankheitskostenberechnung für die HFpEF in Deutschland bisher einmalig. Der Vergleich mit anderen Forschungsarbeiten muss daher vor allem international gesucht werden und andere Entitäten der Herzinsuffizienz einschließen.

Die Herzinsuffizienz insgesamt wurde in Deutschland bereits vielfach auch in ihren ökonomischen Auswirkungen untersucht. So haben Biermann et al. (2012) verschiedene Entitäten der systolischen Herzinsuffizienz auf Ressourcenverbrauch und Kosten analysiert. Dafür wurden Daten von zehn Studien des Kompetenznetz Herzinsuffizienz integriert, deren Patientenkollektive eine symptomatische Herzinsuffizienz mit einer EF $<50 \%$ aufwiesen und alle NYHAKlassen einbezogen. Von den so insgesamt 2710 Patienten nahmen 84,4\% Betablocker, 74,9\% ACE-Hemmer, 17\% AT1-Rezeptorantagonisten und 46,5\% Aldosteronantagonisten ein. Demgegenüber wurden innerhalb unserer Kohorte bei Baseline $72 \%$ der Patienten mit Betablockern behandelt und 77\% mit ACE-Hemmern oder AT1-Rezeptorantagonisten.

Für die ambulanten Arztkontakte verzeichneten die Autoren durchschnittlich 6,1 ( \pm 9 ) Hausarztkontakte und 1,7 $( \pm 2,5)$ Kardiologenkontakte pro Patient und Jahr. Diese Werte sind damit höher als in der vorliegenden Analyse, wo wir $1,8( \pm 3,4)$ Hausarzt- und 0,4 $( \pm 1,0)$ Kardiologenkontakte berechneten. Der Median lag bei 1 bzw. 0 Kontakten.

Die stationären Aufenthalte bei dem Vergleichskollektiv der systolischen Herzinsuffizienz beliefen sich nach Biermann et al. (2012) auf 0,8 ( $\pm 1,2)$, demgegenüber stehen nur 0,2 $( \pm 0,6)$ stationäre Behandlungen im Jahr in unserem Kollektiv mit einem Median von 0 Hospitalisierungen.

Die Gesamtkosten beliefen sich schließlich auf $3150 €$ pro Patient im Jahr, von denen 2620 Euro auf stationäre Aufenthalte entfielen. Für unsere Kohorte konnten wir demgegenüber durchschnittlich $1188( \pm 2475)$ Euro jährliche Kosten berechnen, im Median lediglich 332 Euro. Der Kostenanteil durch herzinsuffizienzbedingte Hospitalisierungen lag im Vergleich bei $641( \pm 1994)$ Euro mit einem Median von 0 Euro.

Ebenfalls wurde von dem Autorenteam der Einfluss des Schweregrades der Herzinsuffizienz auf Ressourcenverbrauch und Kosten untersucht (Biermann et al. 2011). Dabei wurde auf die gleiche Patientenpopulation zurückgegriffen wie bei der eben beschriebenen Analyse. Die 
NYHA-Klassen II (51,7\%) und III (38,1\%) stellten den größten Anteil der Patienten, was eine Vergleichbarkeit mit unseren Daten ermöglicht, die ausschließlich von Patienten in diesen klinischen Schweregraden gewonnen wurden. Die Patienten waren zu 25,2\% weiblich und im Durchschnitt 62,9 $( \pm 13,6)$ Jahre alt, während unser Kollektiv älter war $(67 \pm 8)$ Jahre und deutlich mehr weibliche Probanden aufwies (52\%). Die linksventrikuläre Ejektionsfraktion war bei der Untersuchung von Biermann et al. teilweise deutlich reduziert. 61.3\% der Patienten hatten eine LVEF zwischen 30 und 50\%, 38,7\% sogar kleiner als 30\%. Dagegen lag die durchschnittliche LVEF unserer Kohorte bei $67( \pm 8) \%$. Dass in niedrigeren NYHA-Stadien weniger Ressourcen verbraucht wurden, ist nicht überraschend. Interessant ist, dass der Unterschied in den Gesamtkosten zwischen NYHA I und II sowie zwischen NYHA III und IV nicht signifikant war, jedoch zwischen NYHA II und III mit 2821 Euro vs. 3671 Euro durchschnittlichen Gesamtkosten. Auch in der vorliegenden Arbeit wurde der Unterschied zwischen NYHA II und III als starker unabhängiger Prädiktor für höhere Kosten gefunden. Zwischen NYHA I und IV fanden Biermann et al. (2011) einen Anstieg von 181\% bei Hausarztkosten, einen vergleichsweise milden Anstieg von 19\% für Kardiologenkosten und einen Anstieg von 67\% der Kosten für stationäre Behandlungen. In allen NYHA-Klassen hatten über 90\% der Patienten keinen Reha-Aufenthalt.

Eine in den USA und Kanada durchgeführte multizentrische Studie mit ähnlicher Patientenpopulation ist die sogenannte RELAX-Studie, welche von 2008 bis 2012 von Redfield et al. (2013) geleitet wurde. Getestet wurde der Phosphodiesterase-5-Hemmer Sildenafil im Vergleich mit einem Placebo in einem doppelblinden randomisierten Design. Wie bei ALDODHF war die maximale Sauerstoffaufnahme $\mathrm{VO}_{2}$ max ein primärer Endpunkt, kardiovaskuläre oder renale Hospitalisierungen gehörten zu den sekundären Endpunkten. Das mediane Alter der 216 Patienten betrug 69 Jahre, 49\% der Teilnehmer waren weiblich - beides entspricht annähernd der Verteilung in unserer Kohorte. Bei genauerem Vergleich fällt jedoch auf, dass die RELAX-Population höher durch Komorbiditäten belastet war, schlechtere krankheitsspezifische Parameter bei Baseline aufwies und in der Folge mehr Events im Verlauf der Studie entwickelte. So wiesen in der Vorgeschichte der RELAX-Patienten (im Vergleich dazu ALDO-DHF Patienten) 39\% (40\%) eine KHK, 85\% (92\%) einen arteriellen Hypertonus, 43\% (17\%) einen Diabetes mellitus 19\% (3\%) eine COPD und 51\% (15\%) Vorhofflimmern auf. Entsprechend höher war der Anteil der Patienten, bei denen folgende Medikamentenklassen zum Einsatz kamen (wieder im Vergleich zu ALDO-DHF-Patienten): Schleifendiuretika 77\% (17\%), ACE-Hemmer 70\% (46\%), Betablocker 76\% (73\%) und Statine 64\% (56\%).

Der mediane Wert für NTproBNP lag bei den Patienten der RELAX-Studie bei 700 pg/ml, bei 
unseren Patienten lediglich bei $158 \mathrm{pg} / \mathrm{ml}$. $\mathrm{VO}_{2} \max$ lag im Median bei 11,7 $\mathrm{ml} / \mathrm{min} / \mathrm{kg}$, bei ALDO-DHF dagegen $>16 \mathrm{ml} / \mathrm{min} / \mathrm{kg}$. Ebenfalls schlechter waren die Werte E/e' mit 16 (vs. 11,8) und LAVI mit $44 \mathrm{ml} / \mathrm{m}^{2}$ (vs. $26 \mathrm{ml} / \mathrm{m}^{2}$ ). Entsprechend hoch sind die Raten für Hospitalisierungen aufgrund kardialer Ursachen. In nur einem halben Jahr wurden 28 registriert, während bei unseren Patienten 36 innerhalb eines Jahres anfielen. 3 Patienten starben im Verlauf der Studie gegenüber einem Patienten in der ALDO-DHF-Studie. Über den Ressourcenverbrauch bezüglich ambulanter Arztkontakte gibt es keine Angaben.

Es lässt sich zusammenfassend sagen, dass die RELAX-Studie als randomisierte, Placebokontrollierte Interventionsstudie eine ähnliche Patientenpopulation untersucht hat. Diese war jedoch insgesamt kränker, hatte einen höheren Medikamentenverbrauch und mehr Krankenhausaufenthalte aufgrund kardialer Ursache. Trotz fehlender Angaben zu dem Verbrauch anderer Ressourcen ist von höheren Kosten in dieser Kohorte auszugehen. Eine wesentliche Ursache liegt in den Einschlusskriterien. Diese sahen, im Gegensatz zu ALDO-DHF vor, dass die Patienten in den zwölf Monate vor Baseline wegen dekompensierter Herzinsuffizienz hospitalisiert gewesen sein mussten. Dies ist natürlich ein Hinweis für einen bereits fortgeschrittenen Verlauf. Bei ALDO-DHF waren in den 12 Monaten vor Baseline lediglich 37\% der Patienten aufgrund von Herzinsuffizienz hospitalisiert.

Dieser recht offensichtliche Zusammenhang wird noch deutlicher, wenn man Daten zur Häufigkeit von Re-Hospitalisierung heranzieht. Korves et al. (2012) beobachteten 7814 Patienten mit chronischer Herzinsuffizienz nach einem diesbezüglichen Krankenhausaufenthalt im Hinblick auf im Verlauf anfallende Kosten und Verbrauch von medizinischen Ressourcen. Am teuersten war derjenige Krankenhausaufenthalt, der zur Aufnahme in die Studie führte. Die ambulanten Arztkontakte waren in den ersten drei Monaten danach am höchsten mit 3,6 Kontakten pro Patient und Monat in der Gruppe der < 65-Jährigen und 4,1 Kontakten bei den älteren Patienten > 65 Jahren. Für letztere Gruppe war die Zahl der Re-Hospitalisierungen 3 bis 6 Monate später mit durchschnittlich 0,06 pro Patient und Monat am höchsten, in der Gruppe mit den jüngeren Patienten mit 0,08 dagegen im ersten Quartal am höchsten. Die Kosten für Medikamente wurden mit weniger als 3\% der Gesamtkosten angegeben. Die Autoren kommen also zu dem Schluss, dass in den ersten sechs Monaten nach einem Krankenhausaufenthalt aufgrund von Herzinsuffizienz der Ressourcenverbrauch und die anfallenden Kosten vor allem durch ambulante und (erneute) stationäre Behandlungen entstehen.

Eine noch aktuellere Beobachtungsstudie von Nichols et al. (2015) liefert ebenfalls Erkenntnisse zum Ressourcenverbrauch nach einer initialen Hospitalisierung. Sie ist im Kontext unse- 
rer Analyse noch interessanter, da sie HFrEF- und HFpEF-Patienten miteinander vergleicht. Von 6513 Patienten, die wegen Herzinsuffizienz stationär behandelt wurden, hatten 2205 Patienten eine reduzierte $\mathrm{EF}<40 \%$ und 3631 Patienten eine erhaltene Pumpfunktion (EF $>$ 50\%). 677 Patienten mit einer EF zwischen 41\% und 49\% wurden ausgeschlossen. Der Beobachtungszeitraum erstreckte sich über ein Jahr. Bei Baseline waren die HFpEF-Patienten älter als die HFrEF-Patienten (75,9 \pm 12,3 Jahre vs. 71,4 \pm 13,8 Jahre) und damit älter als das Kollektiv von ALDO-DHF (67 \pm 8 Jahre). 55\% der Studienteilnehmer waren weiblich (36\% bei HFrEF). Bezüglich Komorbiditäten hatten die HFpEF-Patienten im Vergleich zu denen der HFrEF-Gruppe häufiger einen Diabetes mellitus (36\%), einen Bluthochdruck (90\% vs. $76 \%)$ und eine eingeschränkte Nierenfunktion mit einer GFR $<60 \mathrm{ml} / \mathrm{min} / \mathrm{m}^{2}$ (66\% vs. 51\%). Eine geringere Anzahl der HFpEF-Patienten hatte eine KHK (36\% vs. 40\%). Im Vergleich zum Kollektiv von ALDO-DHF ist die Gruppe der HFpEF-Patienten hier neben dem hohen Alter vor allem durch höhere Raten an Diabetes mellitus (49\% vs. 17\%) und schlechterer Nierenfunktion gekennzeichnet. Nach einem Jahr waren die Re-Hospitalisierungsraten im Gruppenvergleich fast gleich (55\% bei HFrEF- und 58\% bei HFpEF-Patienten) und damit auch bemerkenswert hoch. Es wurde allerdings nicht nach Ursache getrennt, sondern davon unabhängig alle Hospitalisierungen erfasst. Vergleicht man die Anzahl der Krankenhausaufenthalte aufgrund von Herzinsuffizienz mit jener unseres Kollektivs, so ist diese verschwindend gering. Insgesamt hatten jedoch auch immerhin 24\% in der Placebo-Gruppe und 28\% in der Spironolacton-Gruppe Hospitalisierungen, die in Form von serious adverse events erfasst wurden. Weitere Ergebnisse von Nichols et al. (2015) zeigten, dass HFpEF-Patienten signifikant mehr ambulante Arztkontakte hatten. Der Unterschied zwischen den beiden Gruppen war jedoch gering $(21,5 \pm 16,9$ vs. $20,1 \pm 17,1)$. In der vorliegenden Analyse wurden lediglich Hausarzt- und Kardiologenkontakte erfasst, die allerdings deutlich seltener verzeichnet wurden $(1,8 \pm 3,4$ bzw. $0,4 \pm 1,0)$. Bei dem erfassten Medikamentenverbrauch gab es keine signifikanten Unterschiede zwischen den beiden Gruppen.

Die Autoren kommen zu dem Schluss, dass sich die Ressourcenverbräuche in dem auf eine Herzinsuffizienz-Hospitalisierung folgenden Jahr in den untersuchten Gruppen nicht nennenswert unterscheiden. Leider fehlen Angaben zu Krankheitsstadien bzw. Hinweise darauf, z.B. NYHA-Klassifikation, natriuretische Peptide, Echokardiographie-Befunde oder die maximale Sauerstoffaufnahme in der Spiroergometrie. Auch das Vorhofflimmern, welches in dieser Arbeit als starker Prädiktor für höhere Kosten identifiziert wurde, fehlt für einen Vergleich. So lässt sich zusammenfassend sagen, dass die Patienten von Nichols et al. (2015) deutlich älter waren, mehr Begleiterkrankungen hatten und vor allem alle mindestens eine 
stationäre Behandlung aufgrund von Herzinsuffizienz hatten. Wichtig ist auch, dass zwischen dieser und der Beobachtung durch die Studie keine Zeit verging. Bei den ALDO-DHFPatienten konnten die ohnehin deutlich selteneren Krankenhausvorbehandlungen schon Monate oder Jahre zurückgelegen haben. In der Zwischenzeit mag es eine Selektion der gesünderen Patienten für die Studie gegeben haben.

Eine andere Interventionsstudie, die zum Vergleich herangezogen werden kann, ist die PARAMOUNT-Studie (Solomon et al. 2012). Über 36 Wochen wurden hier Patienten mit erhaltener EF (> 45\%) und einem erhöhten NTproBNP von > 400 pg/ml doppelt verblindet entweder mit Valsartan $(n=152)$ oder dem neuen Wirkstoff LCZ696 $(n=149)$ behandelt. Primärer Endpunkt war die Veränderung des NTproBNP-Wertes. Das Kollektiv ist mit dem von ALDO-DHF gut vergleichbar. So waren die Patienten etwas älter (71 \pm 9 Jahre vs. $67 \pm 8$ Jahre), zum großen Teil weiblich (56\% vs. 52\%), übergewichtig (BMI $30 \mathrm{~kg} / \mathrm{m}^{2} \pm 5,8$ vs. $29 \mathrm{~kg} / \mathrm{m}^{2} \pm$ $3,6)$ und vorwiegend im NYHA-Stadium II ( $80 \%$ vs. $86 \%)$. Auch handelte es sich bei beiden Studien um ein ambulantes Kollektiv, nur 42\% waren im Vorfeld wegen Herzinsuffizienz hospitalisiert gewesen (im Vergleich 37\% bei unserem Kollektiv). Während das Vorliegen einer arteriellen Hypertonie in beiden Kollektiven ähnlich hoch war (94\% vs. 92\%), hatten die Patienten der PARAMOUNT-Studie häufiger einen Diabetes mellitus (38\% vs. 17\%) und Vorhofflimmern (29\% vs. 5\%). Auch fiel die Nierenfunktion der Patienten etwas schlechter aus (eGFR $66 \mathrm{ml} / \mathrm{kg} / \mathrm{m}^{2} \pm 20,3$ vs. $79 \mathrm{ml} / \mathrm{kg} / \mathrm{m}^{2} \pm 19$ ). Der Median für NTproBNP (Q1, Q3) lag bei 828 (480, 1341) pg/ml in der LCZ696-Gruppe bzw. bei 939 (582, 1490) pg/ml in der Valsartan-Gruppe und damit deutlich höher als bei den ALDO-DHF-Patienten mit 158 (83, 299) pg/ml. Der echokardiographische Parameter E/e' dagegen war im Mittel fast gleich (12,7 $\pm 7,5$ vs. 12,8 $\pm 4,0$ ). Für den Medikamentenverbrauch können nur Angaben bei Baseline verwendet werden, da diese im Verlauf bei der PARAMOUNT-Studie nicht erfasst wurden. Etwas mehr Patienten (im Vergleich zu ALDO-DHF) nahmen Betablocker (79\% vs. 72\%) und ACE-Hemmer oder AT1-Rezeptorantagonisten (93\% vs. 77\%). 100\% nahmen mindestens ein Diuretikum ein (vs. 54\%). Leider finden sich auch keine Angaben zu ambulanten Arztkontakten. Zahlen zu Hospitalisierungen jedoch lassen sich über die veröffentlichten serious adverse events ermitteln. Ein bzw. zwei Todesfälle (LCZ696 bzw. Valsartan-Gruppe) stehen gegenüber einem Todesfall im Studienverlauf von ALDO-DHF. Hospitalisierungen durch Herzinsuffizienz traten allerdings seltener auf (3\% in der LCZ696-Gruppe und 4\% in der Valsartan-Gruppe gegenüber 14,7\% bei ALDO-DHF). Allerdings war auch der Beobachtungszeitraum mit 36 Wochen vs. 1 Jahr kürzer. 
Interessante Daten liefert auch das OPTIMIZE-Register (Fonarow et al. 2007). Es handelt sich dabei zwar nicht um eine randomisierte prospektive Studie, dafür werden Ergebnisse einer großen Fallzahl von fast 50.000 Patienten vorgelegt. Außerdem lassen die Daten einen Vergleich zwischen Patienten mit HFrEF ( $\mathrm{N}=20118)$, hier definiert als $\mathrm{EF}<40 \%$, und jenen mit HFpEF ( $\mathrm{N}=21149), \mathrm{EF}>40 \%$, zu. 7321 der Patienten wiesen eine EF zwischen 40 und $50 \%$ auf. Auch in dieser Studie führte eine Hospitalisierung aufgrund von Herzinsuffizienz zum Einschluss, was im Gegensatz zum ambulanten Kollektiv bei ALDO-DHF steht. Die Patienten mit erhaltener Ejektionsfraktion waren älter als jene mit reduzierter EF $(75.1 \pm 13.1$ Jahre) und damit auch deutlich älter als die unsers Kollektives (67 \pm 8 Jahre). 62\% dieser Patienten waren weiblich und damit ebenfalls deutlich mehr als bei der Vergleichsgruppe mit HFrEF (38\%). Auch hier sollen im Folgenden die wichtigsten Baselineparameter der HFpEFFraktion mit unserem Patientenkollektiv verglichen werden und dann die verfügbaren Daten zu Ressourcenverbräuchen. Mehr Patienten des Optimize-Registers (vs. ALDO-DHF) hatten einen Diabetes mellitus (43\% vs. 17\%) und ein Vorhofflimmern (33\% vs. 15\%), während weniger Patienten bei Baseline einen arteriellen Hypertonus (76\% vs. 92\%) und eine Hyperlipoproteinämie (32\% vs. 64\%) aufwiesen. Die Nierenfunktion lässt sich durch unterschiedliche Parameter nur eingeschränkt vergleich. Es lässt sich aber festhalten, dass bei einem medianen Serum-Kreatinin (Q1, Q3) von $1,3 \mathrm{mg} / \mathrm{dl}(1,0 ; 1,8)$ die Nierenfunktion insgesamt schlechter $\mathrm{zu}$ sein scheint als in unserem Kollektiv mit einer medianen eGFR von 78 $\mathrm{ml} / \mathrm{min} / \mathrm{m}^{2}$. Als natriuretisches Peptid findet sich bei den HFpEF-Patienten des OPTIMIZERegisters ein medianer BNP-Wert (Q1, Q3) von 601,5 pg/ml (320, 1190) während bei ALDO-DHF das NTproBNP gemessen wurde, der Median (Q1, Q3) lag bei 158 pg/ml (83, 299). Der Hb-Wert lag bei 11,9 g/dl $( \pm 2,0)$ gegenüber $13,8 \mathrm{~g} / \mathrm{dl}( \pm 1,8)$. Bezüglich regelmäßig eingenommener Medikamente bei Baseline unterscheiden sich die Kohorten vom OPTIMIZERegister (vs. ALDO-DHF) vor allem in der Einnahme von ACE-Hemmern (36\% vs. 77\%) und Betablockern (52\% vs. 72\%). Geringer sind die Unterschiede hinsichtlich Statinen (39\% vs. 55\%) und Diuretika (58\% vs. 54\%). Die Werte beziehen sich auf den Zeitpunkt der Krankenhauseinweisung, die zur Aufnahme in das OPTIMIZE-Register führte.

Für die ambulanten Arztkontakte fehlen Angaben. Betrachtet man aber die Mortalität und Hospitalisierungsraten nach der initialen Krankenhausbehandlung finden sich über beide Gruppen sehr hohe Werte. So liegt die Mortalität bei den HFpEF- und den HFrEF-Patienten im Zeitraum von 60 bis 90 Tagen nach Baseline bei deutlich über 9\% (9,5 bzw. 9,8\%). Dagegen gab es bei ALDO-DHF im gesamten Zeitraum nur einen Todesfall. Auch die (Re)Hospitalisierungsraten unterscheiden sich drastisch von unseren Werten, jedoch nicht zwi- 
schen HFpEF und HFrEF - sie liegen bei 29,2\% bzw. 29,9\%. Diese Werte lassen auf eine enorme Belastung für das Gesundheitssystem schließen.

Da die oben beschriebenen Parameter den Unterschied zu den Ergebnissen dieser Arbeit nicht erklären können, müssen diejenigen hervorgehoben werden, die in der Publikation von Redfield et al (2011) fehlen und wahrscheinlich von wesentlicher Bedeutung sind. Zum einen gibt es keine Angaben zum klinischen Stadium durch Nennung der NYHA-Klassifikation. Höhere NYHA-Stadien sind mit höheren Kosten assoziiert (vgl. Biermann et al. 2011). Zum anderen stehen die krankheitsspezifischen Parameter aus Echokardiographie und Spiroergometrie nicht zur Verfügung, die den Schweregrad der Erkrankung objektivieren können.

Zusammenfassend kann lediglich die Vermutung aufgestellt werden, dass neben den genannten fehlenden Parametern vor allem die zur Studienteilnahme führende Hospitalisierung, das insgesamt höhere Alter der Patienten sowie das häufigere Vorliegen von Vorhofflimmern und ein niedrigerer $\mathrm{Hb}$-Wert $\mathrm{zu}$ dem deutlichen Unterschied in Mortalität und Hospitalisierung geführt haben. Die zwei letztgenannten wurden in dieser Analyse auch als unabhängige Prädiktoren für höhere Kosten identifiziert. Für den Einfluss der ersten Hospitalisierung bieten die oben beschriebenen Untersuchungen Evidenz (Korves et al. 2012, Nichols et al. 2015)

Die zuletzt beschriebenen internationalen Studien untersuchten primär weder den Ressourcenverbrauch noch die finanziellen Auswirkungen. Anders eine Analyse von Liao et al. (2006), die die Kosten von Herzinsuffizienz mit erhaltener und reduzierter EF miteinander vergleicht. Mit insgesamt 4549 Patienten stand ein großes Kollektiv zur Verfügung, 881 Patienten davon konnten der HFpEF- oder HFrEF-Gruppe zugeordnet werden. Im Gegensatz zu den bereits beschriebenen Studien ist der Beobachtungszeitraum mit fünf Jahren sehr lang. Neben der Einteilung in erhaltene und reduzierte EF wurden die Patienten in jene mit vorbestehender Herzinsuffizienz und jene mit neu diagnostizierter Herzinsuffizienz im Verlauf unterteilt (,prevalent HF“ vs. ,,incident HF“). Die Kosten (in US-Dollar) beziehen sich auf das Basisjahr 2000. Leider sind die Daten bereits sehr alt - sie wurden zwischen 1992 und 1998 erhoben.

In beiden Gruppen waren die HFpEF-Patienten älter und häufiger weiblich als jene mit reduzierter EF. In der „,incident HF“-Gruppe 78,9 Jahre \pm 6,5 (vs. 77,6 Jahre $\pm 6,1$ ) mit 60,2\% Frauen (vs. 37,4\%) und in der ,prevalent HF“-Gruppe 81,6 Jahre \pm 6,3 (vs. 80,1 Jahre \pm 5,6) mit 52,8\% Frauen (vs. 37,7\%). Die Unterschiede sind gut mit den bereits beschriebenen Studien vereinbar, auch mit ALDO-DHF, wo die Teilnehmer allerdings wieder deutlich jünger waren (67 Jahre \pm 8 ). In allen Subgruppen hatten mindestens 94\% der Patienten einen arteriel- 
len Hypertonus und zwischen $27,8 \%$ und $31,7 \%$ einen Diabetes mellitus. In der HFpEFGruppe waren mehr Patienten an einer COPD erkrankt als in der HFrEF-Gruppe und zwar 16,8\% (incident HF) bzw. 21\% (prevalent HF). Eine KHK wiesen zwischen 50\% und 80\% der Patienten auf, wobei jene mit reduzierter EF deutlich häufiger von einer KHK betroffen waren. Ein durchschnittlicher Serum-Kreatininwert von $>1,2 \mathrm{mg} / \mathrm{dl}$ lässt auf eine eingeschränkte Nierenfunktion bei den meisten Teilnehmern schließen. Zusammengefasst waren die Patienten dieser Studie älter als jene von ALDO-DHF, hatten eine schlechtere Nierenfunktion und häufiger COPD und KHK. Wie bei unserer Studie waren $>90 \%$ der Teilnehmer Hypertoniker.

Im Folgenden sollen die Ergebnisse dieser Arbeit und die von Liao et al. hinsichtlich Ressourcenverbrauches und entstandener Kosten durch die HFpEF-Patienten vergleichend betrachtet werden. Dabei werden zunächst die Daten der "prevalent HF"-Gruppe herangezogen, da auch bei ALDO-DHF die Herzinsuffizienz bereits bestand und nicht erst im Verlauf festgestellt wurde. Ambulante Kardiologenkontakte beliefen sich auf durchschnittlich 4,8 in den fünf Jahren Beobachtungszeitraum (vs. 0,4 Kontakte in einem Jahr bei ALDO-DHF). Ambulante Hausarztkontakte fanden im Durchschnitt 21,8-mal statt, also auf ein Jahr umgerechnet etwa 4,4 (vs. 1,8 in dieser Analyse). Außerdem gab es pro Jahr etwa einen stationären Aufenthalt in der Kardiologie, was allerdings nicht auf Herzinsuffizienz als Ursache begrenzt war. In unserer Analyse stellten wir durchschnittlich 0,2 Aufenthalte aufgrund von Herzinsuffizienz fest. Auf 100 Patienten entfielen etwa fünf Reha-Maßnahmen, der Medikamentenverbrauch wurde nicht detailliert erfasst. Die kumulativen Gesamtkosten beliefen sich über fünf Jahre auf 32.580 USD, in den einzelnen Jahren zwischen 5.000 und 10.000 USD. Damit sind diese deutlich höher als die in dieser Analyse berechneten Kosten von unter $1200 €$ pro Jahr. Die absoluten Zahlen sind aufgrund der großen Unterschiede im Hinblick auf die Gesundheitssysteme nur sehr eingeschränkt miteinander zu vergleichen. Außerdem wurden neben den genannten Ressourcen auch alle kardiologischen Prozeduren wie Katheter-Untersuchung, Schrittmacherimplantation etc. sowie ambulante und stationäre Arztkontakte aus nichtkardiologischen Gründen erfasst, was einen Teil der höheren Gesamtkosten erklärt. Interessanterweise fanden die Autoren keinen signifikanten Unterschied zu den HFrEF-Patienten bezogen auf Hospitalisierungen, Notfallaufnahmen und ambulante Arztkontakte. Auch die jährlichen Kosten pro Patient waren fast gleich, wobei auffällt, dass in beiden Gruppen im ersten Jahr deutlich höhere Kosten anfielen als in den drauf folgenden. Dies widerspricht der Annahme, die Kosten würden im Verlauf der Erkrankung jährlich steigen.

Auch in der "incident HF"-Gruppe unterschieden sich die Patienten mit reduzierter EF und die 
mit erhaltener EF im Hinblick auf die kumulativen Kosten nicht signifikant voneinander. Auffallend hohe Kosten fielen auf das Jahr, in dem die Herzinsuffizienz-Diagnose gestellt wurde. Die Autoren gaben einen Anstieg der Kosten gegenüber dem Vorjahr um mehr als 200\% an. Zur Findung möglicher Prädiktoren höherer Kosten wurden auch bei Liao et al. (2006) Regressionsanalysen durchgeführt. Als stärkster Prädiktor in der "prevalent HF"-Gruppe wurde die NYHA-Klasse IV ausgemacht mit einem Kostenanstieg von 77\% verglichen mit NYHAKlassen I oder II. Diese Erkenntnis deckt sich mit den Ergebnissen dieser Arbeit, in der wir die höhere NYHA-Klasse (III gegenüber II) neben dem Vorliegen eines Vorhofflimmerns als einen starken Prädiktor für höhere Kosten identifizieren konnten. Außerdem schien eine Niereninsuffizienz mit einem Kreatinin $>1,4 \mathrm{mg} / \mathrm{dl}$ höhere Kosten verursacht zu haben $(\mathrm{p}=0,07)$. In der "incident HF"-Gruppe konnte neben der Niereninsuffizienz die Koronare Herzkrankheit als stärkster Prädiktor identifiziert werden. Dieses Ergebnis bestätigt damit ebenfalls ein Ergebnis dieser Arbeit.

Die Gesamtkosten, die durch die in unserer Analyse berücksichtigten Ressourcen entstanden, waren nicht so hoch, wie man sie aufgrund der Literaturrecherche und der epidemiologischen Daten vermutet hätte. Dies liegt vor allem an der geringen Rate an stattgefundenen Hospitalisierungen, die sehr kostenintensiv sind. In diesem Zusammenhang sei auf die maximalen Kosten von $18.000 €$ für einen einzigen Patienten der Studie hingewiesen, die durch die Hospitalisierung verursacht wurden. Bei der großen Mehrheit dagegen (360 Patienten) war gar keine stationäre Behandlung notwendig. Jedoch gab es 84 nicht-kardiale Hospitalisierungen, die in Form von serious adverse events erfasst aber nicht in die Kostenanalyse einbezogen wurden. Diese Zahl ist sogar höher als die der durch Herzinsuffizienz verursachteten Hospitalisierungen und lässt auf eine in der Realität deutlich höhere Gesamtbelastung der ALDO-DHFPatienten für das Gesundheitswesen schließen. Bei dem ambulanten Kollektiv dieser Studie waren die meisten Patienten auch im Jahr vor Baseline nicht wegen Herzinsuffizienz im Krankenhaus. Bei den oben beschriebenen Daten zur Häufigkeit von Re-Hospitalisierung erklärt diese Tatsache wesentlich den Unterschied zur Kostenschätzung anderer Studien, in denen eine initiale Hospitalisierung überhaupt erst zur Studienteilnahme führte.

Die bereits veröffentlichten Ergebnisse von ALDO-DHF zeigten, dass die Therapie mit Spironolacton in diesem oligosymptomatischen Kollektiv keinen signifikanten Einfluss auf die Endpunkte körperliche Leistungsfähigkeit und Lebensqualität hat, es also zu keiner klinischen Besserung kam. Diese Beobachtung passt inhaltlich zum Ergebnis der vorliegenden Analyse. Es konnte nämlich auch kein signifikanter Unterschied hinsichtlich der Kosten zwischen den 
Therapiegruppen gefunden werden. Selbst in der Gegenüberstellung der einzelnen kostenverursachenden Ressourcen gab es keinen signifikanten Unterschied. Obwohl dies in Anbetracht der Hauptergebnisse zu erwarten war, wurde ein Schwerpunkt dieser Arbeit auf die Fragestellung des Einflusses von Spironolacton auf die Kosten gelegt, da das Design der Studie und die Randomisierung auf einen potentiellen Unterschied abzielten.

Obwohl die Verteilung der einzelnen Kostenkomponenten insgesamt nicht unterschiedlich ist, fällt dennoch auf, dass die Ausreißer der maximalen Kosten für Hausarztkontakte, RehaAufenthalte, vor allem aber für Hospitalisierungen in die Verum-Gruppe fallen. Möglicherweise besteht ein Zusammenhang zum Nebenwirkungsprofil des Spironolactons. Immerhin wurden bei den adverse events von ALDO-DHF signifikant mehr Patienten in der VerumGruppe mit einer Verschlechterung der Nierenfunktion $(\mathrm{p}<0,001)$, einer neu aufgetretenen oder verstärkten Anämie ( $\mathrm{p}=0,03)$, einer zwischenzeitlichen Hyperkaliämie mit einem Kalium von $>5 \mathrm{mmol} / \mathrm{l}(\mathrm{p}=0,005)$ oder einer Gynäkomastie $(\mathrm{p}<0,001)$ erfasst.

Als unabhängige Prädiktoren für höhere Kosten wurden folgende Parameter identifiziert: ein niedriger $\mathrm{Hb}$-Wert, eine gute maximale Sauerstoffaufnahme $\mathrm{VO}_{2} \mathrm{max}$, ein höheres NYHAStadium, das männliche Geschlecht und das Vorliegen einer KHK, einer Hyperlipoproteinämie sowie eines Vorhofflimmerns. Hier ist zunächst auffällig, dass der für die Diagnosestellung wichtige Wert E/e', aber auch alle anderen echokardiographisch gemessenen Parameter, ebenso wenig als unabhängiger Prädiktor gefunden werden konnten wie das NTproBNP. Und das, obwohl insbesondere E/e' und NTproBNP als Indikatoren für den Schweregrad der HFpEF dienen. Auch das höhere Alter scheint nicht den Einfluss auf die Kosten zu verursachen, wie man hätte vermuten können. Der positive Zusammenhang zwischen einer guten $\mathrm{VO}_{2} \max$ und höheren Kosten widerspricht ebenfalls der Erwartung, dass die besser belastbaren Patienten automatisch weniger Ressourcen im Gesundheitssystem in Anspruch nehmen würden. Allerdings ist dies trotz seiner Signifikanz der schwächste Prädiktor, der IRR liegt nur bei 1,04. Gut nachvollziehbar ist dagegen der Einfluss des NYHA-Stadiums, der, wie bereits erwähnt, auch für die HFrEF in Deutschland beschrieben wurde (Biermann et al. 2011). Anstelle der für die HFpEF etablierten Schweregradparameter zeigt diese Analyse die Rolle der Komorbiditäten als Prädiktoren für höhere Kosten auf. Für KHK und Vorhofflimmern sind die gesundheitsökonomischen Belastungen zum Teil gut untersucht und beschrieben worden (z.B. Maddox et al. 2008, Ringborg et al. 2008, Liu et al. 2002). Ather et al. (2012) untersuchten den Einfluss nicht-kardialer Komorbiditäten auf Mortalität und Morbidität der chronischen Herzinsuffizienz. Sie fanden heraus, dass dieser für die HFpEF deutlich größer 
ist als für die HFrEF. Interessanterweise hatten Patienten mit HFpEF häufiger als jene mit HFrEF eine nicht-kardial bedingte Hospitalisierung, jedoch seltener eine kardial bedingte Hospitalisierung.

\subsection{Limitationen der Arbeit}

Limitierend für die vorliegende Analyse ist die Tatsache, dass die indirekten Kosten nicht erfasst werden konnten. Dazu zählen z.B. Arbeitsunfähigkeitstage, vorzeitiger Ruhestand, Kosten für Wege zu Untersuchungen etc. Zu den Einschlusskriterien gehörte ein Mindestalter von 50 Jahren Tatsächlich waren die Studienteilnehmer im Durchschnitt aber deutlich älter (67 \pm 8 Jahre), sodass ein erheblicher Anteil nicht mehr berufstätig gewesen sein dürfte. Damit ist diese Einschränkung nicht so schwerwiegend wie bei anderen chronischen Erkrankungen mit jüngeren Patientengruppen, wie etwa einer HIV-Infektion.

Während der Studienteilnahme wurden die Patienten regelmäßig ausführlich kardiologisch in der Studienambulanz untersucht. Es stellt sich daher die Frage, ob deshalb weniger Termine beim niedergelassenen Kardiologen oder Hausarzt wahrgenommen wurden, was zu einer Unterschätzung der Kosten führen würde. Dies kann nicht ausgeschlossen werden, jedoch wurden die Patienten dazu angehalten, ihre regelmäßigen Kontrolltermine trotzdem wahrzunehmen, und es wurden auch keine Rezepte für regelmäßig einzunehmende Medikamente ausgestellt.

Eine wesentliche Stärke dieser Analyse ist das Bottom-Up-Verfahren. Hier kann der Ressourcenverbrauch auf Ebene des einzelnen Patienten genau ermittelt werden und es muss nicht auf hochaggregierte Daten zurückgegriffen werden. Um eine Verallgemeinerung zu ermöglichen, muss der Datensatz entsprechend groß sein und höhere Patientenzahlen wären wünschenswert.

Bezüglich der Medikamente stellte sich die Frage, welche Wirkstoffgruppen in die Berechnung eingehen sollten. Auf die Bedeutung der Risikofaktoren und Komorbiditäten bei der HFpEF wurde bereits eingegangen. Wir entschieden uns daher dafür, nicht nur die im engeren Sinne kardiovaskulären Medikamente einzuschließen, sondern auch die zur Behandlung relevanter Nebenerkrankungen und Risikofaktoren, z.B. Antidepressiva.

Zur Bepreisung der Krankenhausaufenthalte und der ambulanten Arztkontakte wurde auf Krauth et al. (2005) zurückgegriffen. Diese Publikation ist sehr alt und das Abrechnungssystem ist nicht mehr identisch. Eine weitere Einschränkung ist, dass die Hauptdiagnosen der Krankenhausaufenthalte nicht bekannt waren und so die Kosten der Aufenthalte nur nähe- 
rungsweise berechnet werden konnten. Für die Wirkstoffe wurde über die Verwendung der Roten Liste der Preis pro mg des günstigsten Generikums und der größten verfügbaren Packung berechnet. Diese Methode ist zwar sehr genau, jedoch entstehen in der Praxis natürlich höhere Kosten bei der Verwendung anderer Generika und Packungsgrößen, sodass die Kosten eher unterschätzt wurden. Demgegenüber steht die Tatsache, dass ausschließlich die Preise für Monopräparate aufgeschlüsselt wurden, während der Preis pro mg Wirkstoff bei Kombipräparaten häufig günstiger ist. So wird zu ACE-Hemmern beispielweise häufig das Hydrochlorothiazid beigemischt.

Die Gefahr einer Überschätzung der Kosten bieten dagegen die ambulanten Arztkontakte. Da hier die Abrechnung quartalsweise erfolgt, ist die Multiplikation der Durchschnittswerte insbesondere bei Patienten mit sehr häufigen Arztkontakten nicht exakt.

\subsection{Fazit und Ausblick}

Die vorliegende Arbeit zeigt den Ressourcenverbrauch eines gut definierten ambulanten Kollektivs mit HFpEF und die damit verbundenen Kosten für die Gesellschaft auf. Es zeigt sich, dass die diastolische Herzinsuffizienz nicht nur mit einer reduzierten Prognose für die Patienten einhergeht, sondern auch aus ökonomischer Sicht eine hohe Belastung für das Gesundheitswesen darstellt. Vergleiche zu internationalen Untersuchungen sind wichtig. Jedoch sind die Berechnungen der Krankheitskosten auf das deutsche Gesundheitssystem limitiert und damit sehr eingeschränkt im internationalen Kontext bewertbar. Dies unterstreicht die Relevanz der Analyse in Deutschland, sie ist hier bislang erstmalig.

Es handelt sich bei ALDO-DHF um ein vergleichsweise junges und gesundes Kollektiv, bei einigen Patienten erfolgte die Erstdiagnose im Rahmen des Screenings. Außerdem wurden weder indirekte Kosten noch die nicht durch Herzinsuffizienz bedingten Hospitalisierungen in die Analyse einbezogen. Es ist daher von tatsächlich deutlich höheren Gesamtkosten auszugehen. Wünschenswert wären weitere Analysen, die einen längeren Beobachtungszeitraum erfassen. Denn im Kontext der diskutierten Studien lässt sich feststellen, dass die Kosten der HFpEF im Verlauf der Erkrankung zunehmen. Daraus kann die Forderung abgeleitet werden, frühzeitig, schon vor der ersten Hospitalisierung, Geld und Ressourcen einzusetzen, um den Verlauf der HFpEF zu bremsen und die Komorbiditäten so gut wie möglich zu behandeln, solange dies finanziell beherrschbar ist. Ein Beispiel ist hier das Angebot an Patienten, sich einem strukturierten und intensiven körperlichen Training zu unterziehen (Edelmann et al. 
2011). Auch sollten Patienten mit einer HFpEF eine regelmäßige ambulante kardiologische Anbindung erhalten. 


\section{Zusammenfassung}

Etwa die Hälfte aller Patienten mit Herzinsuffizienz weist eine erhaltene Ejektionsfraktion (EF) auf.

Die Bedeutung dieser Form der Herzinsuffizienz (heart failure with preserved ejection fraction/ HFpEF) hat in den letzten Jahren zugenommen. Neben einer steigenden Prävalenz wurden auch zunehmend Erkenntnisse zu einer erhöhten Morbidität und Mortalität sowie einer Einschränkung der Lebensqualität gewonnen. Im Gegensatz zur Herzinsuffizienz mit reduzierter EF (HFrEF) liegen in Deutschland kaum Daten vor, die den durch HFpEF verursachten Ressourcenverbrauch und die resultierenden Kosten für die Gesellschaft untersuchen. Dabei sind solche gesundheitsökonomischen Betrachtungen mehr denn je Grundlage gesundheitspolitischer Entscheidungen über den sinnvollen Einsatz begrenzter Ressourcen. Es besteht Konsens darüber, dass Präventions- und Therapiemaßnahmen nicht nur sicher und wirksam, sondern auch kosteneffektiv sein sollen. Immerhin liegt der Anteil der Gesundheitsausgaben am Bruttoinlandsprodukt über 10\% und steigt jährlich beständig an. Auch die Kosten für Herzinsuffizienz steigen von Jahr zu Jahr und stellen eine enorme Belastung für das Gesundheitssystem dar.

Die vorliegende Arbeit untersucht den Ressourcenverbrauch, die resultierenden Krankheitskosten und deren Zusammensetzung für das ambulante stabile Kollektiv der ALDO-DHFStudie. Es wird auch analysiert, ob der Aldosteronantagonist Spironolacton darauf Einfluss hat und welche Prädiktoren für höhere Kosten identifiziert werden können.

Es wurden 422 ambulante Patienten (67 \pm 8 Jahre, 52\% weiblich) in die doppelt blinde, randomisierte, kontrollierte und prospektive ALDO-DHF-Studie eingeschlossen. Über 12 Monate erfolgte entweder die tägliche Gabe von Spironolacton (25 mg) oder eines Placebos. Primäre Endpunkte waren eine verbesserte körperliche Leistungsfähigkeit und eine Verbesserung echokardiographischer Parameter der diastolischen Dysfunktion.

Für die ökonomische Betrachtung wurde der Bottom-Up-Ansatz gewählt, das heißt, die Daten wurden auf Ebene einzelner Patienten erhoben. Menge und Preis der einzelnen Ressourcen gingen in die Berechnung ein. Zu diesen gehörten Medikamente, Arztkontakte beim Hausarzt oder Kardiologen sowie Krankenhaus- und Reha-Aufenthalte aufgrund von Herzinsuffizienz. Schließlich wurden mit Hilfe einfacher und multipler Regressionsanalysen Prädiktoren für höhere Kosten ermittelt.

Die Gesamtkosten pro Patient beliefen sich auf durchschnittlich knapp $1200 €$, im Median dagegen nur etwa $330 €$, da drei Viertel der Patienten weniger als $1000 €$ Ausgaben verur- 
sachten. Den höchsten Anteil daran machten die Hospitalisierungen aus. Die Therapie mit Spironolacton hatte auf den Ressourcenverbrauch und die Gesamtkosten keinen signifikanten Einfluss. Als unabhängige Prädiktoren für höhere Kosten zeigten sich das männliche Geschlecht, ein niedriger Hämoglobinwert, eine gute maximale Sauerstoffaufnahme $\left(\mathrm{VO}_{2} \mathrm{max}\right)$, und das Vorliegen einer KHK, Hyperlipoproteinämie und Vorhofflimmern. Letzteres hatte quantitativ betrachtet den größten Einfluss.

Die Kosten fallen damit deutlich niedriger als angenommen aus und liegen unter denen des Vergleichskollektives mit HFrEF. Es handelt sich bei ALDO-DHF um ein vergleichsweise junges und oligosymptomatisches ambulantes Kollektiv, für das die Diagnose HFpEF häufig erst beim Screening gestellt wurde. Die Ein- und Ausschlusskriterien waren streng und ließen beispielsweise relevante pulmonale Vorerkrankungen nicht zu. Der Vergleich mit anderen Studien deutet auf die große Rolle der Komorbiditäten bei Patienten mit HFpEF hin, gerade im Hinblick auf häufige Krankenhausaufenthalte. Wesentlich höhere Kosten entstehen erst im Verlauf der Erkrankung. Daraus lässt sich ableiten, dass die tatsächlichen Kosten für Patienten mit HFpEF noch deutlich über den hier berechneten Kosten liegen dürften. Daher müsste der Beobachtungszeitraum für weitere Untersuchungen länger gewählt werden.

Die Früherkennung und Therapie einer HFpEF bereits in der frühen Krankheitsphase sowie die konsequente Behandlung der Komorbiditäten sind notwendig, um Kosten im Gesundheitssystem einzusparen. 


\section{Literaturverzeichnis}

Ahmed SH, Clark LL, Pennington WR, Webb CS, Bonnema DD, Leonardi AH, McClure CD, Spinale FG, Zile MR (2006): Matrix metalloproteinases/tissue inhibitors of metalloproteinases: relationship between changes in proteolytic determinants of matrix composition and structural, functional, and clinical manifestations of hypertensive heart disease. Circulation $\underline{113(17)}, 2089-96$

Almuntaser I, Brown A, Murphy R, Crean P, King G, Mahmud A, Feely J (2007): Comparison of echocardiographic measures of left ventricular diastolic function in early hypertension. Am J Cardiol 100(12), 1771-5

Angeja BG, Grossman W (2003): Evaluation and management of diastolic heart failure. Circulation. $\underline{07}(5), 659-63$

Ather S, Chan W, Bozkurt B, Aguilar D, Ramasubbu K, Zachariah AA, Wehrens XH, Deswal A (2012): Impact of noncardiac comorbidities on morbidity and mortality in a predominantly male population with heart failure and preserved versus reduced ejection fraction. J Am Coll

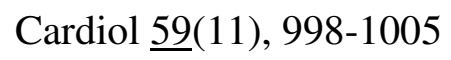

Bauersachs J, Heck M, Fraccarollo D, Hildemann SK, Ertl G, Wehling M, Christ M (2002): Addition of spironolactone to angiotensin-converting enzyme inhibition in heart failure improves endothelial vasomotor dysfunction: role of vascular superoxide anion formation and endothelial nitric oxide synthase expression. J Am Coll Cardiol 39, 351-358

Bhatia RS, Tu JV, Lee DS, Austin PC, Fang J, Haouzi A, Gong Y, Liu PP (2006): Outcome of heart failure with preserved ejection fraction in a population-based study. N Engl J Med. $\underline{355}(3), 260-9$ 
Biermann J, Neumann T, Angermann C, Düngen H, Erbel R, Herzog W, Maisch B, MüllerTasch T, Özcelik C, Pankuweit S (2011): Resource use and costs in systolic heart failure according to disease severity: a pooled analysis from the German Competence Network Heart Failure. Journal of Public Health $\underline{20}(1), 23-30$

Biermann J, Neumann T, Angermann CE, Erbel R, Maisch B, Pittrow D, Regitz-Zagrosek V, Scheffold T, Wachter R, Gelbrich G, Wasem J, Neumann A, German Competence Network Heart Failure. (2012): Economic burden of patients with various etiologies of chronic systolic heart failure analyzed by resource use and costs. Int J Cardiol. 156(3), 323-5

Biermann J, Neumann T, Störk S, Stauffenberg S, Angermann CE, Düngen HD, Erbel R, Herzog W, Maisch B, Müller-Tasch T (2013): Economic burden of chronic heart failure with preserved vs. reduced ejection fraction - an analysis from the German Competence Network Heart Failure. Gesundheitswesen $\underline{75}, 246$

Borbély A, van der Velden J, Papp Z, Bronzwaer JG, Edes I, Stienen GJ, Paulus WJ (2005): Cardiomyocyte stiffness in diastolic heart failure. Circulation 111(6), 774-81

Bowles D, Greiner W (2012): Bevölkerungsentwicklung und Gesundheitsausgaben WIdO $\underline{12}(4), 7-17$

Braunschweig F, Cowie MR, Auricchio A. (2011): What are the costs of heart failure? Europace 2 , ii13-7

Brilla CG, Zhou G, Matsubara L (1994): Collagen metabolism in cultured adult rat cardiac fibroblasts: response to angiotensin II and aldosterone. J Mol Cell Cardiol 26, 809-820 
Bursi F, Weston SA, Redfield MM, Jacobsen SJ, Pakhomov S, Nkomo VT, Meverden RA, Roger VL (2006): Systolic and diastolic heart failure in the community. JAMA 296(18), 2209-16

Cleland JG, Tendera M, Adamus J, Freemantle N, Polonski L, Taylor J; PEP-CHF Investigators (2006): The perindopril in elderly people with chronic heart failure (PEP-CHF) study. Eur Heart J 27(19), 2338-45

Edelmann F, Schmidt AG, Gelbrich G, Binder L, Herrmann-Lingen C, Halle M, Hasenfuss G, Wachter R, Pieske B (2010): Rationale and design of the 'aldosterone receptor blockade in diastolic heart failure' trial: a double-blind, randomized, placebo-controlled, parallel group study to determine the effects of spironolactone on exercise capacity and diastolic function in patients with symptomatic diastolic heart failure (Aldo-DHF). Eur J Heart Fail 12 (8), 874-82

Edelmann F, Gelbrich G, Düngen HD, Fröhling S, Wachter R, Stahrenberg R, Binder L, Töpper A, Lashki DJ, Schwarz S, Herrmann-Lingen C, Löffler M, Hasenfuss G, Halle M, Pieske B (2011): Exercise training improves exercise capacity and diastolic function in patients with heart failure with preserved ejection fraction: results of the Ex-DHF (Exercise training in Diastolic Heart Failure) pilot study. J Am Coll Cardiol 58(17), 1780-91

Edelmann F, Wachter R, Schmidt AG, Kraigher-Krainer E, Colantonio C, Kamke W, Duvinage A, Stahrenberg R, Durstewitz K, Löffler M (2013): Effect of spironolactone on diastolic function and exercise capacity in patients with heart failure with preserved ejection fraction: The Aldo-DHF randomized controlled trial spironolactone in patients with heart failure. JAMA $\underline{309}(8), 781-791$

Elesber AA, Redfield MM, Rihal CS, Prasad A, Lavi S, Lennon R, Mathew V, Lerman LO, Lerman A (2007): Coronary endothelial dysfunction and hyperlipidemia are independently associated with diastolic dysfunction in humans. Am Heart J 153(6), 1081-7 
Erbel R, Neumann T, Zeidan Z, Bartel T, Buck T (2002): Echokardiographische Diagnostik der diastolischen Herzinsuffizienz. Herz 27(2), 96-106

Farquharson, CA and Struthers, AD (2000): Spironolactone increases nitric oxide bioactivity, improves endothelial vasodilator dysfunction, and suppresses vascular angiotensin I/angiotensin II conversion in patients with chronic heart failure. Circulation 101, 594-597

Fonarow GC, Stough WG, Abraham WT, Albert NM, Gheorghiade M, Greenberg BH, O'Connor CM, Sun JL, Yancy CW, Young JB; OPTIMIZE-HF Investigators and Hospitals (2007): Characteristics, treatments, and outcomes of patients with preserved systolic function hospitalized for heart failure: a report from the OPTIMIZE-HF Registry. J Am Coll Cardiol $\underline{50}(8), 768-77$

Fukuta H, Sane DC, Brucks S, Little WC (2005): Statin therapy may be associated with lower mortality in patients with diastolic heart failure: a preliminary report. Circulation 112(3), 35763

Hasenfuß G, Wachter R: Diagnostik und Therapie der Diastolischen Herzinsuffizienz. Georg Thieme Verlag, Stuttgart 2008

Hayashi SY, Rohani M, Lindholm B, Brodin LA, Lind B, Barany P, Alvestrand A, Seeberger A (2006): Left ventricular function in patients with chronic kidney disease evaluated by colour tissue Doppler velocity imaging. Nephrol Dial Transplant 21 (1), 125-132

Heidenreich PA, Albert NM, Allen LA, Bluemke DA, Butler J, Fonarow GC, Ikonomidis JS, Khavjou O, Konstam MA, Maddox TM (2013): Forecasting the Impact of Heart Failure in the United States: A Policy Statement From the American Heart Association. Circulation Heart failure $\underline{6}(3), 606-619$ 
Hunt SA, Abraham WT, Chin MH, Feldman AM, Francis GS, Ganiats TG, Jessup M, Konstam MA, Mancini DM, Michl K (2005): ACC/AHA 2005 Guideline Update for the Diagnosis and Management of Chronic Heart Failure in the Adult: a report of the American College of Cardiology/American Heart Association Task Force on Practice Guidelines (Writing Committee to Update the 2001 Guidelines for the Evaluation and Management of Heart Failure): developed in collaboration with the American College of Chest Physicians and the International Society for Heart and Lung Transplantation: endorsed by the Heart Rhythm Society. Circulation $\underline{112}, 154-235$

Icks A, Chernyak N, Bestehorn K, Brüggenjürgen B, Bruns J, Damm O, Dintsios CM, Dreinhöfer K, Gandjour A, Gerber A (2010): Methoden der gesundheitsökonomischen Evaluation in der Versorgungsforschung. Gesundheitswesen 72(12), 917-33

Jewell CW, Watson LE, Mock J, Dostal DE (2006): Aldosterone receptor antagonists and cardiovascular disease: do we need a change of the guard? Cardiovasc Hematol Agents Med Chem $\underline{4}(2), 129-53$

Kasner M, Westermann D, Steendijk P, Gaub R, Wilkenshoff U, Weitmann K, Hoffmann W, Poller W, Schultheiss HP, Pauschinger M, Tschöpe C (2007): Utility of Doppler echocardiography and tissue Doppler imaging in the estimation of diastolic function in heart failure with normal ejection fraction: a comparative Doppler-conductance catheterization study. Circulation $\underline{116}(6), 637-47$

Klein W. (1999): Gesundheitsökonomische Überlegungen zum Thema Herzinsuffizienz Kosten der Krankheit. Journal für Kardiologie ㅁ, 612-616

Klemmstein D: Das obstruktive Schlafapnoesyndrom als Risikofaktor für eine diastolische Ventrikelfunktionsstörung. Med. Diss. Göttingen 2012 
Korves C, Eldar-Lissai A, McHale J, Lafeuille MH, Hwa Ong S, Sheng Duh M (2012): Resource utilization and costs following hospitalization of patients with chronic heart failure in the US. J Med Econ 15(5), 925-37

Krauth C, Hessel F, Hansmeier T (2005): Empirische Bewertungssätze in der gesundheitsökonomischen Evaluation: ein Vorschlag der AG Methoden der gesundheitsökonomischen Evaluation (AG MEG). Das Gesundheitswesen 67(10), 736-746

Liao L, Jollis JG, Anstrom KJ, Whellan DJ, Kitzman DW, Aurigemma GP, Mark DB, Schulman KA, Gottdiener JS (2006): Costs for heart failure with normal vs reduced ejection fraction. Arch Intern Med. 166(1), 112-8

Linke WA, Grützner A (2008): Pulling single molecules of titin by AFM - recent advances and physiological implications. Pflugers Arch $\underline{456}, 101-115$

Liu JL, Maniadakis N, Gray A, Rayner M (2002): The economic burden of coronary heart disease in the UK. Heart $\underline{88}, 597-603$

Maddox TM, Nash IS, Fuster V: Economic Costs Associated with Atrial Fibrillation. Contemporary Cardiology: Atrial Fibrillation, From Bench to Bedside. Humana Press, Totowa 2008

Massie BM, Carson PE, McMurray JJ, Komajda M, McKelvie R, Zile MR, Anderson S, Donovan M, Iverson E, Staiger C, Ptaszynska A; I-PRESERVE Investigators (2008): Irbesartan in patients with heart failure and preserved ejection fraction. N Engl J Med 359(23), 2456-67

McMurray JJV, Adamopoulos S, Anker SD, Auricchio A, Bohm M, Dickstein K, Falk V, Filippatos G, Fonseca C, Gomez-Sanchez MA (2012): ESC guidelines for the diagnosis and treatment of acute and chronic heart failure 2012: The task force for the diagnosis and treatment of acute and chronic heart failure 2012 of the European society of cardiology. Developed in collaboration with the Heart Failure Association (HFA) of the ESC, Eur J Heart Fail 
$\underline{14}(8), 803-869$

Mizuno Y, Yoshimura M, Yasue H, Sakamoto T, Ogawa H, Kugiyama K, Harada E, Nakayama M, Nakamura S, Ito T, Shimasaki Y, Saito Y, Nakao K (2001): Aldosterone production is activated in failing ventricle in humans. Circulation $\underline{103}(1), 72-77$

Neumann T, Biermann J, Neumann A, Wasem J, Ertl G, Dietz R, Erbel R (2009): Herzinsuffizienz: Häufigster Grund für Krankenhausaufenthalte - Medizinische und ökonomische Aspekte. Dtsch Arztebl 106(16), 269-75

Nichols GA, Reynolds K, Kimes TM, Rosales AG, Chan WW (2015): Comparison of Risk of Re-hospitalization, All-Cause Mortality, and Medical Care Resource Utilization in Patients With Heart Failure and Preserved Versus Reduced Ejection Fraction. Am J Cardiol 116(7), 1088-92

Owan TE, Hodge DO, Herges RM, Jacobsen SJ, Roger VL, Redfield MM (2006): Trends in Prevalence and Outcome of Heart Failure with Preserved Ejection Fraction. Engl J Med Med $\underline{355}, 251-259$

Paulus WJ, Tschöpe C, Sanderson JE, Rusconi C, Flachskampf FA, Rademakers FE, Marino P, Smiseth OA, De Keulenaer G, Leite-Moreira AF, Borbély A, Edes I, Handoko ML, Heymans S, Pezzali N, Pieske B, Dickstein K, Fraser AG, Brutsaert DL. (2007): How to diagnose diastolic heart failure: a consensus statement on the diagnosis of heart failure with normal left ventricular ejection fraction by the Heart Failure and Echocardiography Associations of the European Society of Cardiology. Eur Heart J 28 (20), 2539-50

Pitt B, Pfeffer MA, Assmann SF, Boineau R, Anand IS, Claggett B, Clausell N, Desai AS, Diaz R, Fleg JL, Gordeev I, Harty B, Heitner JF, Kenwood CT, Lewis EF, O'Meara E, Probstfield JL, Shaburishvili T, Shah SJ, Solomon SD, Sweitzer NK, Yang S, McKinlay SM; TOPCAT Investigators (2014): Spironolactone for heart failure with preserved ejection fraction. N Engl J Med $\underline{370}(15), 1383-92$ 
Querejeta R, López B, González A, Sánchez E, Larman M, Martínez Ubago JL, Díez J (2004): Increased collagen type I synthesis in patients with heart failure of hypertensive origin: relation to myocardial fibrosis. Circulation $\underline{110}(10), 1263-68$

Redfield MM, Jacobsen SJ, Borlaug BA, Rodeheffer RJ, Kass DA (2005): Age- and genderrelated ventricular-vascular stiffening: a community-based study. Circulation 112(15), 225462

Redfield MM, Chen HH, Borlaug BA, Semigran MJ, Lee KL, Lewis G, LeWinter MM, Rouleau JL, Bull DA, Mann DL (2012): Effect of Phosphodiesterase-5 Inhibition on Exercise Capacity and Clinical Status in Heart Failure with Preserved Ejection Fraction: A Randomized Clinical Trial. A study conducted by the Heart Failure Clinical Research Network (HFN), J Med Econ 15 (5), 925-37

Ringborg A, Nieuwlaat R, Lindgren P, Jonsson B, Dogan F, Maggioni AP, Lopez-Sendon J, Stepinska J, Cokkinos D, Crijns HJ (2008): Costs of atrial fibrillation in five European countries: results from the Euro Heart Survey on atrial fibrillation. Europace 10(4), 403-11

Rocha R, Rudolph AE, Frierdich GE, Nachowiak DA, Kekec BK, Blomme EA, McMahon EG, Delyani JA (2002): Aldosterone induces a vascular inflammatory phenotype in the rat heart. Am J Physiol Heart Circ Physiol 283(5), H1802-10.

Satoh M, Nakamura M, Saitoh H, Satoh H, Akatsu T, Iwasaka J, Masuda T, Hiramori K (2002): Aldosterone synthase (CYP11B2) expression and myocardial fibrosis in the failing human heart. Clin Sci (Lond) 102(4), 381-6.

Schmidt AG, Pieske B (2012): Die diastolische Herzinsuffizienz - Pathophysiologische Grundlagen, diagnostische Strategien, therapeutische Optionen. Journal für Kardiologie Austrian Journal of Cardiology 19(5-6), 107-117 
Schöffski O, von der Schulenburg JM: Gesundheitsökonomische Evaluationen. 4. Auflage; Springer-Verlag, Berlin Heidelberg 2012

Schunkert H, Hense HW, Muscholl M, Luchner A, Kürzinger S, Danser AH, Riegger GA (1997): Associations between circulating components of the renin-angiotensin-aldosterone system and left ventricular mass. Heart $\underline{77}(1), 24-31$

Shah R, Wang Y, Foody JM (2008): Effect of statins, angiotensin-converting enzyme inhibitors, and beta blockers on survival in patients $>$ or $=65$ years of age with heart failure and preserved left ventricular systolic function. Am J Cardiol 101(2), 217-22

Solomon SD, Zile M, Pieske B, Voors A, Shah A, Kraigher-Krainer E, Shi V, Bransford T, Takeuchi M, Gong J, Lefkowitz M, Packer M, McMurray JJ (2012): The angiotensin receptor neprilysin inhibitor LCZ696 in heart failure with preserved ejection fraction: a phase 2 double-blind randomised controlled trial. Lancet 380(9851), 1387-1395

Stahrenberg R, Edelmann F, Mende M, Kockskämper A, Düngen HD, Scherer M, Kochen MM, Binder L, Herrmann-Lingen C, Schönbrunn L, Gelbrich G, Hasenfuss G, Pieske B, Wachter R (2010): Association of glucose metabolism with diastolic function along the diabetic continuum. Diabetologia 54(4), 990

Stålhammar J, Stern L, Linder R, Sherman S, Parikh R, Ariely R, Deschaseaux C, Wikström $\mathrm{G}$ (2014): The burden of preserved ejection fraction heart failure in a real-world Swedish patient population. J Med Econ $\underline{17}(1), 43-51$

Statistisches Bundesamt Wiesbaden (2013a), www.destatis.de: Diagnosedaten der Patienten und Patientinnen in Krankenhäusern (einschl. Sterbe- und Stundenfälle) für das Jahr 2011. Gesundheit Fachserie 12, Reihe 6.2.1

Statistisches Bundesamt Wiesbaden (2013b), www.destatis.de: DRG-Statistik 2011 - Vollstationäre Patientinnen und Patienten in Krankenhäusern. Gesundheit Fachserie 12, Reihe 6.4 
Statistisches Bundesamt Wiesbaden (2015), www.destatis.de: Krankheitskosten nach Krankheitsklassen und Alter 2008 in Euro je Einwohner der jeweiligen Altersgruppe; Bevölkerungspyramide

https://www.destatis.de/DE/ZahlenFakten/GesellschaftStaat/Gesundheit/Krankheitskosten/Kr ankheitskosten.html; https://service.destatis.de/bevoelkerungspyramide;

Zugriff am 12.12.2015. Verwendung der Abbildungen mit freundlicher Genehmigung des Statistischen Bundesamtes

Stewart S (2005): Review: Financial aspects of heart failure programs of care. Eur J Heart Fail $\underline{7}, 423-428$

Struthers AD (2002): Evidence for myocardial synthesis of aldosterone producing myocardial fibrosis in man. Clin Sci 102(4), 387

Struthers AD, MacDonald TM (2004): Review of aldosterone- and angiotensin II-induced target organ damage and prevention. Cardiovasc Res $\underline{61}$, 663-670

Szucs TD (2003): Gesundheitsökonomische Aspekte der chronischen Herzinsuffizienz Teil 1: Krankheitslast und ökonomische Bewertung. Schweizerische Ärztezeitung 84(46), 2431-35

Tang WH, Parameswaran AC, Maroo AP, Francis GS (2005): Aldosterone receptor antagonists in the medical management of chronic heart failure. Mayo Clin Proc 80(12), 1623-30

Tschöpe C, Kasner M, Westermann D, Gaub R, Poller WC, Schultheiss HP (2005): The role of NT-proBNP in the diagnostics of isolated diastolic dysfunction: correlation with echocardiographic and invasive measurements. Eur Heart J 26 (21), 2277-84

Van Putte-Katier N, Rooman RP, Haas L, Verhulst SL, Desager KN, Ramet J, Suys BE (2008): Early cardiac abnormalities in obese children: importance of obesity per se versus 
associated cardiovascular risk factors. Pediatr Res $\underline{64}(2), 205-9$

Vasan RS, Larson MG, Benjamin EJ, Evans JC, Reiss CK, Levy D (1999): Congestive heart failure in subjects with normal versus reduced left ventricular ejection fraction: prevalence and mortality in a population-based cohort. J Am Coll Cardiol 33, 1948-55

Wachter R, Lüers C, Kleta S, Griebel K, Herrmann-Lingen C, Binder L, Janicke N, Wetzel D, Kochen MM, Pieske B (2007): Impact of diabetes on left ventricular diastolic function in patients with arterial hypertension. Eur J Heart Fail g (5), 469-76

Yamamoto N, Yasue H, Mizuno Y, Yoshimura M, Fujii H, Nakayama M, Harada E, Nakamura S, Ito T, Ogawa H (2002): Aldosterone is produced from ventricles in patients with essential hypertension. Hypertension $\underline{39}(5), 958-62$

Yusuf S, Pfeffer MA, Swedberg K, Granger CB, Held P, McMurray JJ, Michelson EL, Olofsson B, Ostergren J; CHARM Investigators and Committees (2003): Effects of candesartan in patients with chronic heart failure and preserved left-ventricular ejection fraction: the CHARM-Preserved Trial. Lancet 362(9386), 777-81

Zannad F, Dousset B, Alla F (2001): Treatment of congestive heart failure: interfering the aldosterone-cardiac extracellular matrix relationship. Hypertension $\underline{38}$, 1227-1232

Zile MR, Brutsaert DL (2002): New concepts in diastolic dysfunction and diastolic heart failure: Part II: causal mechanisms and treatment. Circulation 105(12), 1503-8

Zugck C, Müller A, Helms T, Wildau H, Becks T, Hacker J, Haag S, Goldhagen K, Schwab J (2010): Gesundheitsökonomische Bedeutung der Herzinsuffizienz: Analyse bundesweiter Daten. Dtsch Med Wochenschr 135, 633-638 


\section{Abkürzungsverzeichnis}

A

$\mathrm{ACC}$

ACE

$\mathrm{ACVB}$

AHA

ASS

ATP

AZV

BMI

BNP

CERV

CI

COPD

DD

DM

DRG

DT

E

$\mathrm{EF}$

eGFR

EKG

FEV1

$\mathrm{Hb}$

HF

HFpEF

HFrEF

HIV

HLP

IQR späte Mitralklappenflussgeschwindigkeit

American College of Cardiology

Angiotensin-converting Enzym

Aorto-koronarer Venenbypass

American Heart Association

Acetylsalicylsäure

Adenosintriphosphat

Atemzeitvolumen

Body Mass Index

Brain natriuretic peptide

zerebrovaskuläre Erkrankung

chronotrope Inkompetenz

Chronisch obstruktive Lungenerkrankung

diastolische Dysfunktion

Diabetes mellitus

Diagnose-bezogene Fallgruppen

Dezelerationszeit

frühe Mitralklappenflussgeschwindigkeit

Ejektionsfraktion

glomeruläre Filtrationsrate

Elektrokardiogramm

funktionelle Einsekundenkapazität

Hämoglobin

Heart Failure, Herzinsuffizienz

Heart failure with preserved ejection fraction

Heart failure with reduced ejection fraction

Humanes Immundefizienz-Virus

Hyperlipoproteinämie

Interquartilsabstand 
IVRT isovolumetrische Relaxationszeit

KHK koronare Herzerkrankung

LAVI linksatrialer Volumenindex

LVEDP linksventrikulärer enddiastolischer Druck

LVEDVI enddiastolischer Volumenindex

LVEF linksventrikuläre Ejektionsfraktion

LVMI linksventrikulärer Massenindex

MAD mittlerer arterieller Druck

MED Median

MMP Matrixmetalloproteinasen

MW Mittelwert

NSAR nicht-steroidale Antirheumatika

NT-proBNP n-terminales Spaltprodukt des Vorläufermoleküls von BNP

NYHA New York Heart Association

pAVK periphere arterielle Verschlusskrankheit

PW-Doppler Pulsed-Wave-Doppler

RAAS Renin-Angiotensin-Aldosteron-System

SAS Schlafapnoesyndrom

$\mathrm{SD}$

Standardabweichung

SERCA Kalziumpumpe des sarkoplasmatischen Retikulums

SR

sarkoplasmatisches Retikulum

TIMP

Tissue inhibitors of metalloproteinases

USD

US-Dollar

VACI

Ventricular-atrial Coupling Index

VC

Vitalkapazität

VHF

Vorhofflimmern

$\mathrm{VO}_{2} \max$

maximale Sauerstoffaufnahme

VPI

Verbraucherpreisindex 


\section{Tabellen und Abbildungen}

Abb. 1

Abb. 2

Abb. 3

Abb. 4

Abb. 5

Abb. 6

Abb. 7

Abb. 8

Abb. 9

Abb. 10

Tabelle 1

Tabelle 2

Tabelle 3

Tabelle 4

Tabelle 5

Tabelle 6

Tabelle 7

Tabelle 8

Tabelle 9

Tabelle 10

Tabelle 11

Tabelle 12

Tabelle 13

Tabelle 14

Tabelle 15

Tabelle 16

Tabelle 17

Tabelle 18

Tabelle 19
Gesundheitsausgaben nominal 2004-2013

Anteil der Gesundheitsausgaben am Bruttoinlandsprodukt 2004-2013

Gesundheitsausgaben je Einwohner 2004-2013

Krankheitskosten nach Klasse

Krankheitskosten nach Alter und Geschlecht

Bevölkerungspyramiden 2012 und 2050

Verteilung der Hausarztkosten nach Verum und Placebo

Verteilung der Kardiologenkosten nach Verum und Placebo

Verteilung der Medikamentenkosten nach Verum und Placebo

Verteilung der Gesamtkosten für Gesamtkohorte

Einteilung der Herzinsuffizienz nach NYHA-Stadien

Kontaktwerte nach Facharztgruppe, inflationsbereinigt für das Jahr 2011

Dropouts bis zur jeweiligen Visite, getrennt nach Verum und Placebo

Deskriptive Kenngrößen der metrischen Baselinevariablen

Absolute (und relative) Häufigkeiten der kategorialen Baseline-Variablen

Deskriptive Kenngrößen der Arztkontakte, Krankenhaus- u. Reha-Aufenthalte

Deskriptive Kenngrößen der Kosten ohne Medikamente für die Gesamtgruppe 38

Deskriptive Kenngrößen für die Kosten ohne Medikamente

Häufigkeiten der Änderung von Medikation und/oder Dosis

Patientenbezogene Anzahl an Änderungen von Medikation und/oder Dosis

Häufigkeiten der Medikamentengruppen bezogen auf alle Zeitpunkte

Häufigkeiten der Medikamentengruppen getrennt für die Behandlungsgruppen 43

Preis der jeweiligen Medikamentengruppen für die gesamte Studienpopulation 44

Preis in den Medikamentengruppen, getrennt nach Behandlungsgruppen

Gesamtkosten in den beiden Therapiegruppen

Zusammenhangsanalyse von Gesamtkosten und möglichen Prädiktoren

Punktschätzer der Einfachregression und Prädiktoren der multiplen Regression 49

Punktschätzer für das finale Modell und das incidence rate ratio 


\section{Lebenslauf}

Der Lebenslauf ist aus Gründen des Datenschutzes in der Online-Version der Dissertation nicht veröffentlicht. Er ist in den gedruckten Exemplaren zu finden. 